110 Nordic Council of Ministers

\title{
NORDSYN STUDY \\ ON AIR-TO-AIR HEAT \\ PUMPS IN HUMID \\ NORDIC CUIMAT:
}

40

$\leq r$

J

$\Rightarrow$

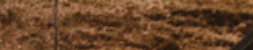

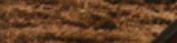
䍏四 $1<+$

1. 12

围田

因

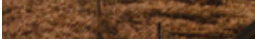

minco

minn

一周国陪

merement

mone

rar -2

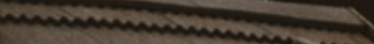

眐

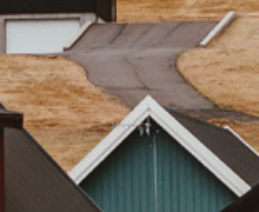

舴 


\section{Nordsyn study on air-to-air heat pumps in humid Nordic climate}

Caroline Haglund Stignor and Tommy Walfridson

\footnotetext{
TemaNord 2019:504
} 


\section{Nordsyn study on air-to-air heat pumps in humid Nordic climate}

Caroline Haglund Stignor and Tommy Walfridson

ISBN 978-92-893-5977-1 (PRINT)

ISBN 978-92-893-5978-8 (PDF)

ISBN 978-92-893-5979-5 (EPUB)

http://dx.doi.org/10.6027/TN2019-504

TemaNord 2019:504

ISSN 0908-6692

Standard: PDF/UA-1

ISO 14289-1

(c) Nordic Council of Ministers 2019

Cover photo: Unsplash.com

\section{Disclaimer}

This publication was funded by the Nordic Council of Ministers. However, the content does not necessarily reflect the Nordic Council of Ministers' views, opinions, attitudes or recommendations.

\section{Rights and permissions}

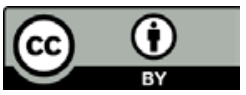

This work is made available under the Creative Commons Attribution 4.0 International license (CC BY 4.0) https://creativecommons.org/licenses/by/4.0

Translations: If you translate this work, please include the following disclaimer: This translation was not produced by the Nordic Council of Ministers and should not be construed as official. The Nordic Council of Ministers cannot be held responsible for the translation or any errors in it.

Adaptations: If you adapt this work, please include the following disclaimer along with the attribution: This is an adaptation of an original work by the Nordic Council of Ministers. Responsibility for the views and opinions expressed in the adaptation rests solely with its author(s). The views and opinions in this adaptation have not been approved by the Nordic Council of Ministers.

Third-party content: The Nordic Council of Ministers does not necessarily own every single part of this work. The Nordic Council of Ministers cannot, therefore, guarantee that the reuse of third-party content does not infringe the copyright of the third party. If you wish to reuse any third-party content, you bear the risks associated with any such rights violations. You are responsible for determining whether there is a need to obtain permission for the use of third-party content, and if so, for obtaining the relevant permission from the copyright holder. Examples of third-party content may include, but are not limited to, tables, figures or images. 
Photo rights (further permission required for reuse):

Any queries regarding rights and licences should be addressed to:

Nordic Council of Ministers/Publication Unit

Ved Stranden 18

DK-1061 Copenhagen K

Denmark

Phone +4533960200

pub@norden.org

\title{
Nordic co-operation
}

Nordic co-operation is one of the world's most extensive forms of regional collaboration, involving Denmark, Finland, Iceland, Norway, Sweden, and the Faroe Islands, Greenland and Åland.

Nordic co-operation has firm traditions in politics, economics and culture and plays an important role in European and international forums. The Nordic community strives for a strong Nordic Region in a strong Europe.

Nordic co-operation promotes regional interests and values in a global world. The values shared by the Nordic countries help make the region one of the most innovative and competitive in the world.

\author{
The Nordic Council of Ministers \\ Nordens Hus \\ Ved Stranden 18 \\ DK-1061 Copenhagen K, Denmark \\ Tel.: +4533960200 \\ www.norden.org
}

Download Nordic publications at www.norden.org/nordpub 



\section{Contents}

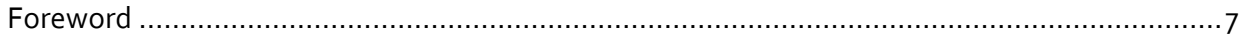

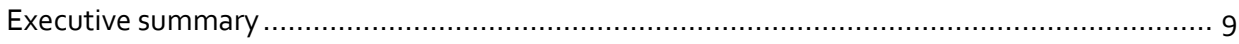

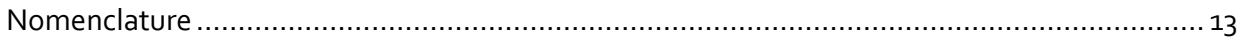

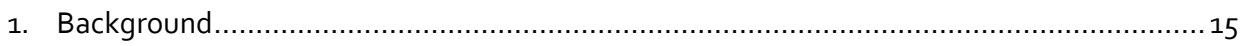

1.1 Regulations 206/2012 and 626/2012 .................................................... 15

1.2 European standards harmonized with regulations $206 / 2012$ and $626 / 2012 \ldots \ldots \ldots \ldots .21$

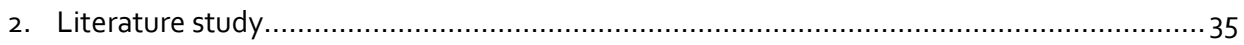

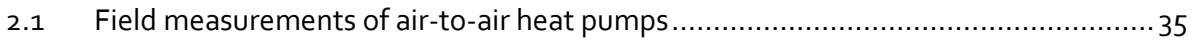

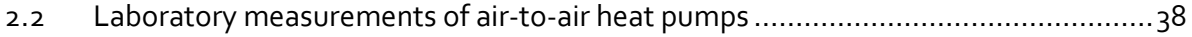

2.3 Dependency of performance on the humidity of the climate ..............................44

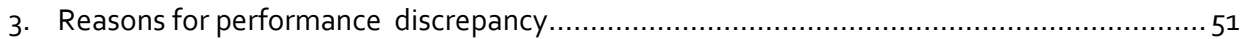

3.1 Performance difference due to low heat spreading in the building........................ 51

3.2 Performance difference due to test methods ................................................ 52

3.3 The test period in the standards are not long enough to include a defrost period .....56

3.4 Energy label tests performed at lower humidity than the real climate? ....................57

3.5 The heat pumps are declared at lower capacity than they operate at......................68

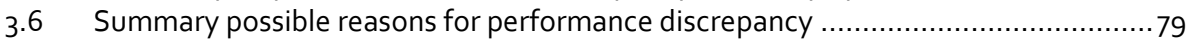

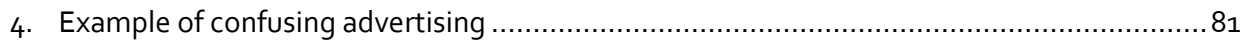

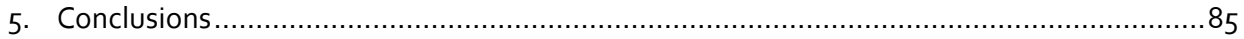

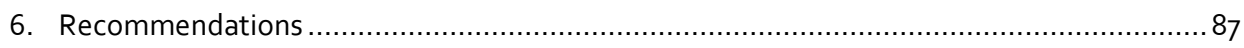

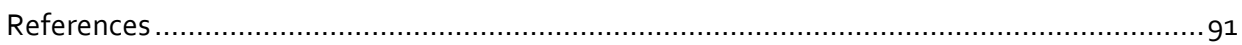

References for air-to-water heat pumps not yet analysed .......................................92

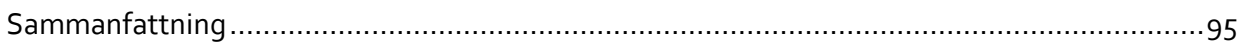




\section{Foreword}

The study presented in this report has been performed on behalf of the Swedish Energy Agency within the Nordic cooperation project Nordsyn sponsored by the Nordic Council of Ministers. The study was performed by Caroline Haglund Stignor and Tommy Walfridson at RISE Research Institutes of Sweden $A B$, in cooperation with Nordsyn project leader Lovisa Blomqvist at Swedish Energy Agency.

The aim of this study was to analyse if the information given on the Energy Labels of air-to-air heat pumps give the consumer in Nordic countries sufficiently relevant information regarding the energy performance of the products. If this was found not to be the case, the reasons behind should be analysed and recommendations given. The methods used in the study are literature studies in open sources, browsing on the internet for product data available for consumers and interviews with relevant parties.

25 April 2019

Lovisa Blomqvist, Swedish Energy Agency 


\section{Executive summary}

In 2013 Ecodesign and energy labelling regulations for air-to-air heat pumps were introduced in EU. Some of the Nordic market surveillance authorities suspects or have the perception that the declared efficiencies for the products on the energy labels and supporting data sheets are considerably higher compared to what have been measured in real installations in the field, especially in cold and humid climates, which in such case would give the consumer misleading information. The purpose of this study was to confirm or reject this suspicion and if confirmed, clarify the reasons for the divergences.

The Ecodesign regulations for air-to-air heat pumps stipulate minimum efficiencies for products placed on the European market. According to the energy label regulations the air-to-air heat pumps must have an energy label showing both efficiency and rated capacity. There is a possibility to label the products for three different climates - cold, average and warm, but it is only mandatory to label them for the average climate. The results from this study show that it is still rare that products sold on the Swedish and Norwegian market has information on their labels for the cold climate.

The test methods for determination of the capacity and efficiency at for air-to-air heat pumps are described in the standard EN 14511. The standard EN14825 describes calculation methods to determine the averaged performance during the heating season, the SCOP - the Seasonal Performance factor. In case frosting take place on the outdoor unit during the test, both the heating and defrosting period is included in the evaluation of the test. However, the evaluation period is limited to maximally three hours to limit the cost of the tests.

The capacities (with corresponding efficiencies) that are used in the SCOP calculations can be defined freely (with some limitations) by the manufacturer. The efficiency of a heat pump normally increases with lower capacity, down to a certain limit. Therefore, to be able to declare the heat pump with a high SCOP on the energy label, it might be beneficial to declare the heat pump for a low capacity. In addition, according to the standards, if the manufacturer gives instructions for the setting of the frequency for the different test points, this setting shall be done. 
When reporting and evaluating results from field measurements it is important to relate to which system boundary that had been applied. The SEPEMO project defined four different system boundaries for SPF (Seasonal Performance Factors), which can be applied and the results presented in this report are related to them. There are few results from field measurements reported in the open literature for air-to-air heat pumps, especially in the Nordic climate. Those found report SPFH2 values between 2.2-2.6 and $\mathrm{SPFH}_{4}$ values between 1.8-2.1. However, these are probably underestimated, since they did not take part capacity operation into account. Reported SPF values from field measurements in average climates where considerably higher, mainly due to the warmer climate.

Several air-to-air heat pumps have been tested by SP (RISE) since the beginning of this century, before the present regulations and harmonized standards for this product were published. Therefore, a compensation method was applied, instead of setting the frequency of the compressor, and the test periods were longer than the present standards prescribe. During these tests all the heat pumps defrosted regularly and that the defrost strategies as well as the overall performance improved over the years.

Results from market surveillance tests show that it has become more and more rare that heat pumps defrost during the laboratory tests. In addition, many heat pumps are declared for low capacities, lower than their "real" capacity, to obtain a higher SCOP value.

It has been shown that frost growth take place more rapidly at a higher relative humidity of the outdoor air and hence frosting must take place more frequently. There are studies indicating that a high humidity will have a negative influence of the overall efficiency of the heat pump, but no clear trends have been found.

During the study, no real proof of that the performance presented on the energy labels are differing (higher) than the performance experienced in real life installations has been found, but the perceptions remain and is strengthened. The analysis performed resulted in that there are several possible reason for the divergences and the explanation is probably a combination of the reasons listed below:

- One reason, especially for non-ducted air-to-air heat pumps, is the non ideal distribution of heat in the house due to the floor plan of the house.

- Another reason can be that the heat pumps are declared and labelled for much lower capacities and warmer climate than they are normally used for in a Nordic climate. 
- A third possible reason could be the fact that the heat pump operates differently with different performance when the frequency is set or fixed during laboratory tests compared to in the field when the normal control system of the heat pump are in operation.

- A fourth reason can be that the tests in the laboratory are not long enough for enough frosting and thereby defrosting to take place, especially at low capacities.

- One reason why air-to-air heat pumps do not perform as well in the field as in the laboratory tests, could be the fact that the defined test conditions in the standard has lower humidity of the air compared to the climate in the Nordic countries. This could still be a reason, but no real proof has been found.

The following recommendations are given:

- First of all, stronger incentives should be created to label air-to-air heat pumps sold on a Nordic market for the Cold climate.

- To avoid that the heat pumps are labelled for lower capacities than they are intended to be used for, it should not be allowed to state higher capacities in the promotion material than the Pdesign value.

- It is important to continue the development of a compensation method to use in the standard tests, instead of setting or fixing the frequency, as it could ultimately lead to declared performance closer to real life performances. The commission should encourage or mandate the standardization organization to develop such a method.

- More data from continuous field measurements on air-to-air heat pumps during complete heating seasons, especially in the Nordic Climate, is needed in order to develop the regulations and standards in the direction to give the consumer more reliable data as basis for their selection.

- Market surveillance authorities and consumer organizations should make sure that they are represented in the standardization work when developing new or revising standards to be used for ecodesign and energy labelling regulations. 


\section{Nomenclature}

EER Energy Efficiency Ratio for air conditioners in cooling mode

COP Coefficient of Performance for air conditioners in heating mode

SEER Seasonal Energy Efficiency Ratio for air conditioners, cooling mode

SCOP Seasonal Coefficient of Performance for air conditioners, heating mode

SPF Seasonal Performance Factor for heat pumps

$\mathrm{Ph}_{\mathrm{h}} \quad$ Heating capacity

$P_{\text {Design }} \quad$ Heating capacity, according to manufacturer at lowest operating temperature of climate zone, $T_{\text {Design }}$

$P_{\text {Rated }} \quad$ The cooling or heating capacity of the vapour compression cycle of the unit at standard rating conditions [2]

$\mathrm{T}_{\mathrm{j}} \quad$ Temperature of bin in SCOP calculation

$\mathrm{T}_{\text {Design }} \quad$ Lowest operating temperature of climate zone, according to EN 14511

TOL Operating temperature limit, below this temperature the heat pump will stop

$\mathrm{H}_{\text {TO }} \quad$ The number of hours the unit is considered to work in thermostat off mode for air conditioners

$\mathrm{H}_{\mathrm{SB}} \quad$ The number of hours the unit is considered to work in standby mode for air conditioners

$\mathrm{H}_{\mathrm{CK}} \quad$ The number of hours the unit is considered to work in crankcase heater mode for air conditioners

HofF $\quad$ The number of hours the unit is considered to work in off mode for air conditioners

$P_{\text {TO }} \quad$ The electricity consumption during thermostat off mode for air conditioners

$P_{S B} \quad$ The electricity consumption during standby mode for air conditioners

$\mathrm{P}_{\mathrm{CK}} \quad$ The electricity consumption during crankcase heater mode for air conditioners

PoFf The electricity consumption during off mode

$\mathrm{Q}_{C E} \quad$ The reference annual cooling demand for air conditioners in cooling mode

$\mathrm{Q}_{\mathrm{HE}} \quad$ The reference annual heating demand for air conditioners in heating mode 


\section{Background}

Ecodesign and energy labelling regulations for air source heat pumps were introduced in 2013 in EU and applies for all products that are put on the EU market. The regulations 206/2012 [1] and 626/2012 [2] applies for air-to-air heat pumps. Some of the Nordic market surveillance authorities suspects or have the perception that the declared efficiencies for the products on the energy labels and supporting data sheets are considerably higher compared to what have been measured in real installations in the field, especially in cold and humid climates, which in such case gives the consumer misleading information.

The purpose of this study was first and foremost to confirm or reject this suspicion. Thereafter, if confirmed, the reasons for the divergences should be clarified. Possible reasons for divergences and weaknesses that had been identified by the market surveillance authorities on beforehand are that:

- Tests do not take humidity sufficiently into account.

- Unclear definition and use of $P_{\text {design, }} P_{\text {rated }}$ and maximum capacity.

Which could mislead the consumer.

\subsection{Regulations 206/2012 and 626/2012}

In this section the purpose, content and requirements of the Ecodesign regulation for airconditioners and air-to-air heat pumps, 206/2012, and the corresponding energy label regulation, 626/2012, are summarized. Even though they apply for both air-conditioners, air-to-air heat pumps and reversible units, air-conditioners and reversible units in cooling mode is the main focus of the regulation, since that product group and mode correspond to more energy use compared to air-to-air heat pumps (and reversible units) in heating mode. 
The regulations where approved in 2012 and now, five years later the process for review and possibly revision of the regulations have started.

The purpose of the Ecodesign regulations is to remove the less efficient products from the market. The Ecodesign regulation mentioned above include minimum efficiency requirements and requirements for maximum allowed sound power level. They also include requirements for product information in manuals for installers and users and on websites of the manufacturer.

From 1 January 2014 the efficiency performance of air-conditioners and air-to-air heat pumps shall correspond to the requirement in Table 1 below. For the cooling mode of the products, the requirements are based on EER (Energy Efficiency Ratio) for ducted units and on SEER (Seasonal Energy Efficiency Ratio) for non-ducted units (freeblowing). For the heating mode, which is most important for this study, the requirements are based on COP (Coefficient of performance) for ducted units and SCOP (Seasonal Coefficient of Performance) for non-ducted units. For reversible units, i.e. such units that can be used for both heating and cooling, both requirements apply. Worth to note is also that the requirements are different for different capacity of the units and depends on the GWP (Global Warming Potential) of the refrigerants used.

Table 1: Ecodesign requirements from Regulation (EU) 206/2012

\begin{tabular}{|c|c|c|c|c|c|c|}
\hline & \multicolumn{2}{|c|}{$\begin{array}{l}\text { Air conditioners, except } \\
\text { double and single duct air } \\
\text { conditioners }\end{array}$} & \multicolumn{2}{|c|}{ Double duct air conditioners } & \multicolumn{2}{|c|}{ Single duct air conditioners } \\
\hline & SEER & $\begin{array}{r}\text { SCOP (heating } \\
\text { season: } \\
\text { Average) }\end{array}$ & EERrated & COPrated & EERrated & COPrated \\
\hline $\begin{array}{l}\text { If GWP of refrigerant } \\
>150 \text { for }<6 \mathrm{~kW}\end{array}$ & 4.60 & 3.80 & 2.60 & 2.60 & 2.60 & 2.04 \\
\hline $\begin{array}{l}\text { If GWP of refrigerant } \\
\leq 150 \text { for }<6 \mathrm{~kW}\end{array}$ & 4.14 & 3.42 & 2.34 & 2.34 & 2.34 & 1.84 \\
\hline $\begin{array}{l}\text { If GWP of refrigerant } \\
>150 \text { for } 6-12 \mathrm{~kW}\end{array}$ & 4.30 & 3.80 & 2.60 & 2.60 & 2.60 & 2.04 \\
\hline $\begin{array}{l}\text { If GWP of refrigerant } \\
\leq 150 \text { for } 6-12 \mathrm{~kW}\end{array}$ & 3.87 & 3.42 & 2.34 & 2.34 & 2.34 & 1.84 \\
\hline
\end{tabular}

Note: The SCOP values should be compared to SPFH 4 according to SEPEMO, see Figure 6 on page 36 . Double and single duct air conditioners are rare in the Nordic countries. 
The energy labelling regulation aims to promote energy efficient heating and cooling by making the products energy efficiency class visible to the consumers in a standardised manner. The Ecodesign regulations alone could otherwise have resulted in that all products perform just above the threshold value.

The Energy labelling regulations requires that energy labels are displayed where products are sold and promoted. Climate zones is one important aspect of the energy labels for heat pumps and the heating mode. Information on the energy label directly refers to a specific climate zone and the figures are calculated based on the conditions of one. The European Reference for climate conditions divides Europe geographically into three zones: colder, average and warmer climate conditions. The simplest method to determine the climate zone of a country is to consult the map of climate zones, see Figure 1. A similar map is shown on the energy label of individual product. It can be seen from the map that Denmark is located in "average" climate zone, whereas Norway, Sweden, and Finland are located in "colder" climate zone. Iceland is in "colder" climate zone though not shown on Figure 3 [3]. A large portion of continental Europe is also in the colder climate zone, for example Estonia, Latvia, Lithuania, Poland, Czech republic, Slovakia, Hungary, Romania, Bulgaria, Austria, Slovenia, Croatia and parts of Germany and Italy. 
Figure 1: European map of climate conditions [3]

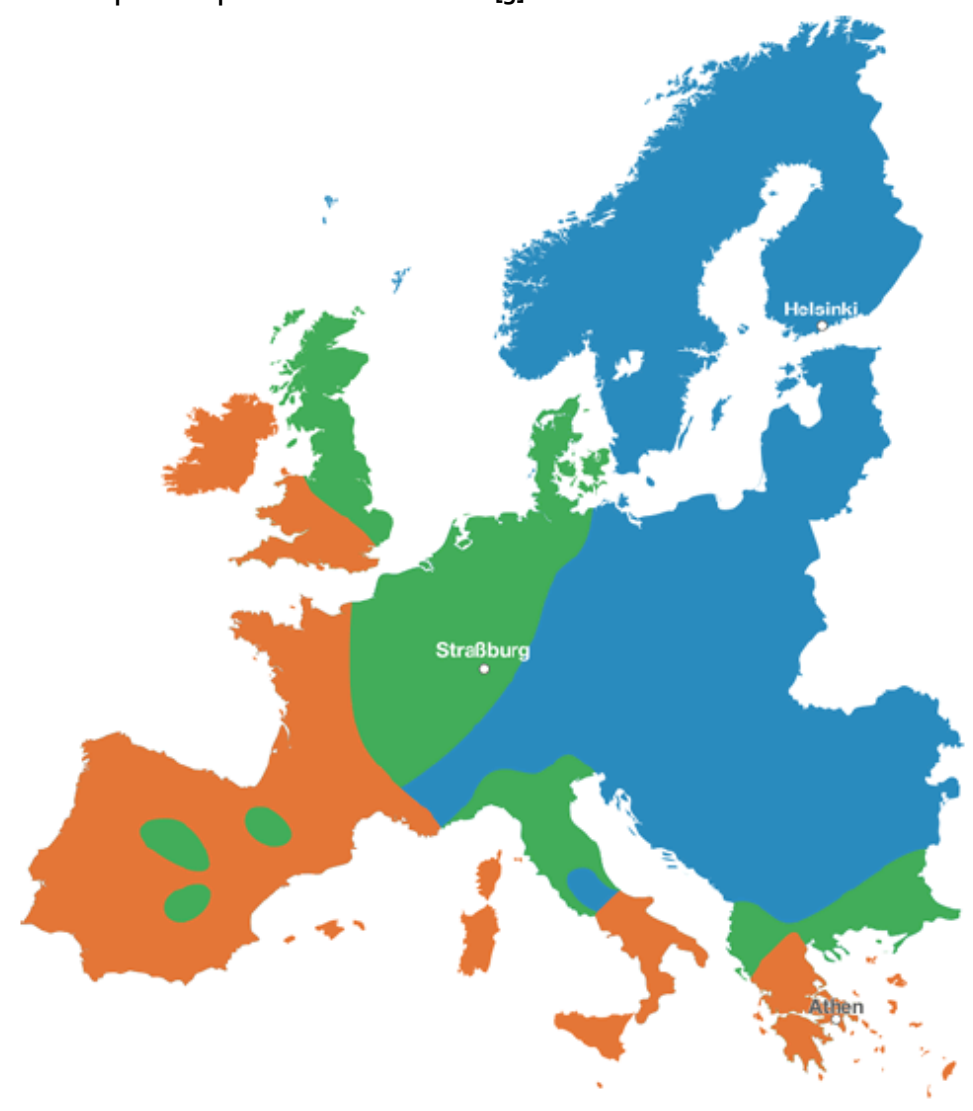

For different types of heat pumps and package products, the energy labels display different information, according to Viegand and Maagøe [3]. As shown in Table 2 below (Table 3 in [3]), it is usually mandatory to indicate information for average climate conditions, but for colder climate conditions it is often optional or no indication at all on the label. On the energy labels of air to air heat pumps (reversible), it is mandatory to indicate the energy efficiency class SCOP for heating and SEER for cooling, rated output (i.e. the output the coldest or warmest hour of the year) and annual energy consumption for average climate conditions, but it is also possible to indicate the information for colder or warmer climate conditions. However, this is only optional. Examples of air to air heat pump energy labels can be seen in Figure 2 [3]. 
Table 2: Information shown for colder and average climate conditions on energy labels

\begin{tabular}{llllll} 
Information & Air to air HP & $\begin{array}{l}\text { HP Space } \\
\text { heaters }\end{array}$ & $\begin{array}{l}\text { HP } \\
\text { combination } \\
\text { heaters }\end{array}$ & $\begin{array}{l}\text { HP Water } \\
\text { heaters }\end{array}$ & Packages \\
\hline $\begin{array}{l}\text { SCOP - average } \\
\text { SCOP - cold }\end{array}$ & $\begin{array}{l}\text { Mandatory } \\
\text { Optional }\end{array}$ & - & - & N/A & - \\
$\begin{array}{l}\text { Efficiency Class - average } \\
\text { Efficiency Class - cold }\end{array}$ & Mandatory & Mandatory & Mandatory & Mandatory & Mandatory \\
$\begin{array}{l}\text { Rated output - average } \\
\text { Rated output - cold }\end{array}$ & Mandatory & Mandatory & Mandatory & - & - \\
$\begin{array}{l}\text { Annual energy/fuel } \\
\text { consumption - average }\end{array}$ & Mandatory & - & Mandatory & - & - \\
$\begin{array}{l}\text { Annual energy/fuel } \\
\text { consumption - cold }\end{array}$ & Optional & - & - & Mandatory & - \\
\hline
\end{tabular}

Based on the experiences of market surveillance of air to air heat pumps in Denmark, Sweden and Finland, information for colder climate conditions are not shown on the energy labels for air to air heat pumps, even though it is possible to be indicated, according to Viegand and Maagøe [3]. This is potentially a problem, as the Nordic consumers may be misled by the higher efficiency, rated power and lower energy consumption for average climate, at the same time consumers are not getting the most realistic information if they live in colder conditions [3]. However, lately some products, also labelled for the cold climates, have appeared at least on the Swedish market, even though they still are rare. 
Figure 2: Air to air heat pump (air conditioners) with heating and cooling (left), and heating only (right) energy labels [3]
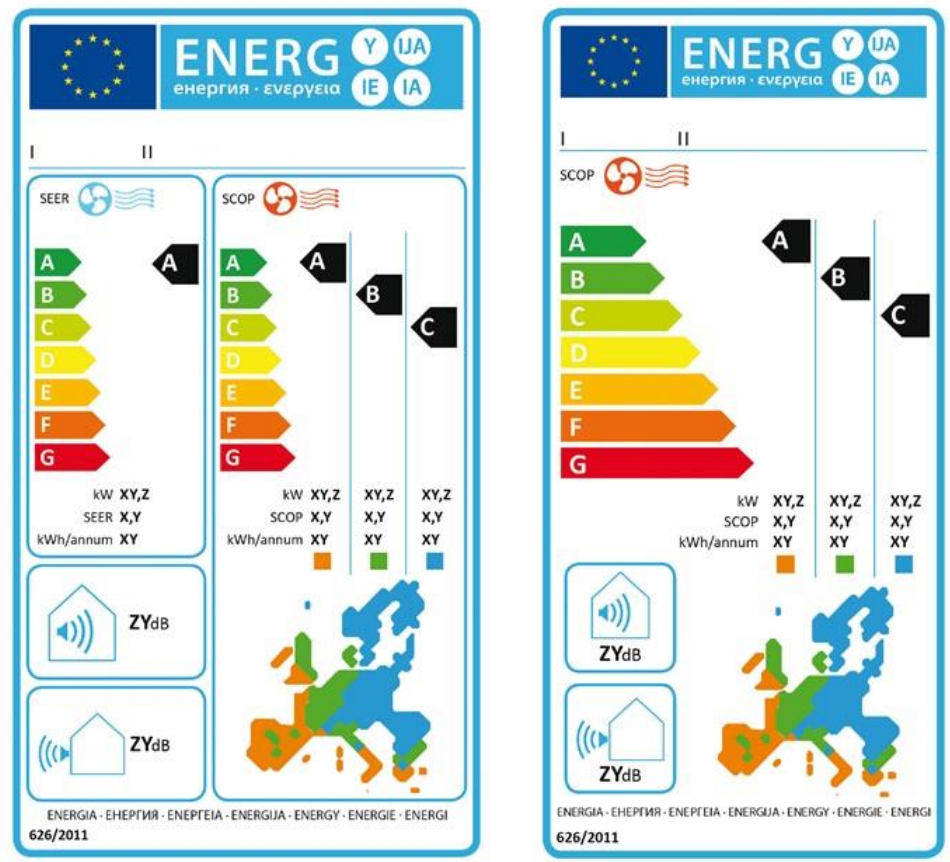

\subsubsection{Summary Regulations}

The Ecodesign regulations for air-to-air heat pumps stipulate minimum efficiencies for products placed on the European market. According to the energy label regulations the air-to-air heat pumps must have an energy label showing both efficiency and rated capacity. There is a possibility to label the products for three different climates - cold, average and warm, but only mandatory to label them for the average climate. It is still rare that products sold on the Swedish and Norwegian markets have information on their labels for the cold climate even though the climate in these countries is most coherent with the cold climate described on the regulation. 


\subsection{European standards harmonized with regulations 206/2012 and $626 / 2012$}

After the regulations had been approved by the EU member states, a mandate were issued by the EC to the European Standardization Organizations "M488 - Mandate to CEN, CENELEC and ETSI for standardisation in the field of air conditioners and comfort fans". This mandate supported the development of harmonised standards regarding regulation 626/2011 and 206/2012 for air conditioners and fans. As a consequence of this, the standards below were developed or revised to fulfil the mandate.

The performance data presented in the ecodesign and energy labelling documentations shall be produced according to pre described methods described in certain standards developed for that purpose, and accepted by the Commission, i.e. harmonized standards. The standards harmonized with the regulations 206/2012 and $626 / 2012$ are summarized below in the same way as they are summarized by Huang et al. [4] in the Draft Review study for revision of the regulations, Task 1 and 2 performed in 2017.

Standards regarding energy performance of EU Regulation 206/2012/EU and EU Regulation $-626 / 2011$ are:

- EN14511 which defines the rated performance and measurement methods to be used for all air conditioners in cooling and in heating mode, with the exception of air conditioners with evaporatively cooled condensers whose ratings are defined in $E N 15218$ standard.

- For other than single duct, double duct and evaporatively cooled air conditioners, the standard $E N 14825$ defines the calculation and testing points to calculate the seasonal energy efficiency (SEER) and seasonal coefficient of performance (SCOP) and completes where required measurement methods defined in standard EN14511.

- Standby and off mode power consumption measurement method is specified in EN14511-3 for single duct and double duct air conditioners, in EN15218 for evaporatively cooled single duct or double duct air conditioners and in the EN14825 standard for other air conditioners. [4] 


\subsubsection{EN14511}

EN 14511:2013 Air conditioners, liquid chilling packages and heat pumps with electrically driven compressors for space heating and cooling.

The standard is divided in 4 parts which are: scope, terms and definitions, test conditions, test methods and requirements. This standard defines test conditions for rating the performances of the units at their maximum available capacity for these operating conditions; only the tests in the standard conditions are mandatory, application conditions are facultative. The test conditions are defined in cooling mode and the heating mode following the classification by outdoor side and indoor side fluids. Rating conditions in heating and cooling mode are given in Table 3 and Table 4 [4].

Table 3: Air to air, testing conditions in the heating mode (EN 14511:2013) [4]

\begin{tabular}{|c|c|c|c|c|c|}
\hline & & \multicolumn{2}{|c|}{ Outdoor heat exchanger } & \multicolumn{2}{|c|}{ Indoor heat exchanger } \\
\hline & & $\begin{array}{r}\text { Inlet dry bulb } \\
\text { temperature }{ }^{\circ} \mathrm{C}\end{array}$ & $\begin{array}{r}\text { Inlet wet bulb } \\
\text { temperature }{ }^{\circ} \mathrm{C}\end{array}$ & $\begin{array}{r}\text { Inlet dry bulb } \\
\text { temperature }{ }^{\circ} \mathrm{C}\end{array}$ & $\begin{array}{r}\text { Inlet wet bulb } \\
\text { temperature }{ }^{\circ} \mathrm{C}\end{array}$ \\
\hline \multirow[t]{3}{*}{$\begin{array}{l}\text { Standard } \\
\text { rating } \\
\text { conditions }\end{array}$} & $\begin{array}{l}\text { Outdoor air/recycled air } \\
\text { (e.g. window, double } \\
\text { duct, split units) }\end{array}$ & 7 & 6 & 20 & 15 max. \\
\hline & $\begin{array}{l}\text { Exhaust air/recycled air } \\
\text { (e.g. single duct heat } \\
\text { pump) }\end{array}$ & 20 & 12 & 20 & 12 \\
\hline & Exhaust air/outdoor air & 20 & 12 & 7 & 6 \\
\hline \multirow[t]{6}{*}{$\begin{array}{l}\text { Application } \\
\text { rating } \\
\text { conditions }\end{array}$} & $\begin{array}{l}\text { Outdoor air/recycled air } \\
\text { (e.g. window, double } \\
\text { duct, split units) }\end{array}$ & 2 & 1 & 20 & 15 max. \\
\hline & $\begin{array}{l}\text { Outdoor air/recycled air } \\
\text { (e.g. window, double } \\
\text { duct, split units) }\end{array}$ & -7 & -8 & 20 & 15 max. \\
\hline & $\begin{array}{l}\text { Outdoor air/recycled air } \\
\text { (e.g. window, double } \\
\text { duct, split units) }\end{array}$ & -15 & - & 20 & 15 max. \\
\hline & $\begin{array}{l}\text { Outdoor air/recycled air } \\
\text { (e.g. window, double } \\
\text { duct, split units) }\end{array}$ & 12 & 11 & 20 & 15 max. \\
\hline & Exhaust air/outdoor air & 20 & 12 & 2 & 1 \\
\hline & Exhaust air/outdoor air & 20 & 12 & -7 & -8 \\
\hline
\end{tabular}

Note: Double and single duct air conditioners are rare in the Nordic countries. 
Table 4: Air to air, testing conditions in the cooling mode (EN 14511:2013) [4]

\begin{tabular}{|c|c|c|c|c|c|}
\hline & & \multicolumn{2}{|c|}{ Outdoor heat exchanger } & \multicolumn{2}{|c|}{ Indoor heat exchanger } \\
\hline & & $\begin{array}{r}\text { Inlet dry bulb } \\
\text { temperature }{ }^{\circ} \mathrm{C}\end{array}$ & $\begin{array}{r}\text { Inlet wet bulb } \\
\text { temperature }{ }^{\circ} \mathrm{C}\end{array}$ & $\begin{array}{r}\text { Inlet dry bulb } \\
\text { temperature }{ }^{\circ} \mathrm{C}\end{array}$ & $\begin{array}{r}\text { Inlet wet bulb } \\
\text { temperature }{ }^{\circ} \mathrm{C}\end{array}$ \\
\hline \multirow[t]{6}{*}{$\begin{array}{l}\text { Standard } \\
\text { rating } \\
\text { conditions }\end{array}$} & $\begin{array}{l}\text { Comfort (outdoor } \\
\text { air/recycled air) } \\
\text { (e.g. window, double duct, } \\
\text { split units) }\end{array}$ & 35 & $24 a$ & 27 & 19 \\
\hline & $\begin{array}{l}\text { Exhaust air/recycled air (e.g. } \\
\text { single duct heat pump) } \\
\text { Comfort } \\
\text { (exhaust air/recycled air) }\end{array}$ & 27 & 19 & 27 & 19 \\
\hline & $\begin{array}{l}\text { Comfort } \\
\text { (exhaust air/outdoor air) }\end{array}$ & 27 & 19 & 35 & 24 \\
\hline & Single duct $b, c$ & 35 & 24 & 35 & 24 \\
\hline & Control cabinet & 35 & 24 & 35 & 24 \\
\hline & Close control & 35 & 24 & 24 & 17 \\
\hline \multirow[t]{5}{*}{$\begin{array}{l}\text { Application } \\
\text { rating } \\
\text { conditions }\end{array}$} & $\begin{array}{l}\text { Comfort } \\
\text { (outdoor air/recycled air) } \\
\text { (e.g. window, double duct, } \\
\text { split units) }\end{array}$ & 27 & $19 a$ & 21 & 15 \\
\hline & Single duct $b, c$ & 27 & 19 & 27 & 19 \\
\hline & $\begin{array}{l}\text { Comfort } \\
\text { (outdoor air/recycled air) } \\
\text { (e.g. window, double duct, } \\
\text { split units) }\end{array}$ & 46 & $24 a$ & 29 & 19 \\
\hline & Control cabinet & 50 & 30 & 35 & 24 \\
\hline & Close control & 27 & 19 & 21 & 15 \\
\hline
\end{tabular}

Note: a) The wet bulb temperature condition is not required when testing units which do not evaporate condensate.

b) When using the calorimeter room method, pressure equilibrium between indoor and outdoor compartments shall be obtained by introducing into indoor compartment, air at the same rating temperature conditions.

c) The pressure difference between the two compartments of the calorimeter room shall not be greater than $1.25 \mathrm{~Pa}$. This pressure equilibrium can be achieved by using an equalising device or by creating an open space area in the separation partition wall, which dimensions shall be calculated for the maximum airflow of the unit to be tested. If an open space is created in the partition wall, an air sampling device or several temperature sensors shall be used to measure the temperature of the air from the outdoor compartment to the indoor compartment. 
The rated cooling capacity of the unit is determined at standard rating conditions (outdoor air $35^{\circ} \mathrm{C}$ / indoor air $27^{\circ} \mathrm{C}$ / chosen compressor frequency). For units with single speed compressors, this used to be the maximum capacity of the unit in cooling mode. However, for inverter drive compressor units, this is a design choice made by the manufacturer. This is the rated capacity that appears in product information and, as such, this value is used to determine if the unit is included or excluded in Regulation (EU) No 206/2012 (included if the cooling capacity lies below $12 \mathrm{~kW}$ ). The rated cooling capacity and performance at standard rating conditions is an input to the SEER according to EN14825 standard (see below). This means that the compressor frequency chosen to declare the cooling capacity has an influence on the energy performance, in cooling mode.

However, in heating mode, if the capacity standard rating conditions (outdoor air $7^{\circ} \mathrm{C} /$ indoor air $20^{\circ} \mathrm{C} /$ chosen frequency) is still used for heating only air-to-air heat pumps to classify the unit in the scope of Regulation (EU) No 206/2012 (if heating capacity is lower than $12 \mathrm{~kW}$ ), this capacity and related COP are not used in SCOP calculation. It means that the manufacturers freely can adjust the frequency of this point to optimize the declared rated heating capacity and/or sound power value." [4]

In the review study [4], it has been identified that the reference to standard rated conditions in heating mode is to be modified in Regulation (EU) No 206/2012 [1] to take this point into account.

\subsubsection{Evaluation during frosting and defrosting}

In real life air-to-air heat pumps defrost at certain combinations of air temperatures and capacities. Therefore, this must be taken into account when testing heat pumps in the laboratory, and the test periods must be sufficiently long to be able to evaluate if frosting take place on the heat exchanger surface or not. On the other hand, to keep down the cost for testing a heat pump, the evaluation periods are limited to a certain length.

The evaluation periods when evaluating an air source heat pump according to EN14511 is described below, see Figure 3 . 
Figure 3: Schematics describing the evaluation periods in EN14511 [5]

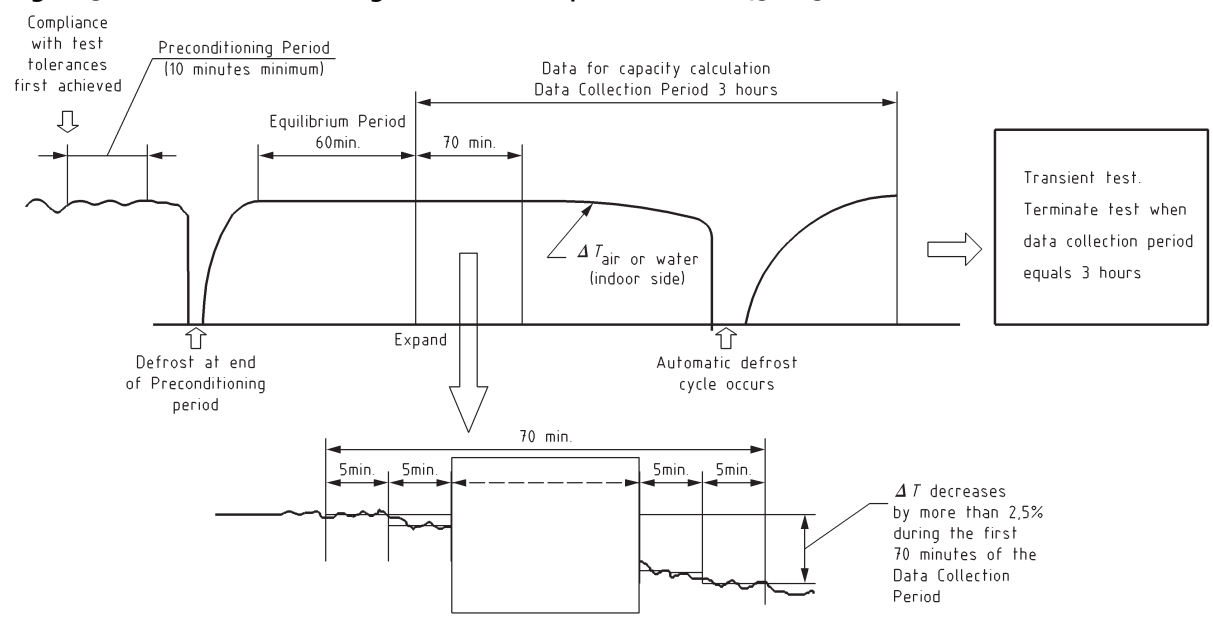

To start with, the test room reconditioning apparatus and the heat pump under test shall be operated until the test tolerances specified in the standard are attained for at least $1 \mathrm{~h}$, which is called the equilibrium period. After this the duration of measurement during the data collection period shall not be less than $70 \mathrm{~min}$. To indicate if frosting occur on the heat exchanger surface, the difference between the leaving and entering temperatures of the heat transfer medium at the indoor heat exchanger (in this case air) shall be measured. For each interval of 5 min during the data collection period, an average temperature difference shall be calculated, $\Delta \mathrm{T}_{\mathrm{i}}(\tau)$. The average temperature difference for the first $5 \mathrm{~min}$ of the data collection period, shall be compared to the temperature difference during the last 5 min period.

If a defrost occurs before the start of the data collection period, or if the difference between the 5 min periods in the start and the end of the 70 min data collection period exceeds $2.5 \%$, the heating capacity test shall be designated a transient test. Likewise, if the heat pump initiates a defrost cycle during the equilibrium period or during the data collection period, the heating capacity test shall be designated a transient test.

If the above conditions do not occur and the test tolerances specified in the standard are satisfied during both the equilibrium period and the data collection period, then the heat capacity test shall be designated a steady state test. Steady-state tests shall be terminated after 70 min of data collection. 
For a transient test, the data collection period shall be extended until $3 \mathrm{~h}$ have elapsed or until the heat pump completes three complete cycles during the period, whichever occurs first. If at an elapsed time of $3 \mathrm{~h}$, the heat pump is conducting a defrost cycle, the cycle shall be completed before terminating the collection of data. A complete cycle consists of a heating period and a defrost period; from defrost termination to defrost termination. Hence, both the heating period and the defrosting period is included in the data evaluation period. Data used in evaluating the integrated heating capacity and the integrated power input of the heat pump shall be sampled more frequently during defrost.

\subsubsection{EN14825[6]}

EN 14825:2016 Air conditioners, liquid chilling packages and heat pumps, with electrically driven compressors, for space heating and cooling - Testing and rating at part load conditions and calculation of seasonal performance.

This European Standard provides describes how to calculate the Seasonal Energy Efficiency Ratio (SEERon) and Seasonal Coefficient of Performance (SCOP on and $\mathrm{SCOP}_{n e t}$ ) for air-conditioners and air-to-air heat pumps when they are used to fulfil the cooling and heating demands. It also gives the part load conditions and calculation methods. This standard is harmonized for air conditioner regulation No 206/2012 and space heater EU regulations No 813/2013 and No 811/2013. The overall methods and numerical values used are defined in the regulations above. However, the test methods are defined in this specific standard.

The version from 2016 is the latest published version of this standard, which has replaced the version from 2013. However, it is the version from 2013 which is harmonized with the regulations according to the EU Official Journal. However, regarding air-to-air heat pumps there are not any significant differences.

This standard has the same scope as defined in $\mathrm{EN}_{14511-1}$ but does not apply to single duct and double duct air conditioners, for which no seasonal performance rating is defined. There is a revision project of $\mathrm{EN}_{14825}$ (prEN14825:2017) to satisfy the requirements of EU regulations 1095/2015 and 2281/2016 [4]. The standard has already been revised to satisfy the requirements of EU regulations 811/2013 and 813/2013, but it has not been accepted (approved) by the Commission yet and hence, it is not yet harmonized. 


\subsubsection{Heating mode}

The same procedure is applied in heating mode as in cooling mode. For the purpose of reference SCOP and reference $\mathrm{SCOP}_{\text {on, }}$ there are 3 reference conditions: average $(A)$, warmer (W) and colder (C). A supplementary $\mathrm{SCOP}_{\text {net, }}$ without backup nor consumption of the low power modes, is defined in view of the renewable energy directive (Commission decision 2013/114/EU)14.

For air-to-water heat pumps, the seasonal space heating efficiency in primary energy $\eta s[\%]$, defined in regulations (EU) No 811/2013 and (EU) 813/2013 is also included, but does not apply for air-to-air heat pumps as it was not defined in Regulation (EU) 206/2012." [4]

\subsubsection{The Reference design conditions for heating ( $\left.T_{\text {Design }}\right)$}

The lowest ambient temperature conditions for average, colder and warmer climates.

- Average: $-10^{\circ} \mathrm{C}$ dry bulb outdoor temperature and $20^{\circ} \mathrm{C}$ dry bulb indoor temperature.

- Cold: $-22^{\circ} \mathrm{C}$ dry bulb outdoor temperature and $20^{\circ} \mathrm{C}$ dry bulb indoor temperature.

- Warm: $+2{ }^{\circ} \mathrm{C}$ dry bulb outdoor temperature and $20^{\circ} \mathrm{C}$ dry bulb indoor temperature. [4]

$\mathrm{P}_{\text {Design }}$ is defined as the heating capacity declared by the manufacturer at $\mathrm{T}_{\text {Design. }} . \mathrm{P}_{\text {Design }}$ for each individual heat pump model type can be chosen more or less freely, see restrictions in 2.2.7 and description in Figure 4 below.

\subsubsection{Bivalent temperature ( $\left.T_{\text {bivalent }}\right)$}

The bivalent point is the lowest outdoor temperature point at which the heat pump is declared to be able to meet $100 \%$ of the heating demand without additional backup.

NOTE: Below this point, the unit may still deliver capacity, but additional back up heating is necessary to fulfill the heating demand. 
The declared bivalent temperature can be any outdoor temperature (dry bulb) within following limits (this is defined in Regulation (EU) 206/2012:

- For the average heating season, the bivalent temperature is $+2{ }^{\circ} \mathrm{C}$ or lower.

- For the colder heating season, the bivalent temperature is $-7^{\circ} \mathrm{C}$ or lower.

- For the warmer heating season, the bivalent temperature is $+7^{\circ} \mathrm{C}$ or lower. [4]

Figure 4 below gives a schematic overview of the part load ratios, test points and the bivalent temperature described in the standard EN14825. The description apply for an air-to-water on-off controlled heat pump where the capacity of the heat pump is larger than the heat load above the bivalent point. For a variable capacity heat pump (air-towater or air-to-air) the capacity can be continuously lowered to follow the load curve (orange line) down to a certain limit. For the highest outdoor temperatures, for example above $10^{\circ} \mathrm{C}$ the capacity will be higher than the load curve and the heat pump will in real life cycle on and off.

Figure 4: Schematic overview of the SCOPon calculation points (for an on-off cycling air to water unit, in $E_{14}$ 825:2016, Annex $E$, p 74) [6]

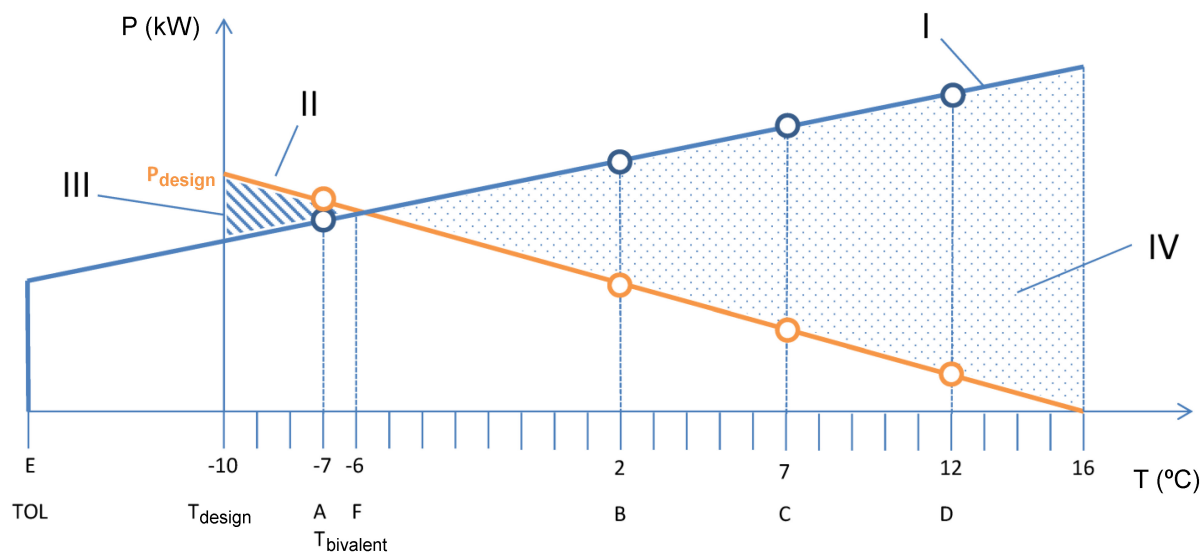

Note: $\quad \mathrm{T}$ : outdoor temperature $\left({ }^{\circ} \mathrm{C}\right), \mathrm{P}$ : capacity/load $(\mathrm{kW})$, I: declared capacity line and declared capacities at conditions $A, B, C$ and $D$, II: load curve and part load capacity at conditions $A, B, C$, and D, III: electric back up heater, IV: on off cycling, Tdesign: reference design temperature and Tbivalent: bivalent temperature. 


\subsubsection{The bin calculation}

The calculation method described in $\mathrm{EN}_{14825}$ is based on a so called bin method, where the performance of the heat pump is determined, step by step, for the different conditions during the heating season. The heating bins (one for each degree outdoor temperature) are given hereunder. The load curve in heating mode is computed with $16^{\circ} \mathrm{C}$ as the balance point temperature (ie outdoor dry bulb temperature with no heating load) with the following formula:

The heating demand, $P_{h}\left(T_{j}\right)$, for each bin can be determined by multiplying the full load value $\left(P_{\text {designh }}\right)$ with the part load ratio \% for each corresponding bin. This part load ratio $\%$ is calculated as follows:

- For the average climate: Part load ratio $\%=\left(\mathrm{T}_{\mathrm{j}-16)} /(-10-16) \%\right.$.

- For the warmer climate: Part load ratio $\%=\left(\mathrm{T}_{\mathrm{j}-16)} /(+2-16) \%\right.$.

- For the colder climate: Part load ratio $\%=\left(\mathrm{T}_{\mathrm{j}}-16\right) /(-22-16) \%$. [4] 
Table 5: Bin number $\mathrm{j}$, outdoor temperature $\mathrm{T}_{\mathrm{j}}$ in ${ }^{\circ} \mathrm{C}$ and number of hours per bin $\mathrm{hj}$ corresponding to the reference heating seasons -warmer, -average, - colder [4]. Blue shaded bins show declarations (test) points according to $\mathrm{EN} 14825$, were $-15^{\circ} \mathrm{C}$ is mandatory, depending on lower operation limit for the heat pump

\begin{tabular}{|c|c|c|c|c|}
\hline \multicolumn{3}{|c|}{ Warmer (W) } & Average (A) & Colder (C) \\
\hline j & $T_{j}$ & $h_{j} W$ & $h_{j} A$ & $h_{j} \mathrm{C}$ \\
\hline$\#$ & {$\left[{ }^{\circ} \mathrm{C}\right]$} & [h] & [h] & [h] \\
\hline 1 to 8 & -30 to -23 & 0 & 0 & 0 \\
\hline 9 & -22 & 0 & 0 & 1 \\
\hline 10 & -21 & 0 & 0 & 6 \\
\hline 11 & -20 & 0 & 0 & 13 \\
\hline 12 & -19 & 0 & 0 & 17 \\
\hline 13 & -18 & o & 0 & 19 \\
\hline 14 & -17 & 0 & 0 & 26 \\
\hline 15 & -16 & 0 & 0 & 39 \\
\hline 16 & -15 & 0 & 0 & 41 \\
\hline 17 & -14 & 0 & 0 & 35 \\
\hline 18 & -13 & 0 & 0 & 52 \\
\hline 19 & -12 & 0 & 0 & 37 \\
\hline 20 & -11 & o & 0 & 41 \\
\hline 21 & -10 & 0 & 1 & 43 \\
\hline 22 & -9 & 0 & 25 & 54 \\
\hline 23 & -8 & o & 23 & 90 \\
\hline 24 & -7 & 0 & 24 & 125 \\
\hline 25 & -6 & 0 & 27 & 169 \\
\hline 26 & -5 & o & 68 & 195 \\
\hline 27 & -4 & 0 & 91 & 278 \\
\hline 28 & -3 & 0 & 89 & 306 \\
\hline 29 & -2 & 0 & 165 & 454 \\
\hline 30 & -1 & 0 & 173 & 385 \\
\hline 31 & 0 & o & 240 & 490 \\
\hline 32 & 1 & o & 280 & 533 \\
\hline 33 & 2 & 3 & 320 & 380 \\
\hline 34 & 3 & 22 & 357 & 228 \\
\hline 35 & 4 & 63 & 356 & 261 \\
\hline 36 & 5 & 63 & 303 & 279 \\
\hline 37 & 6 & 175 & 330 & 229 \\
\hline 38 & 7 & 162 & 326 & 269 \\
\hline 39 & 8 & 259 & 348 & 233 \\
\hline 40 & 9 & 360 & 335 & 230 \\
\hline 41 & 10 & 428 & 315 & 243 \\
\hline 42 & 11 & 430 & 215 & 191 \\
\hline 43 & 12 & 503 & 169 & 146 \\
\hline 44 & 13 & 444 & 151 & 150 \\
\hline 45 & 14 & 384 & 105 & 97 \\
\hline 46 & 15 & 294 & 74 & 61 \\
\hline & Total & 3,590 & 4,910 & 6,446 \\
\hline
\end{tabular}


Figure 5: Diagram over the bins of each climate shown in Table 5
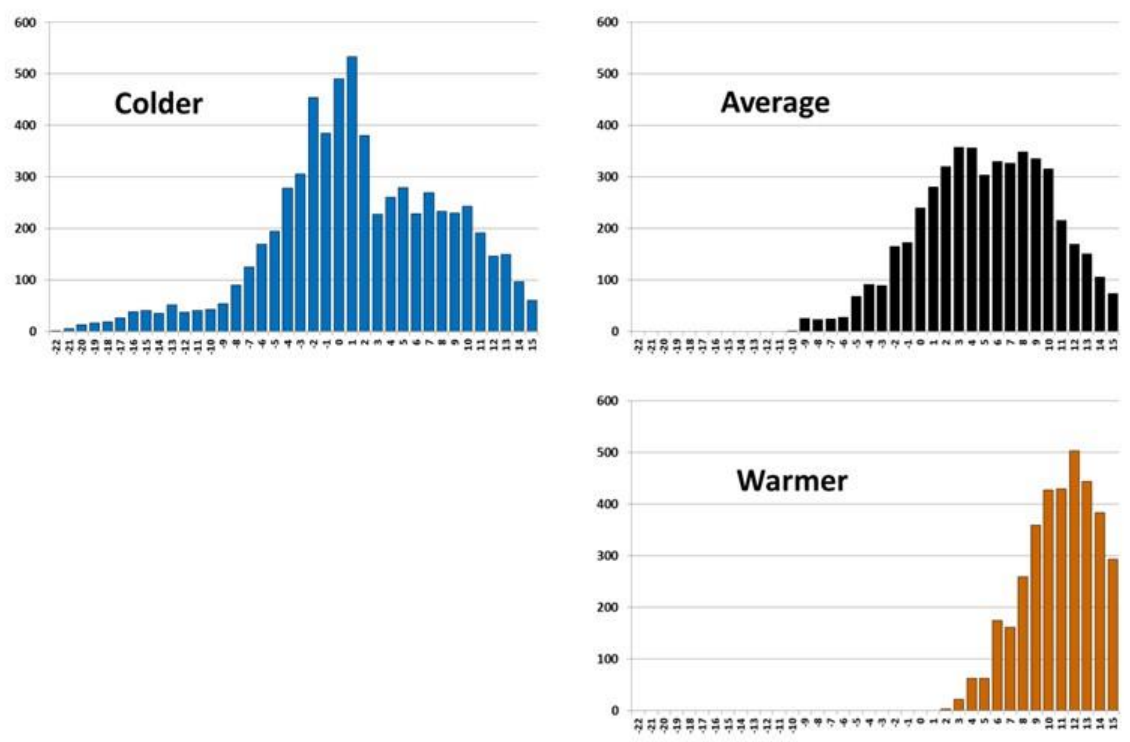

The SCOP on are computed by summarising the heating demand for all the bins and electricity consumption for all the bins, separately, and then dividing the total heating demand by the total electricity consumption. The electric heating required to cover the heating load below the bivalent point is also considered and included.

To calculate the reference SCOP value, the equivalent full load hours and the performance and the number of hours the heat pump are in other modes than on mode (low power mode consumption), are also taken into consideration. Default equivalent full load hours are given for air to air reversible units with cooling capacity as well as hours for low power mode consumption to compute reference SCOP value. These number of hours are defined in Regulation (EU) 206/2012. There are differences between values used for air-to-air air conditioners and air-to-water heat pumps that should be further analysed [4].

$$
\operatorname{SCOP}_{\text {on }}=\frac{\sum_{j=1}^{n} h_{j} * P h\left(T_{j}\right)}{\sum_{j=1}^{n} h_{j}\left(\frac{P h\left(T_{j}\right)-\operatorname{elbu}\left(T_{j}\right)}{\operatorname{COP}_{P L}\left(T_{j}\right)}+e l b u\left(T_{j}\right)\right)}[6
$$




$$
\begin{gathered}
Q_{H E}=\frac{Q_{H}}{S C O P_{O n}}+H_{T O} \times P_{T O}+H_{S B} \times P_{S B}+H_{C K} \times P_{C K}+H_{O F F} \times P_{O F F} \\
S C O P=\frac{Q_{H}}{Q_{H E}}
\end{gathered}
$$

When calculating the $\mathrm{SCOP}_{\text {on, }}$ the input data for the bins between the test points are interpolated as described in $\mathrm{EN}_{14825}$ [6], quoted below.

"The $\mathrm{COP}_{\text {bin }}$ values and capacity values at each bin are determined via interpolation of the $\mathrm{COP}_{\text {bin }}$ and capacity values at part load conditions $\mathrm{A}, \mathrm{B}, \mathrm{C}, \mathrm{D}, \mathrm{E}, \mathrm{F}$ and $\mathrm{G}$ where applicable" [6]. If looking at Figure 4 , this means that for the bins representing the temperatures between the circles on the lines, $P_{h}$ and COP $P_{P L}$ values are interpolated from the bins for which there are declared values (based on tests).

"Interpolation is done between the $\mathrm{COP}_{\text {bin }}$ and capacities of the 2 closest part load conditions (as mentioned in the tables of Clause 5). The $\mathrm{COP}_{\text {bin }}$ values and capacity values for part load conditions above $D$ are extrapolated from the $\mathrm{COP}_{\text {bin }}$ values and capacity values at part load conditions $C$ and $D$.

In case of the colder climate, and if the TOL (operation limit) is below $-20^{\circ} \mathrm{C}$, an additional calculation point has to be taken from the capacity and $\mathrm{COP}_{\text {bin }}$ at $-15^{\circ} \mathrm{C}$ condition (condition $\mathrm{G}$ ). However, if the capacity of the unit is lower than the value of $\mathrm{P}_{h}\left(T_{j}\right)$, correction needs to be made for the missing capacity either with an electric back up heater with a COP of 1 or with the fossil fuel back up heater having an efficiency $\eta_{\text {sffbu }}$ if the fossil fuel boiler is integrated in the unit. Below TOL (operation limit) the unit is not running. The capacity of the unit at outside air temperatures below TOL is o kW and correction needs to be made for the missing capacity either with an electric back up heater with a COP of 1 or with the fossil fuel back up heater having an efficiency $\eta_{\text {sffbu }}$ if the fossil fuel boiler is integrated in the unit." [6]

"The steady-state heating and cooling capacities determined using the calorimeter method shall be determined with a maximum uncertainty of:

- $5 \%$ when the capacity measured is greater than $2.0 \mathrm{~kW}$.

- $10 \%$ when the capacity measured is between $1.0 \mathrm{~kW}$ and $2.0 \mathrm{~kW}$.

- $15 \%$ if it is lower than $1.0 \mathrm{~kW}$. 
The heating capacities determined during transient operation (defrost cycles) using the calorimeter method shall be determined with a maximum uncertainty of $10 \%$. The heating and cooling capacities measured on the air side using the air enthalpy method shall be determined with a maximum uncertainty of $(4+6 /$ part load ratio) $\%$.

All uncertainties of measurement are independent of the individual uncertainties of measurement including the uncertainties on the properties of fluids. The maximum uncertainty of the measurement of the power input for off, thermostat off, standby and crankcase heater modes shall be $\pm 0.1 \mathrm{~W}$ up to $10 \mathrm{~W} ; \pm 1 \%$ for powers greater than $10 \mathrm{~W} . "[4]$

\subsubsection{Setting of test objects to obtain required capacity ration}

In Regulation 206/2012 the following is written "The manufacturer of air conditioners and comfort fans shall provide laboratories performing market surveillance checks, upon request, the necessary information on the setting of the unit as applied for the establishment of declared capacities, SEER/EER, SCOP/COP values and service values and provide contact information for obtaining such information." This statement is repeated in the harmonized standard EN14825 with the addition that "For inverter type control units, if the manufacturer gives instructions for the setting of the frequency for each rating condition, this setting shall be done." 


\subsubsection{Summary standards}

The conditions and test methods for determination of the capacity and efficiency at standard rating conditions for air-to-air heat pumps are described in the standard EN 14511.

The standard EN14825 describes calculation methods and part load conditions (for the different outdoor temperatures during the heating season) for determination of the seasonal coefficient of performance, SCOP, displayed on the energy label.

The test methods described in EN14511 for determination of capacity and efficiency are used also in $\mathrm{EN}_{14825}$. In case frosting take place on the outdoor unit during the test, both the heating and defrosting period is included in the test. However, the evaluation period is limited to maximally three hours to limit the cost of the tests.

The capacities (with corresponding efficiencies) that are used in the SCOP calculations can be defined freely (with some limitations) by the manufacturer and is NOT related to the capacity at standard rating conditions for which for which the sound level is declared.

According to the standards, if the manufacturer gives instructions for the setting of the frequency for the different test points, this setting shall be done. 


\section{Literature study}

\subsection{Field measurements of air-to-air heat pumps}

Field measurements of the performance of heat pumps can be made of different reasons and for different purposes, and therefore it can vary from case to case what has been included in the measurement results and what has been excluded. Because of this, when evaluating and comparing results from different field measurements for heat pumps, it is very important to relate to which system boundary that has been applied.

The SEPEMPO-Build project [7] elaborated guidelines for field measurements, for example for air-to-air heat pumps [8] and defined four different system boundaries that could be applied and should be referred to when performing and reporting results from field measurements for heat pumps. These are shown in figure below and can be concluded as follows. SPF is the abbreviation for Seasonal Performance Factor and is the average performance of the heat pump during a year or the heating season.

- $\mathrm{SPF}_{1}$ includes only the heat pump unit itself. Thereby $\mathrm{SPF}_{1}$ is similar to the average COP for the measured period.

- $\mathrm{SPFH}_{2}$ consist of the heat pump unit and the equipment needed to make the heat source available the heat pump.

- $\mathrm{SPF}_{\mathrm{H}_{3}}$ represents the heat pump system SPF. SPF $\mathrm{H}_{3}$ includes the heat pump and the heat source pump as in $\mathrm{SPF}_{2}$, but also the backup heater.

- $\mathrm{SPF}_{4}$ includes all parts related to $\mathrm{SPF}_{3}$, additionally $\mathrm{SPF}_{4}$ also includes the distribution of the heat. 
Figure 6: The system boundaries defined by the SEPEMO project [7]

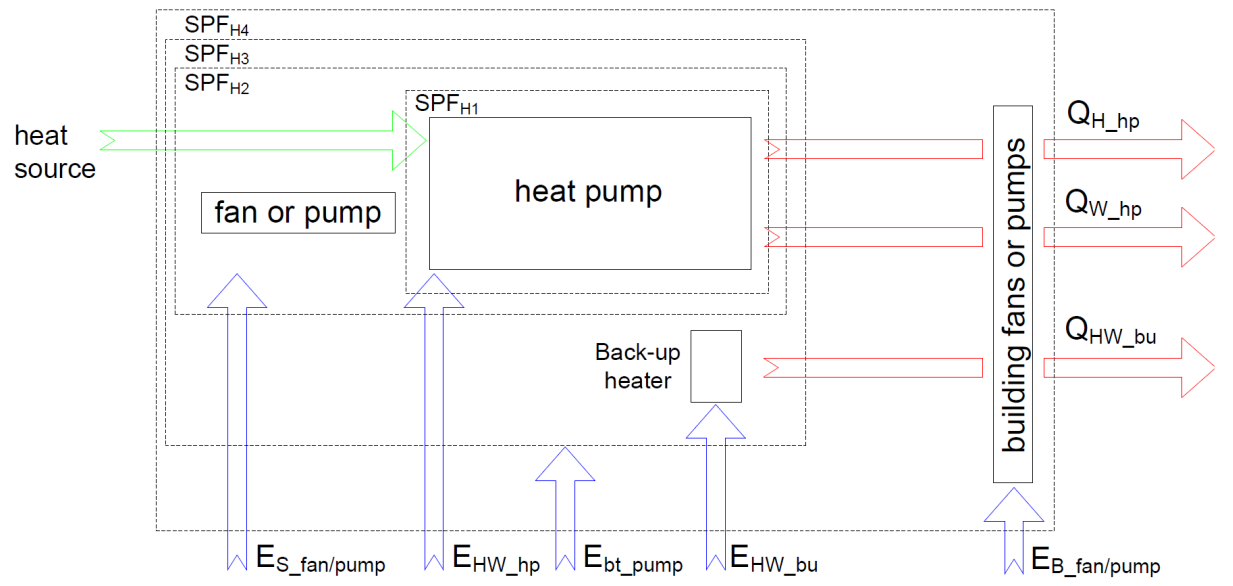

Very few reports from field measurements have been found in the open literature, especially for the cold climate, even though searches have been done in several databases.

The SEPEMO project [7] reported results from four different sites. The reported values are according to system boundary $\mathrm{H}_{3}$, i.e. $\mathrm{SPF}_{\mathrm{H}_{3}}$, hence including also the backup heat. The measurement method applied was the so called "Armine" method described by Rivière et al. [8] which means the heat capacity is measured by continuously measuring the air temperature and air speed from the indoor unit. They reported a uncertainty of $15 \%$ for the SPF values. $\mathrm{SPF}_{\mathrm{H}_{3}}$ values from four sites in France where reported, three in an average climate and one in a mildy warm climate. The reported $\mathrm{SPF}_{\mathrm{H}_{3}}$ values ranged from 3.4 to 3.8 .

Lidbom et al. [8] reported results from field measurements for five different air-to-air heat pumps in the south west part of Sweden performed on behalf of the Swedish Energy Agency in 2008. Since it was not possible in this case to continuously measure the heating capacity with sufficient accuracy in the indoor air flow from the non-ducted air-to-air heat pumps, the methodology used was to perform short measurement campaigns with a duration of a couple of hours at different outdoor temperatures. Even though all the evaluated heat pumps were inverter controlled and normally operated continuously at lower capacity than their maximal capacity during parts of the year, they were controlled to operate at full capacity at measurements campaigns. The reason for that was that in 
order to measure the heating capacity, the indoor air flow was temporally ducted and then the control system of the heat pump could not work as normal.

The results from the field measurements showed that the efficiency of the air-toair heat pump systems lied within a range, with some corrections, corresponding to earlier data from SP's laboratory test (see the section below). The heat pumps in the investigation returned annual COPs of between 2.3 and 2.6, with an average of 2.5. It is likely that the annual COP would have been higher if also part load performance had been included. These annual COPs are almost the same as the $\mathrm{SPF}_{\mathrm{H}_{2}}$ values described above, but they do also include the electric energy consumption of the indoor fan (for the heat distribution indoor). From the presented data, $\mathrm{SPF}_{\mathrm{H}_{4}}$ values can be calculated and they range from 1.8 to 2.1. However, again these are probably underestimated since no operation at part load has been included in the evaluation. The heat pumps used between 2,650 and 3,750 kWh per year.

Since there are no really good and smooth methods for evaluating non-ducted air-to-air heat pumps available, Tran et al. [10] tested and evaluated two possible methods in the lab. The first method is based on refrigerant fluid measurements. This method uses almost only non-intrusive sensors. The second method is based on measurements where the air flow is determined by a multi-port velocity measurement. According to the results these methods are fully applicable in the field.

Note that the refrigerant fluid measurement method referred to is the ClimaCheck AB method, available since 2004, patented in 1986.

\subsubsection{Summary-Field measurements of air-to-air heat pumps}

When reporting and evaluating results from field measurements it is important to relate to which system boundary that had been applied. The SEPEMO project defined four different system boundaries for SPF (Seasonal Performance Factors) values, SPFH1-SPFH 4 , which can be applied and the results presented in this report are related to them.

There are few results from field measurements reported in the open literature for air-to-air heat pumps, especially in the Nordic climate. Those found report SPFH 2 values between $2.2-2.6$ and $\mathrm{SPFH}_{4}$ values between 1.8 to 2.1. However, these are probably underestimated.

Reported SPF values from field measurements in average climates where considerably higher, mainly due to the warmer climate.

There are methods presented in the literature which could be applied for continuous field monitoring of air-to-air heat pumps with satisfying measurement uncertainty. 


\subsection{Laboratory measurements of air-to-air heat pumps}

Due to the lack of openly presented data for field measurements of air-to-air heat pumps, it is relevant to also include openly presented data from laboratory measurements in this study, especially such performed with a focus on Nordic climate.

Karlsson et al. [11] reported results from twelve variable-speed capacity controlled air-to-air heat pumps that had been evaluated by laboratory measurements at SP in 2005 and the results were compared to similar investigations made in 2001 (variablespeed capacity control) and 1991 (single-speed compressors). The heat pumps were evaluated in terms of efficiency, performance of defrost system and ability to operate in a cold climate. The results show that heat pumps have become more efficient since 1991 and 2001. On average, the coefficient of performance (COP) had increased by 7-24\% (different values for different test points) since 1991. The defrost systems had also improved, although there were still systems that in practice operated under simple time control, and thus performed unnecessarily many defrost cycles, which reduced performance and probably also equipment life.

At that time the standard for evaluating heat pumps at part load (part capacity) and calculating SCOP, EN 14825, had not yet been developed and published. The heating capacity and coefficient of performance (COP) was evaluated in accordance with the existing EN 14511:2004 [12] standard (for which SP was accredited), and the performance at part load (part capacity) was determined in accordance with CEN/TS 14825 [12]. The calorimeter room test procedure was used. The heat pumps were tested at the outdoor air temperatures and capacities listed in Table 6, and the air temperature entering the indoor unit was $+20^{\circ} \mathrm{C}$. The $75 \%$ and $50 \%$ part-load operation denotes the percentage of maximum heating capacity determined by the $\mathrm{EN}_{14511}$ tests. These part-load operation points were performed according to a "compensation method", which means that the calorimetric chamber was cooled to get $75 \%$ or $50 \%$ of the capacity measured at the $\mathrm{EN} 14511$ test point. Then the set value for the indoor air temperature was set to $20^{\circ} \mathrm{C}$, or a set value that gives $20^{\circ} \mathrm{C}$ inlet temperature to the indoor unit, in the heat pump's control system. In this way, the heat pump's own control system adjusts the compressor capacity, such that the desired indoor air temperature is kept constant. The tests were performed for at least ten hours, maximum 24 hours, and analysed for a whole number of operating cycles with defrost, which means that the tests continued over a longer period of time than prescribed in EN 14511. The reason for this was to validate proper operation of the defrost system. The heating capacity should not continually decrease during consecutive defrosts. 
Table 6: Test conditions in the tests performed by SP based on EN14511:2004 and CEN/TS14825

\begin{tabular}{rrr}
+7 & +6 & 100 \\
+2 & +1 & 100 \\
-7 & -8 & 100 \\
-15 & - & 100 \\
+7 & +6 & 75 \\
+7 & +6 & 50 \\
+2 & +1 & 50 \\
\hline
\end{tabular}

The test from 2001 was performed in accordance with the former EN 255 European standard, and the part-load operation was performed as specified in CEN/TS 14825. A minor deviation was that the wet bulb temperature at the outdoor temperature of $+2{ }^{\circ} \mathrm{C}$ was $+1,5^{\circ} \mathrm{C}$ in EN 255 and $+1{ }^{\circ} \mathrm{C}$ in EN 14511 . The tests from 1991 were performed in accordance with Swedish standard SS 2095 which, for air-to-air heat pumps, is similar to EN 14511. The only difference here is that the wet bulb temperature at $+7^{\circ} \mathrm{C}$ is $+5.5^{\circ} \mathrm{C}$. Note that there were no variable-speed controlled heat pumps in the test from 1991. For all three methods, the evaluations were made for a whole number of operating cycles with defrost.

Due to the differences in performance at different temperatures and part loads, calculation of the seasonal performance factor (SPF) is a good tool for comparing these heat pumps. Therefore, in this study, seasonal performance calculations were performed for two buildings with energy demands of 11,000 and $20,000 \mathrm{kWh}$ (space heating only) at an annual average outdoor air temperature of $+6^{\circ} \mathrm{C}$.

The results from such a calculation for two different buildings reported by Karlsson et al. [11] are shown in Figure 7. Note that the electricity used by the back-up heater is included in the SPF values (hence comparable with $\mathrm{SPF}_{\mathrm{H}_{3}}$ in Figure 6). The weakness of this comparison is that the heat pumps included in the test are not of equal capacity (see the right diagram in Figure 7) and thus cannot be directly compared, as the SPF value will depend on both capacity and efficiency. A large-capacity heat pump with a lower efficiency can have a higher SPF than an efficient low-capacity heat pump, which of course is relevant to include in an analysis as it is important properly to match the heat pump to the load. 
Figure 7: The left-hand diagram show the SPF for the heat pumps evaluated in 2005 when used in two different buildings (calculated values). The right-hand diagram show the capacity of the heat pumps at $+7^{\circ} \mathrm{C}$ and $100 \%$ load [11]
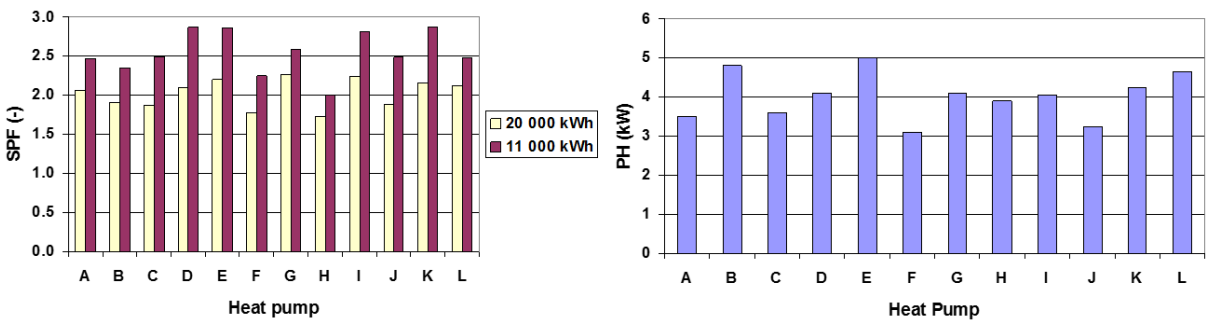

Karlsson et al. [11] did also compare cycling and cycle time for defrost for the evaluated heat pumps. The defrost systems were found to work properly, in the sense that no ice build-up was noticed on the evaporators after several consecutive operating cycles. The cycle times (from initiation of defrost until initiation of next defrost) for the heat pumps in 1991 and 2005 are shown in Figure 8. Comparing the cycle times for operation at $+2{ }^{\circ} \mathrm{C}$ and $-7{ }^{\circ} \mathrm{C}$, as shown in, Figure 8 , the cycle times for operation at $-7^{\circ} \mathrm{C}$ are in most cases longer than for operation at $+2{ }^{\circ} \mathrm{C}$, and so the defrosting strategies in that sense work properly.

Figure 8: The diagrams show the cycle time for operation at $+2{ }^{\circ} \mathrm{C}$ and $-7^{\circ} \mathrm{C}$ for the heat pumps evaluated in 1991 (left) and 2005 (right) [11]
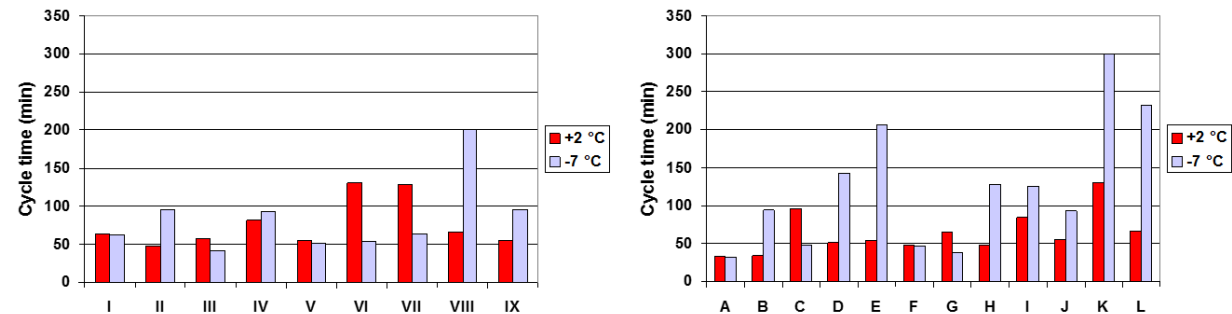

Defrosting is necessary in order to ensure proper operation of the heat pumps, but imposes energy losses on the system if allowed to continue after the last ice has been melted. According to Karlsson et al. [11] something can be said about the defrosts by comparing the defrost time for the different heat pumps. The time used for defrosting the evaporator varies considerably between the different heat pumps, from about two 
minutes up to over ten minutes, as shown in Figure 9. The right-hand diagram in Figure 9 shows the relative defrost time, which is the defrost time divided by the cycle time. The time necessary for defrosting the evaporator will depend on how much frost and ice that has formed on the surface, which in its turn depends on the cycle time and sizing of the evaporator coil and the surface load $\left(\mathrm{W} / \mathrm{m}^{2}\right)$. So the long defrost time for heat pump $\mathrm{K}$ is not as long when considered in relative terms. Further, it seems as the defrost operation is in some sense demand-controlled, since it differs between operating points.

Figure 9: Defrost times (left) and relative defrost time, i.e. defrost time divided by cycle time (right) at $+2{ }^{\circ} \mathrm{C}$ and $7^{\circ} \mathrm{C}$ for the heat pumps evaluated in 2005 [11]
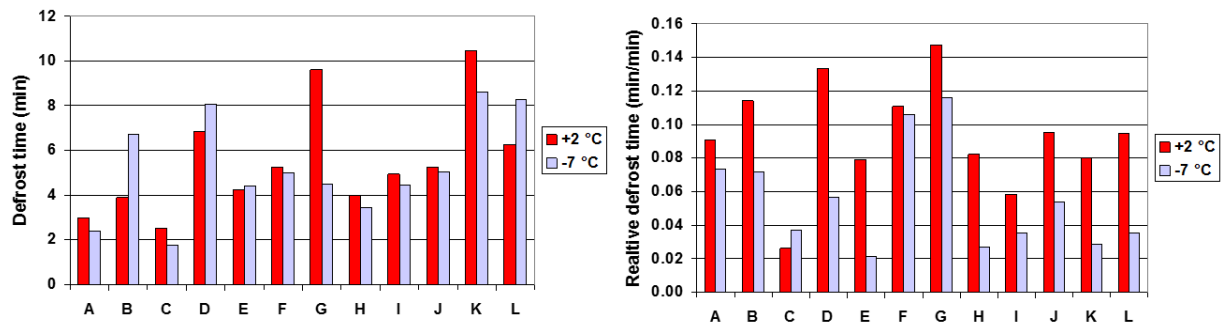

However, some summarising conclusion from this study is that all the evaluated heat pumps defrosted regularly during these tests, and the reported SPF values are in accordance with the results from the field measurements reported in 2009 by Lidbom et al. [8].

Nakos et al. [14] presented results from independent tests performed by SP on behalf of the Swedish Energy Agency of air-to-air heat pumps sold on the Swedish market during 2004-2013. The heat pumps were evaluated in terms of efficiency and capacity for space heating as well as noise emissions. The objective of the tests was to compare the performance of the different test objects. The results show that the efficiency of the best performing heat pumps have improved considerably since the year of 2004, but also that there is a large spread in the performance of the heat pumps sold today.

The majority of the heat pumps, for which the results are presented in this study, were tested by SP are on behalf of the Swedish Energy Agency in agreement with a manufacturer or a distributor. Figure 10 shows the COP as a function of heating capacity at $+7^{\circ} \mathrm{C}$ for different heating loads.

The evaluated test objects include the ones evaluated by Karlsson et al. [11] from 2005 and the same test points and test methods were used. (Except that the standard 
EN14511 from 2004 was replaced by the edition from 2007, with no significant differences for these tests).

In addition, during 2011 the Swedish Energy agency performed tests for market surveillance purposes (for the energy labelling regulation valid at that time) on six airto-air heat pumps. The markings with a cross show the six heat pumps that were tested for marketing surveillance during 2011. The heat pumps tested for market surveillance purposes were tested at rated capacity at $+7^{\circ} \mathrm{C}$ which is the same as the value that was presented on the energy label at that time. These values are commonly not consistent with the maximum capacity of the units, but rather a part-load, and do not deviate from the values for the tests performed on behalf of the manufacturers or distributors.

It is clearly shown in Figure 10 that the COP of an inverter controlled air-to-air heat pump generally increases as the capacity decreases, even though there is a large spread.

Figure 10: COP as a function of heating capacity at $+7^{\circ} \mathrm{C}[14]$

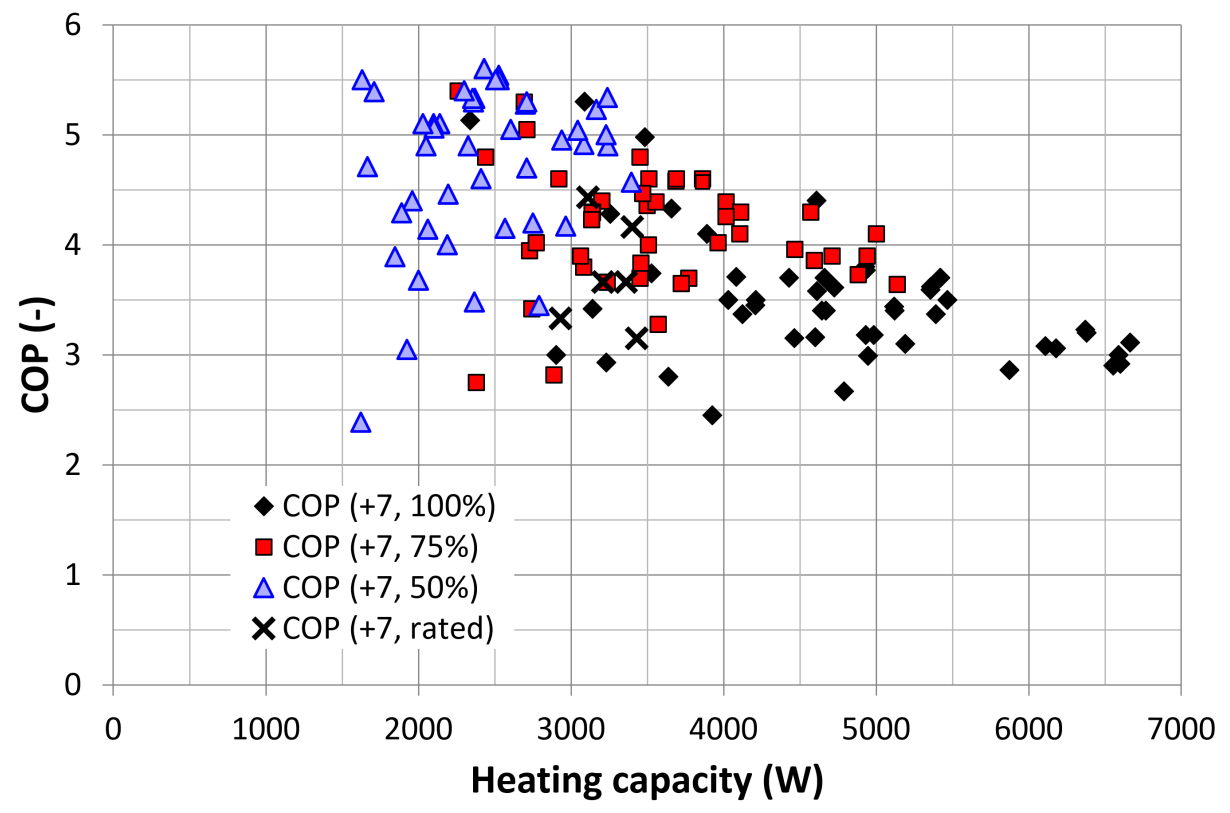


Figure 11 presents the COP for the heat pumps tested during 2004-2012 reported by Nakos et al. [14]. They concluded that the units have improved since 2004 and that the trend continued to be positive. The conclusion is based on a limited selection of data with a wide spread and thus is somewhat uncertain. Also, for all heat pumps annual seasonal performance factors were calculated in accordance with the SP method 0033 described in the study and these are also presented in Figure 11. By comparing the SPF $\left(\mathrm{SPF}_{\mathrm{H}_{4}}\right.$ according to Figure 5 ) values over the years, the above conclusion that the units have improved during the years 2004-2012 was affirmed.

Figure 11: COP at different test points and SPF tested during different years

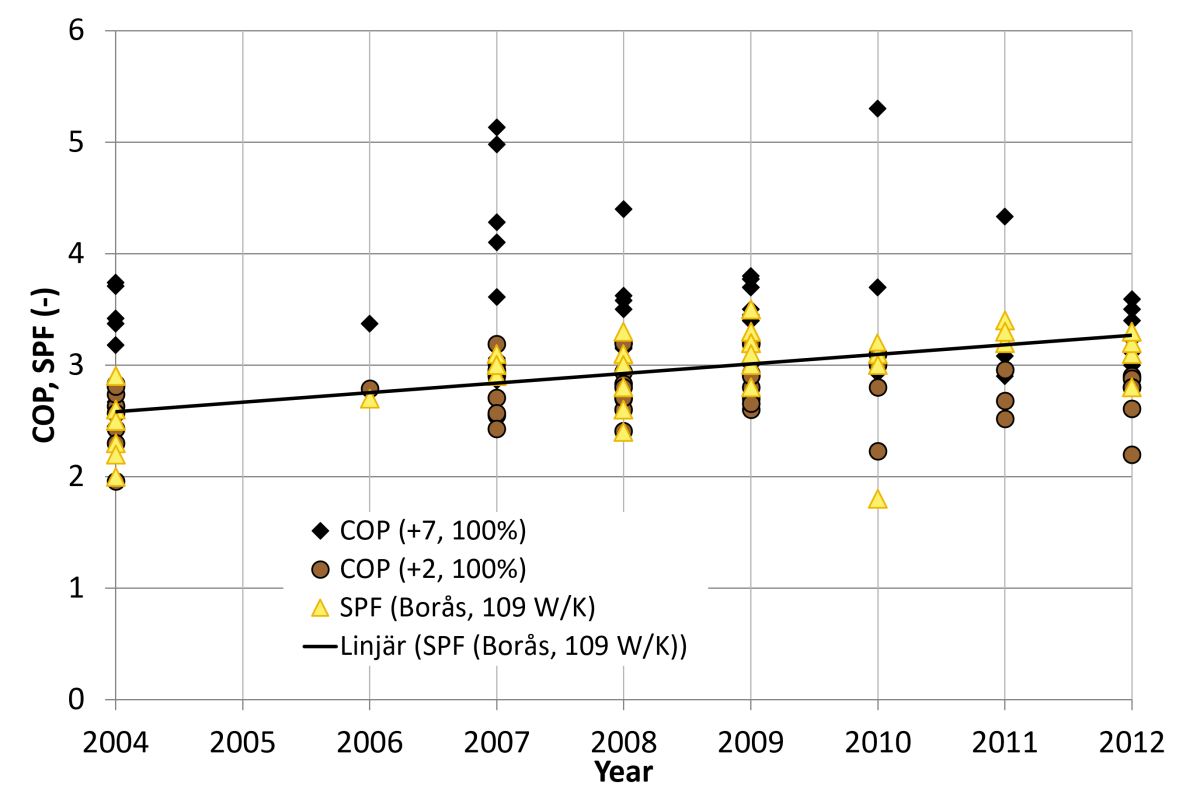

Nakos et al. [11] did also report about results from market surveillance tests, performed according to the harmonized standards, which had been compared to test results on the same products performed according to a compensation method, which is further described in chapter 4, Reasons for performance discrepancy. 
Several air-to-air heat pumps have been tested by SP since the beginning of this century, this means even before the present regulations and harmonized standards for this product were published. Therefore, a compensation method was applied, instead of setting the frequency of the compressor, and the test periods were longer than the present standards prescribe.

The presented data show that all the heat pumps defrosted regularly during these tests and that the defrost strategies had improved over the years.

The presented data show that the overall performance of the heat pumps has improved over the years but there is a large spread. It also show that the efficiency of the heat pump (COP) generally increases with lower frequencies, i.e. lower capacities of the heat pump.

$\mathrm{SPFH}_{4}$ calculations were performed for type houses with a heating demand of $11000 \mathrm{kWh}$ and 20 $000 \mathrm{kWh}$ placed in a Nordic climate (close to the cold climate defined in the Energy Label Regulation). The presented values ranged from 1.7-2.3 for the large house and from 2.3-2.9 for the small house in the tests up to 2005 .

\subsection{Dependency of performance on the humidity of the climate}

The efficiency (COP) of an air-to-air heat pump depends on the outdoor climate, both temperature and humidity. Therefore, those parameters are precisely defined in the test standards. At outdoor temperatures where frosting occurs the grade of humidity can have both a positive and negative effect on the performance of the heat pump. A high humidity means a higher enthalpy and thereby energy content of the heat source, i.e. the outdoor air, which can have a positive effect. On the other hand, the more water content of the outdoor air, the more likely is it that frosting take place on heat exchanger surface and the larger is the magnitude of frost, that must be melted during defrost.

Haugerud et al. [17] reported results from field measurements of five air-to-water heat pumps, AWHP, in Norway, all installed between 2009 and 2011. The field measurements were analysed for the year 2014. A small increase in SPF can be seen on heat pumps, (note not air-to-air heat pumps but still relevant for this study) when outdoor air humidity decreases, even if the outdoor air temperature is decreasing at the same time, see Figure 12. The increase is about $5 \%$ at one occasion, but another time a decrease is seen. As the AWHP produces domestic hot water, along with heating, it is difficult to compare different days, the variations are too large and cause disturbances in the result. This risk the researcher to draw erroneous conclusions from the data set. 
Figure 12: COP (red, top) as function of outdoor temperature (blue, bottom) and outdoor humidity (green, middle) [17]

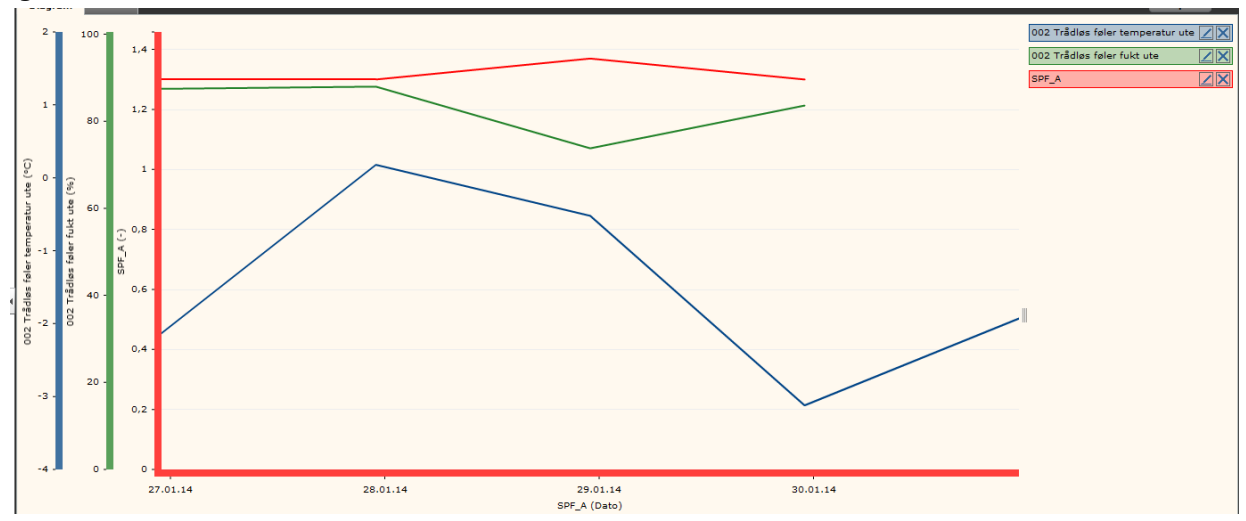

In Figure 12 another week from the same study is shown, but it is very difficult to draw any certain conclusions if COP is lower or higher at lower relative humidity.

Figure 13: COP (red, top) as function of outdoor temperature (blue, bottom) and outdoor humidity (green, middle) [17]

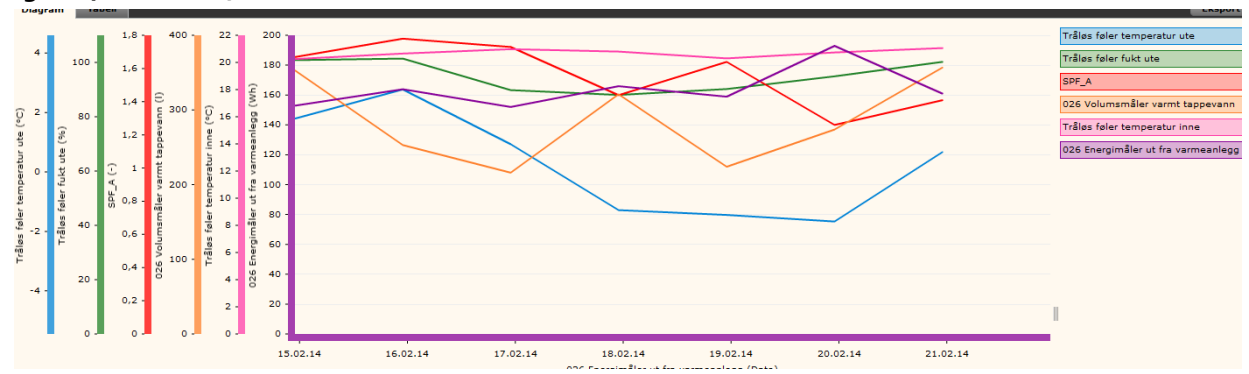

Klein [21] refers to performance tests of air-to-water heat pump system. According to them COP will decrease 0.3 to 1.0 if defrosting is accounted for, at a specific ambient temperature (not given in this article). They also state that frost normally does not form at higher ambient temperatures than $+7^{\circ} \mathrm{C}$ and that frost growth is lower at lower winter temperatures due to low absolute humidity, see below. This means that the Seasonal Performance Factor for the heat pump, SPF $\mathrm{H}_{2}$, will possibly not decrease as much as stated by Klein [21] if the heat pump is frosting and defrosting or not, since the SPF is an averaged COP of the heat pump over the whole heating season. 
Formation of frost on the evaporator was studied and shown Guo et al. [19], see Figure 14 and Figure 15 , where frost were found to form more rapidly at a higher relative humidity than at lower. When frost accumulates on the evaporator the temperature of evaporation decreases thus causing lower COP. The air-to-air heat pump used in the test has an evaporator temperature about $8{ }^{\circ} \mathrm{C}$ lower than the ambient temperature, which is somewhat low compared to a heat pump in real operation, as it will likely not operate at full heating capacity at $0^{\circ} \mathrm{C}$ ambient temperature. The frost growth shown in [19] should not be taken generically, since evaporator temperatures and thus frost growth will vary between heat pump brands and series.

Figure 14: Evaporator wall temperature and Heating capacity/COP over time as frost accumulates on evaporator [19]
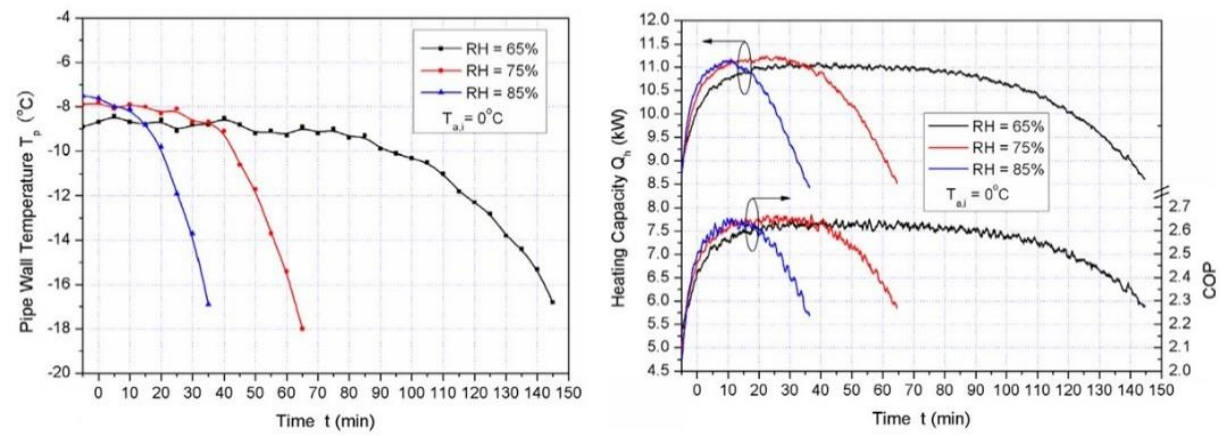

The formation of frost has a maximum at $\pm 0^{\circ} \mathrm{C}$ according to the tests performed, see Figure 15. The curves are smooth and thus extrapolations, both to lower and higher humidity levels, were done. This should be seen as an indication of possible frost growth at humidity levels that were not tested. The test is done with a specific air-to-air heat pump (AAHP) and should be used with caution, as difference in evaporator sizes will cause different frost behaviours, as heat exchanger size will influence the evaporator temperature and thus frost growth. 
Figure 15: Frost growth at different relative humidity, with curves extrapolated up to $100 \%$ and down to zero frost growth

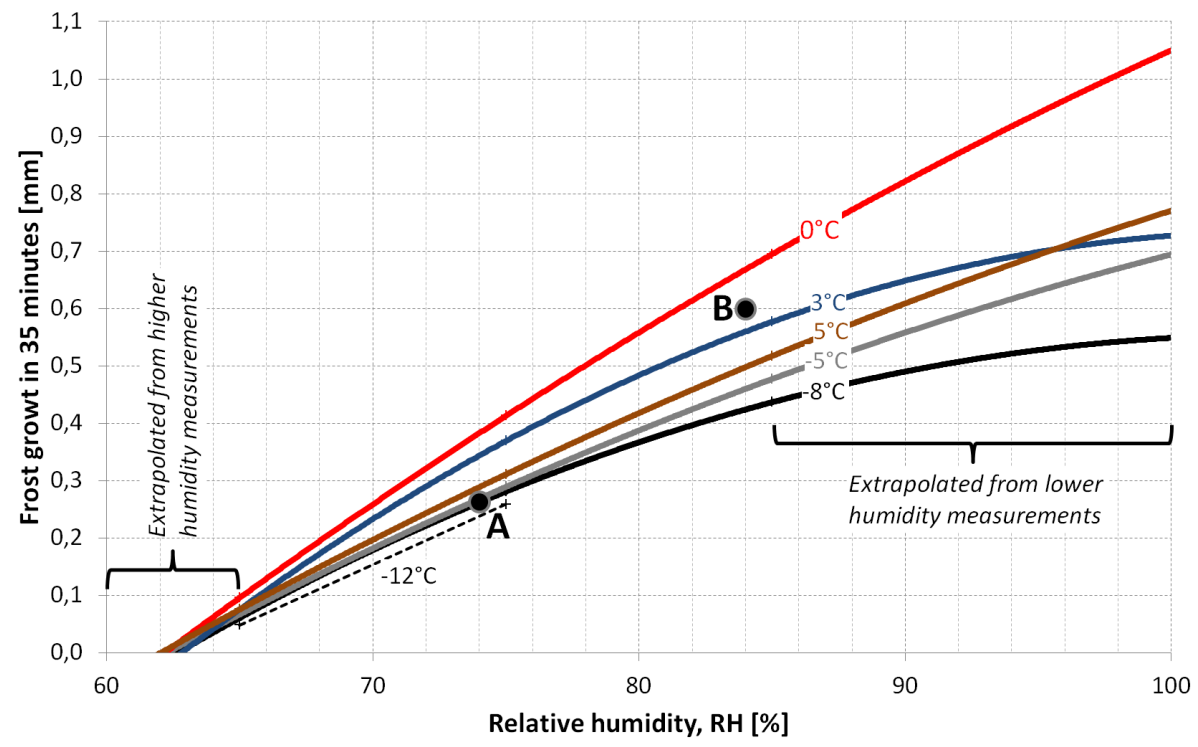

Note: Mandatory test points ( $A$ and $B$ ) used for the Energy Labelling with temperatures within test range of study (defined in EN14825) are seen as large dots, see Table 10.

Source: Data set from [17].

From the study presented by Guo et al. [19] the following diagram can be derived, see Figure 16 , showing the relative time to grow a specific thickness of frost at 65,75 and $85 \%$ relative humidity $(\mathrm{RH})$. This shows clearly that the defrosting at $75 \%$ relative humidity will have to be done at an interval that is 1.3-1.8 longer than that at $85 \%$ (reference). At $65 \% \mathrm{RH}$ defrosting has to be done at an interval being 3.6-4.8 times longer than the reference. The data set is extrapolated to $100 \%$ relative humidity, those values indicate that defrosting would have to be done at an interval of $0.7-0.9$ of the interval at $85 \% \mathrm{RH}$ (reference). 
Figure 16: Relative time to grow a certain frost thickness compared to growth time at relative humidity of $85 \%$

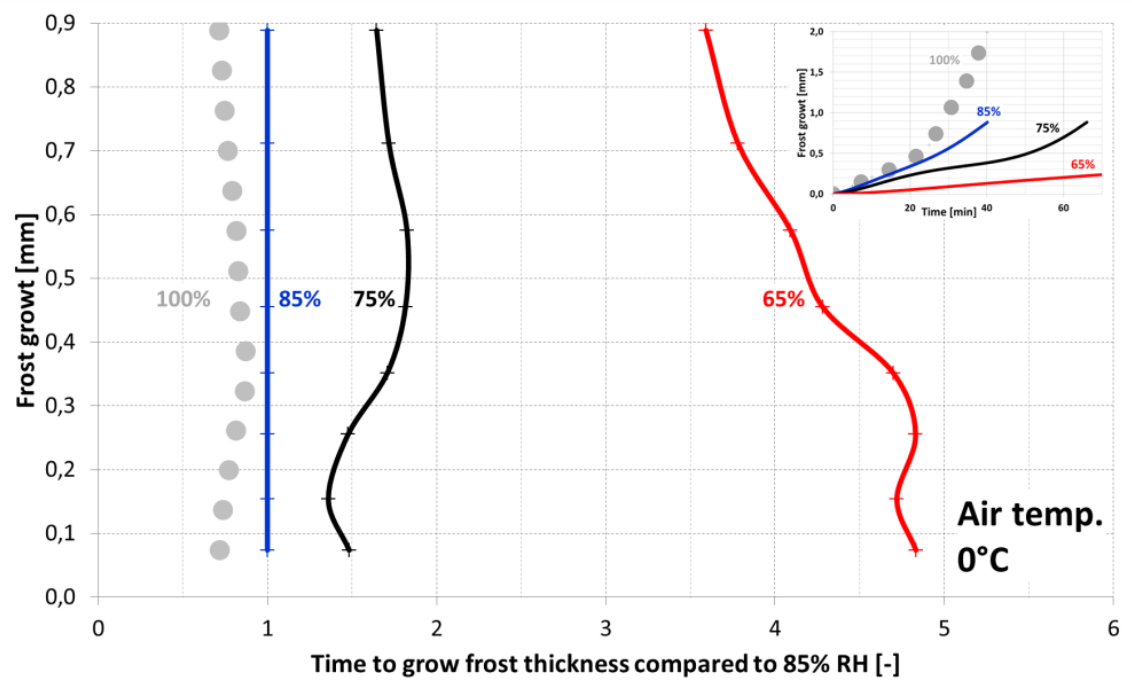

Note: Absolute growth times are seen in the small diagram to the top right. The data for $100 \% \mathrm{RH}$ is extrapolated and should be used only as an indication.

Source: Data set from [17].

To further clarify what the frost growth means for the overall operation of the system see Table 7.

Table 7: Number of defrosting cycles per day, at an ambient temperature of $\pm 0^{\circ} \mathrm{C}$, assuming 24 cycles at $\mathrm{RH} 85 \%$

\begin{tabular}{lrr} 
& Defrostings per day [-] & Time between defrostings [hh:mm] \\
& & $03: 35-04: 50$ \\
$65 \%$ & $5-7$ & $01: 20-01: 50$ \\
$75 \%$ & $13-18$ & $01: 00$ \\
$85 \%$ & 24 & $00: 40-00: 55$ \\
$100 \%$ & $27-34$ & \\
\hline
\end{tabular}

Note: Note that this is for a specific heat pump and that $100 \%$ humidity is extrapolated.

This means that there is likely no drastic increase in the number of defrostings above $85 \%$ relative humidity, at least not at $\pm 0^{\circ} \mathrm{C}$ ambient temperature. 


\subsubsection{Summary regarding air humidity and performance of the heat pump}

It has been shown that frost growth take place more rapidly at a higher relative humidity of the outdoor air and hence frosting must take place more frequently. There are studies indicating that a high humidity will have a negative influence of the overall efficiency of the heat pump, but no clear trends have been found. At conditions when frosting occurs higher humidity will cause more frost to form, giving lower COP, but this is necessarily not valid for the entire heating season, since no frosting generally occur at higher outdoor temperatures. 


\section{Reasons for performance discrepancy}

There a several possible reasons why the performance displayed on the energy labels differ from the performance in real installations in a building. In the chapters below the most obvious ones from this study are presented and explained.

\subsection{Performance difference due to low heat spreading in the building}

One major reason why air-to-air heat pumps do not always deliver as good SPF/SCOP in the field, compared to calculations based on laboratory measurements, is that the floor plan of the house is not open enough. This means that the heat from the heat pump will not reach all parts of the house, thus the electric radiators (or other heating devices) have to heat parts of the house instead. This is true regardless of ambient temperatures, but is of course more significant at lower temperatures.

In the calculations methods used for obtaining the data for the Energy Labels, the heat is assumed to reach all parts of the house, thus the electric back-up (radiators) in the house is only assumed to be used at outdoor temperatures when the heating capacity of the heat pump is lower than the heating demand of the house, and does not take into account the distribution in the house, since it differ from house to house.

In the field measurement done by SP (RISE) in 2009 [8] the $\mathrm{SPF}_{\mathrm{H}_{4}}$ of 1.9-2.3 was calculated, significantly lower than would be expected monitoring information on the energy labels today. However, the measured values are underestimated as mentioned chapter 3.1, since they do not take operation at part capacity into account.

Note that the heat pumps tested are old, installed 2003-2006, and thus will have somewhat lower performance than new heat pumps. The $\mathrm{SPF}_{\mathrm{vpa}}$ values (corresponding to $\mathrm{SPF}_{\mathrm{H}_{2}}$ ) were calculated from in situ measurements to $2.4-2.7$, but as stated in chapter 3.1 this was measured at full heat capacity of the heat pump, causing lower 
performance. According to marketing information three of heat pumps studied had "COP" or "efficiency" of 5.22, 4.0 (klass A) and 3.60 (nom.) respectively at the years they were sold. The test methods for the different COP values presented by the manufacturers are unknown, but are likely steady state tests at fixed ambient temperature at $+7^{\circ} \mathrm{C}$ according to the version of EN255 or EN14511 valid at that time. COP-data for the other two heat pumps in the test where not found.

\subsection{Performance difference due to test methods}

Huang et al. [4] states that "It is important to keep in mind that for variable speed units, the test requires the manufacturer to supply information on how to fix (or lock-in) the frequency of the compressor (and probably of fans) according to European standards EN14825 and EN14511-3. This is the general method used in performance test standards of air conditioners worldwide."

"In Regulation 206/2012 the following is written 'The manufacturer of air conditioners and comfort fans shall provide laboratories performing market surveillance checks, upon request, the necessary information on the setting of the unit as applied for the establishment of declared capacities, SEER/EER, SCOP/COP values and service values and provide contact information for obtaining such information.' This does not mean that the manufacturer is allowed to use a specific software or other means to activate a mode dedicated to standard tests, in which the control of the unit is bypassed (or partially bypassed e.g. in case of the need to defrost). However, it does mean that the performance of units in real life may differ from the performances measured in standard test conditions." [4]

Huang et al. [4] also report that "an alternative is to use a compensation method; in that method, the unit has to maintain the required set point temperature to compensate a given heat load (when working in cooling mode). Figure 3 below shows the comparison of tests realised in locked (lock-in) and unlocked (compensation method) modes for an inverter unit following test conditions of the AS/NZS 3823.4 test standard [16]. The efficiency difference may be significant." 
Figure 17: Impact of using lock-in mode versus compensation method on the energy efficiency of an inverter air conditioning unit [16] [4]

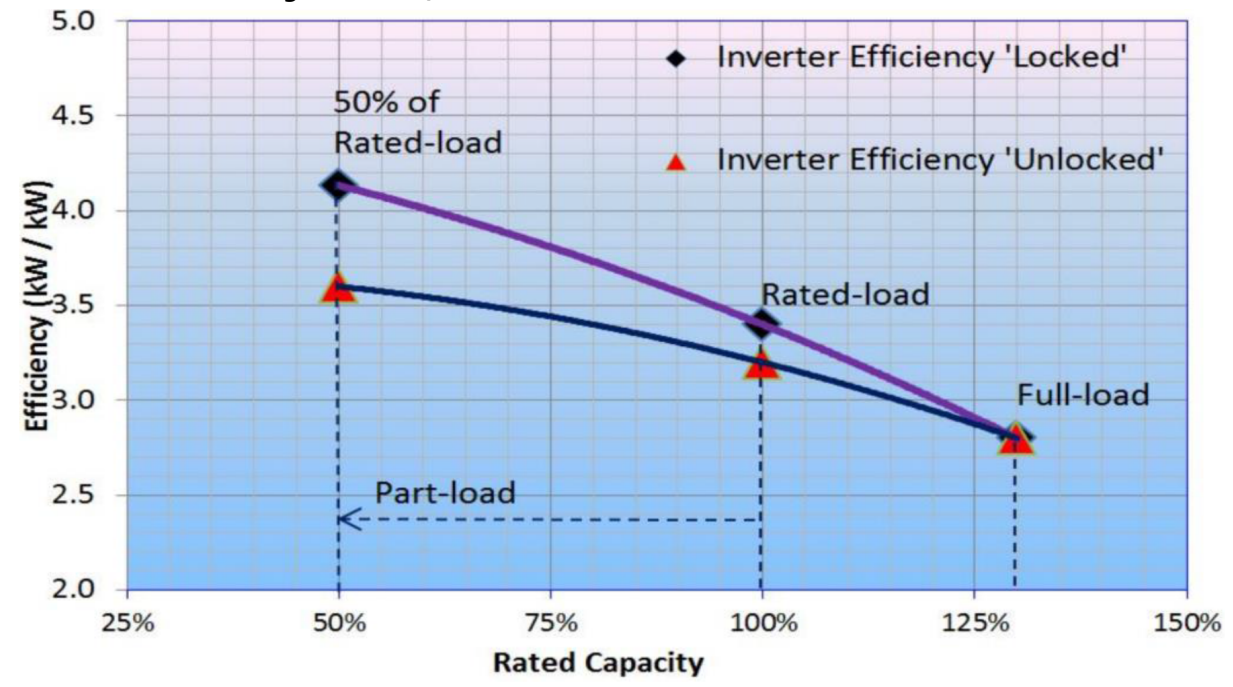

"Although test laboratories in Europe are aware of this method and the potential differences in results, there are issues for practical application that remain to be solved:

- there is no such method for ducted units,

- there are repeatability issues because the results obtained are dependent on the control of the unit and then in turn on the air inertia of the cell (and then on its size) and possibly on the control used to maintain the heat load (in cooling mode)

- test results are dependent on the temperature sensor of the unit being tested and on the setting of the indoor temperature (in general with $1 \mathrm{~K}$ precision), which may make it difficult to respect the deviation tolerances of the standard or/and may require ad-hoc corrections.

- time for testing increases significantly

Nevertheless, it is important to continue the development of compensation method as it could ultimately lead to seasonal figures closer to real life performances." [4]

Nakos et al. [14] reported about results from market surveillance tests, performed according to the harmonized standards, which had been compared to test results on 
the same products performed according to a compensation method, see Figure 18 below. As can be seen, the results agree well in some test points (high part loads, i.e. capacities), but differ in several test points, especially at low part load (capacities) conditions and at some test points were the heat pump did not defrost during the test according to the harmonized standards. As seen in Figure 19 the differing performance in the different test points has an influence on the SCOP values.

Table 8: Space heating test points for seasonal performance calculation according to EN14825
Standard/test
Test point
Outdoor temperature $\left[{ }^{\circ} \mathrm{C}\right]$

Test point

Outdoor temperature $\left({ }^{\circ} \mathrm{C}\right)$ dry bulb(wet bulb)a

$\begin{array}{llll}\text { Method } & \text { (Letter }^{\text {d }} & \text { Dry bulb } & \text { Wet bulb } \\ & 8(\mathrm{~A}) & -7 & -8 \\ \text { EN14825 } & 9(\mathrm{~B}) & 2 & 1 \\ & 10(\mathrm{C}) & 7 & 6 \\ & 11(\mathrm{D}) & 12 & 11 \\ & 12(\mathrm{E}) & \mathrm{TOL}^{\mathrm{b}} & \\ & 13(\mathrm{~F}) & \mathrm{T}_{\text {Bivalent }^{c}} & \end{array}$

Note: A) The temperature in brackets shows the wet bulb temperature

B) Operation limit temperature

C) Lowest outdoor air dry bulb temperature at which the heat pump is capable of covering the total heating demand of the building

D) Enumeration of test point according to EN 14825.

Source: Nakos et al. [14]. 
Figure 18: Calculated COP and measured heating capacity at each test point with either a set frequency or a compensation method [14]
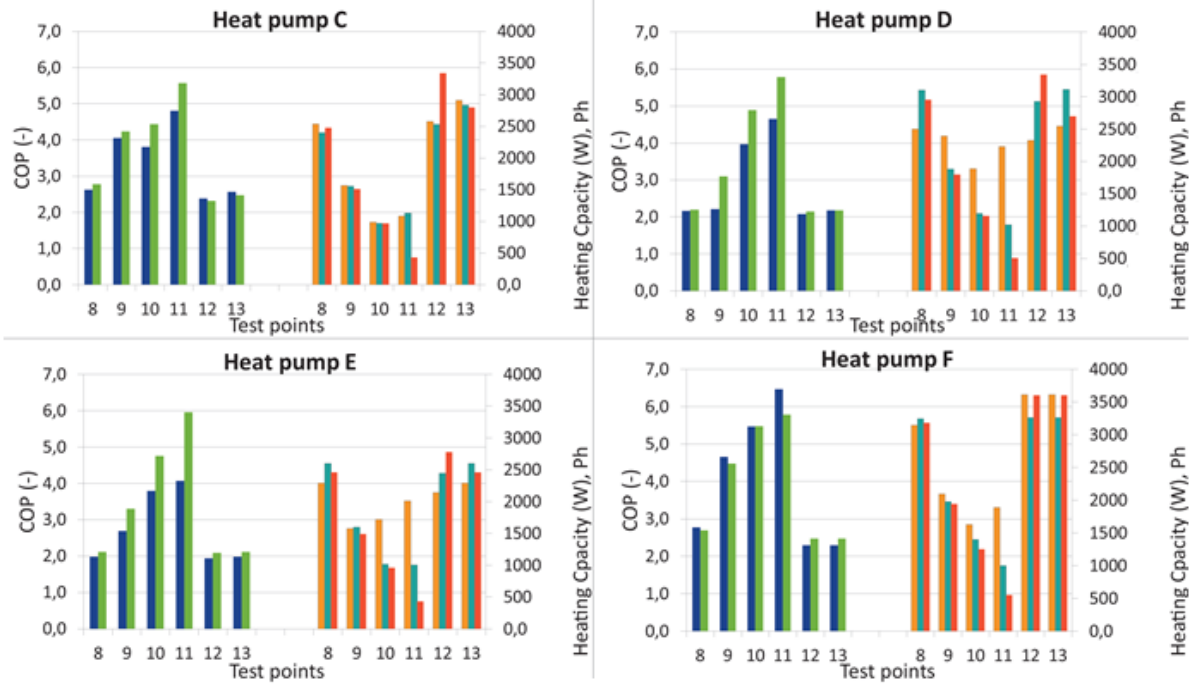

a Calculated COP-Tested using the compensation method

a Calculated COP-Tested by setting the compressor frequency

a Measured Ph- Tested using the compensation method

a Measured Ph-Tested by setting the compressor frequency

= Sought heating capacity

Figure 19: Calculated SCOP (for the average climate) with either a set compressor frequency or a compensation method

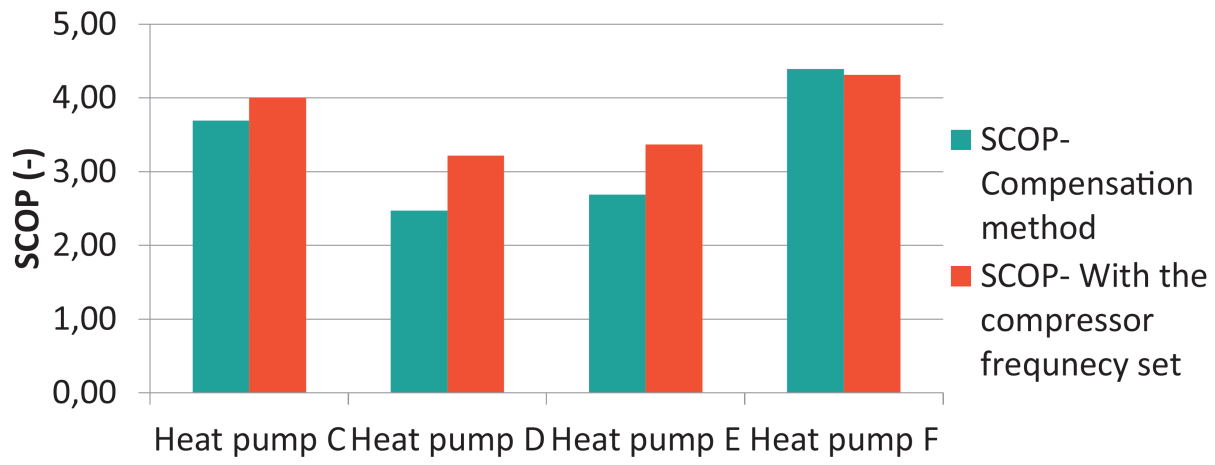

Source: Nakos et al. [14]. 


\subsection{The test period in the standards are not long enough to include a defrost period}

Market surveillance test were performed in Sweden in 2013, 2014 and in 2017. The results regarding if the heat pumps did defrost or not during the various test points are summarized in the Table below. As can be seen, it has become more and more rare that the heat pumps defrost during the prescribed test periods according to EN14511 [5]. In the section describing EN14511, page 22, it is explained how the tests are performed.

Table 9: Summarized result from various market surveillance tests regarding if the heat pump defrost or not during the test according to $\mathrm{EN}_{14511}$ and EN14825 [13]

\begin{tabular}{|c|c|c|c|c|c|c|}
\hline \multirow[t]{2}{*}{ Test object } & \multirow[t]{2}{*}{ Settings } & \multicolumn{5}{|c|}{ Test point dry temperature $\left[{ }^{\circ} \mathrm{C}\right]$ (wet temperature $\left[{ }^{\circ} \mathrm{C}\right]$ ) } \\
\hline & & $-15(-)$ or TOL & $-7(-6)$ & 2(1) & $7(6)$ & 12(11) \\
\hline \multicolumn{7}{|l|}{2013} \\
\hline Heat Pump C & \multirow{4}{*}{$\begin{array}{l}\text { Settings } \\
\text { according to } \\
\text { manufac-turer }\end{array}$} & Yes & Yes & No & No & No \\
\hline Heat Pump D & & Yes & Yes & Yes & No & No \\
\hline Heat Pump E & & Yes & Yes & Yes & No & No \\
\hline Heat Pump F & & No & No & No & No & No \\
\hline \multicolumn{7}{|l|}{2013} \\
\hline Heat Pump C & \multirow{4}{*}{$\begin{array}{l}\text { Compensation } \\
\text { method }\end{array}$} & Yes & Yes & No & No & No \\
\hline Heat Pump D & & Yes & Yes & Yes & No & No \\
\hline Heat Pump E & & Yes & Yes & Yes & No & No \\
\hline Heat Pump F & & Yes & No & No & No & No \\
\hline \multicolumn{7}{|l|}{2014} \\
\hline Heat Pump G & \multirow{4}{*}{$\begin{array}{l}\text { Settings } \\
\text { according to } \\
\text { manufacturer }\end{array}$} & No & No & No & No & No \\
\hline Heat Pump H & & Yes & Yes & No & No & No \\
\hline Heat Pump I & & No & No & No & No & No \\
\hline Heat Pump J & & No & No & No & No & No \\
\hline \multicolumn{7}{|l|}{2017} \\
\hline Heat Pump K & \multirow{3}{*}{$\begin{array}{l}\text { Settings } \\
\text { according to } \\
\text { manufacturer }\end{array}$} & No & No & No & No & No \\
\hline Heat Pump L & & No & No & No & No & No \\
\hline Heat Pump M & & No & No & No & No & No \\
\hline
\end{tabular}


As reported above by Nakos et al. [14], for the market surveillance test performed in 2013, the test were repeated with the compensation method. For some test points with defrosting cycles, differences between the operations, such as cycle times, defrosting times and whether the operation was stable or not, could be seen for the different test methods.

\subsection{Energy label tests performed at lower humidity than the real climate?}

Running a heat pump at a more humid climate will cause the heat pump to defrost the evaporator more often than at a dryer climate according to Guo et al. [19]. The following climates are applied in EN14825 [6], see Table 10.

Table 10: Outdoor heat exchanger air conditions at test points used for the Energy Label measurements

\begin{tabular}{|c|c|c|c|c|c|c|}
\hline & $\begin{array}{r}\text { Dry } \\
\text { temperature } \\
{\left[{ }^{\circ} \mathrm{C}\right]}\end{array}$ & $\begin{array}{r}\text { Wet } \\
\text { temperature } \\
{\left[{ }^{\circ} \mathrm{C}\right]}\end{array}$ & $\begin{array}{r}\text { Relative } \\
\text { humidity [\%] }\end{array}$ & $\begin{array}{r}\text { Dew point } \\
\text { temperature } \\
{\left[{ }^{\circ} \mathrm{C}\right]}\end{array}$ & $\begin{array}{r}\text { Absolute } \\
\text { humidity } \\
{\left[\mathrm{g} / \mathrm{m}^{3}\right]}\end{array}$ & $\begin{array}{r}\text { Maximum } \\
\text { absolute } \\
\text { humidity } \\
{\left[\mathrm{g} / \mathrm{m}^{3}\right]}\end{array}$ \\
\hline$A^{*}$ & -7 & -8 & 74 & -104 & 2.0 & 2.8 \\
\hline B & 2 & 1 & 84 & -0.4 & 4.6 & 5.6 \\
\hline C & 7 & 6 & 87 & 4.9 & 6.7 & 7.8 \\
\hline D & 12 & 11 & 89 & 10.2 & 9.4 & 10.7 \\
\hline$E$ & TOL & TOL - 1 & $<66$ & - & - & - \\
\hline $\mathrm{F}$ & $T_{\text {bivalent }}$ & $T_{\text {bivalent }}-1$ & $<90$ & - & - & - \\
\hline $\mathrm{G} * *$ & -15 & -16 & 56 & -21.2 & 0.8 & 1.4 \\
\hline
\end{tabular}

Note: * Not used for the Warmer climate and ** Not used Average and Warmer climate.

As seen, the relative humidity decreases with colder temperatures, even though the temperature difference between the dry and the wet temperature is fixed at all temperature levels. This is due to the lower absolute water vapour content in air at low temperatures. Maximum absolute humidity at all temperatures are shown as a reference, this is the amount of humidity in the air when the relative humidity is $100 \%$. 
Figure 20: Absolute water vapour content of air (right axis)

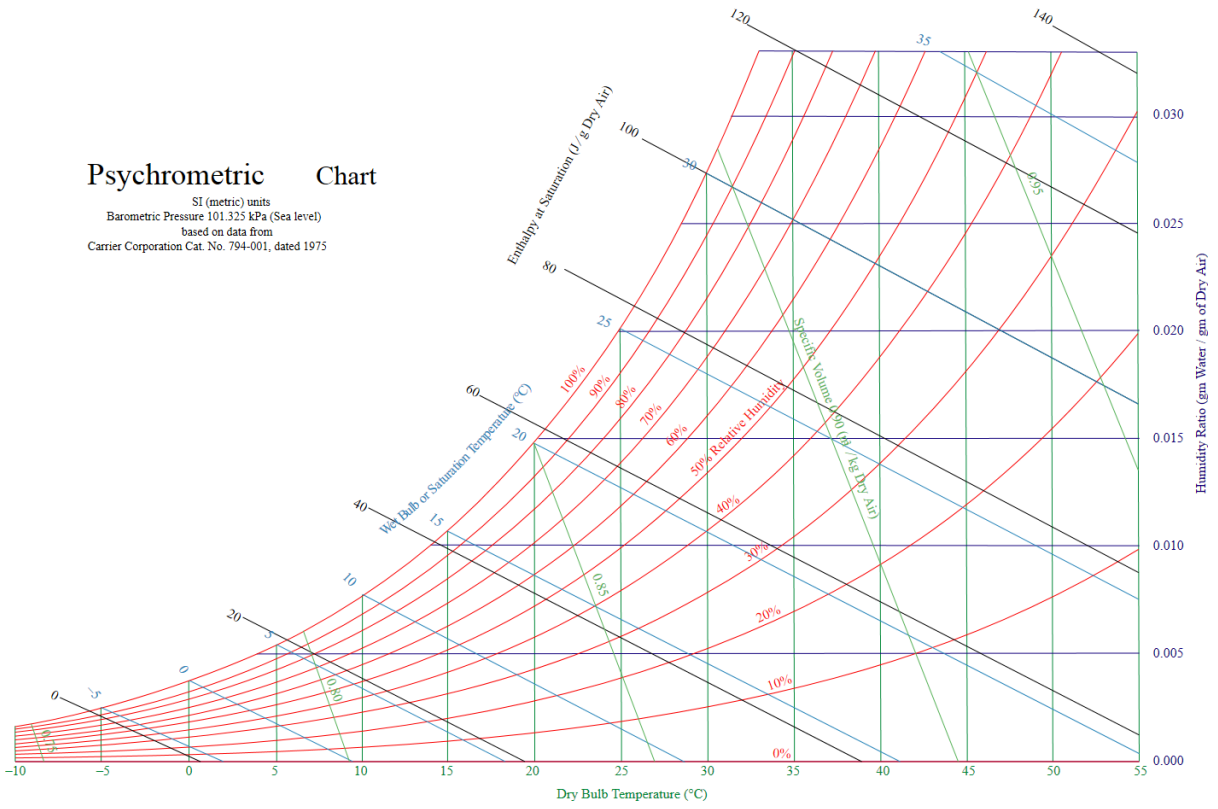

Source: By ArthurOgawa - Own work, CC BY-SA 3.0,

https://commons. wikimedia.org/w/index. php?curid $=2803863$

To extract heat from the ambient air, the heat pump evaporator has to have a temperature that is lower than the air temperature. Typically, a temperature difference of $5^{-} 8^{\circ} \mathrm{C}$ could be assumed. This means that humidity can be condensed (or sublimised to frost) to that surface temperature. The surface will draw humidity out of the air, but only to an amount that corresponds to the difference between the dew point of the air and the temperature of the evaporator surface. The lower the ambient air temperature, the less heat the evaporator will draw from the air, as the performance of the refrigeration cycle degrades with temperature. This means that the evaporator will be more "oversized" at lower temperatures, causing the temperature difference between them to decrease. 


\subsubsection{Climates in examples of cities in Norway and Sweden}

The following diagrams show the climate, from Meteonorm 6.1, in Malmö, Borås, Stockholm and Uppsala in Sweden and Oslo, Bergen, Stavanger and Trondheim in Norway presented as duration curves based on the dry outdoor temperature. Meteonorm uses the years 2000-2009 for their data climate (except for irradiation, but that is not used in this report). As seen in all diagrams the humidity varies a lot at the same dry outdoor temperature, but the test point for $+2^{\circ} \mathrm{C}(\mathrm{B})$ is near the real averaged curves. However, at lower temperatures the humidity for the test points ( $A$ and $G$ ) are lower than the averaged curve, meaning that the heat pumps likely will frost and defrost less in the tests than in the real climate.

For the higher temperatures (test points $C \& D$ ), the tests are performed at higher humidity than the average humidity levels of the example cities. However, frosting is not likely to take place at any of them, not in the test nor in reality. The higher humidity at the test could in this case be beneficial for the performance, since the enthalpy of the air is higher. The opposite could apply, since condensation of water vapour could result in higher pressure drop through the heat exchanger. Note that the curves represent the average humidity, meaning that there are as many hours at higher humidity levels, as at lower humidity levels. These more wet hours will cause more defrosting, while the dryer hours will cause less. The defrosting pattern is not linear, as seen in Figure 15 and Figure 16.

The fact air-source heat pumps are tested at humidity levels that are sometimes lower than in a real installation could be a contributing reason for that the efficiency displayed on the energy label than what experienced in real life. However, no real proof of this has been found since the test points where frosting generally is most severe (around $+2^{\circ} \mathrm{C}$ ) seem to represent the average humidity in many parts of at least Sweden and Norway. However, there are trends reported that the humidity is increasing and this shall therefore be monitored in the future.

Common description of Figure 21 to Figure 28: The red lower lines are dry temperatures and the top thin black lines relative humidity. The top thick straight line is a 6 th degree curve fit, the fuzzy line is 255 value moving average, both of the relative humidity. The blue dots show the test points according to EN 14825 [6], see Table 10. 
Figure 21: Temperature and relative humidity profile of Malmö, Sweden

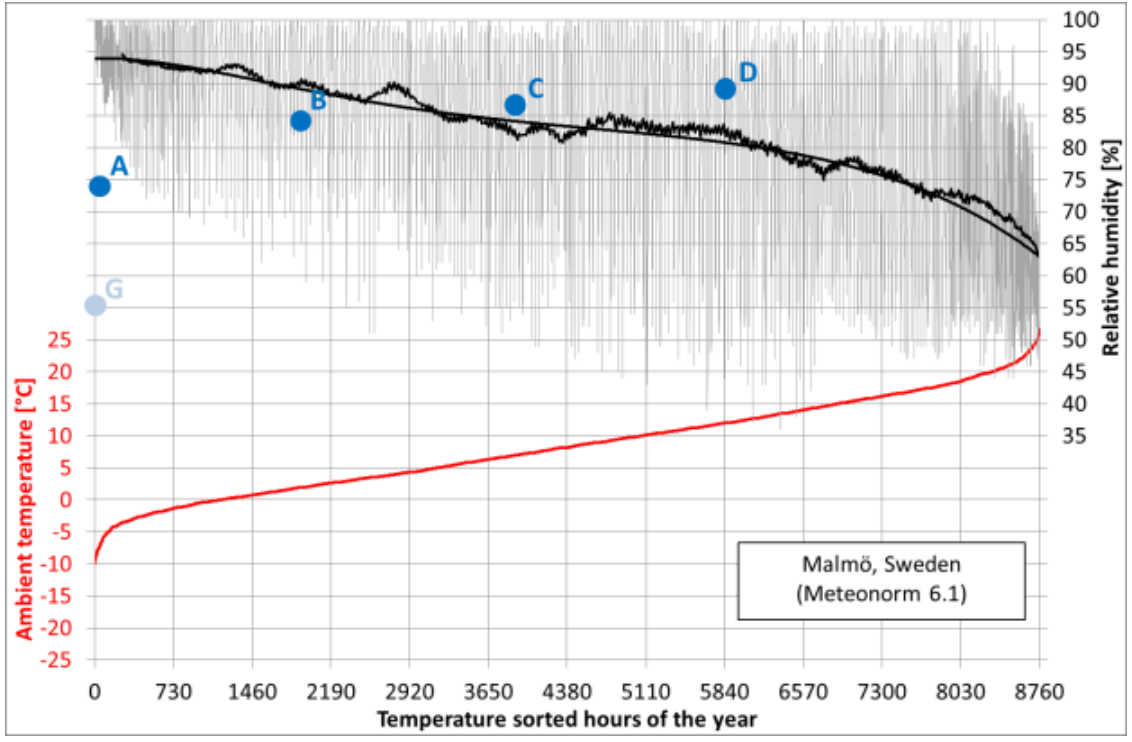

Figure 22: Temperature and relative humidity profile of Borås, Sweden

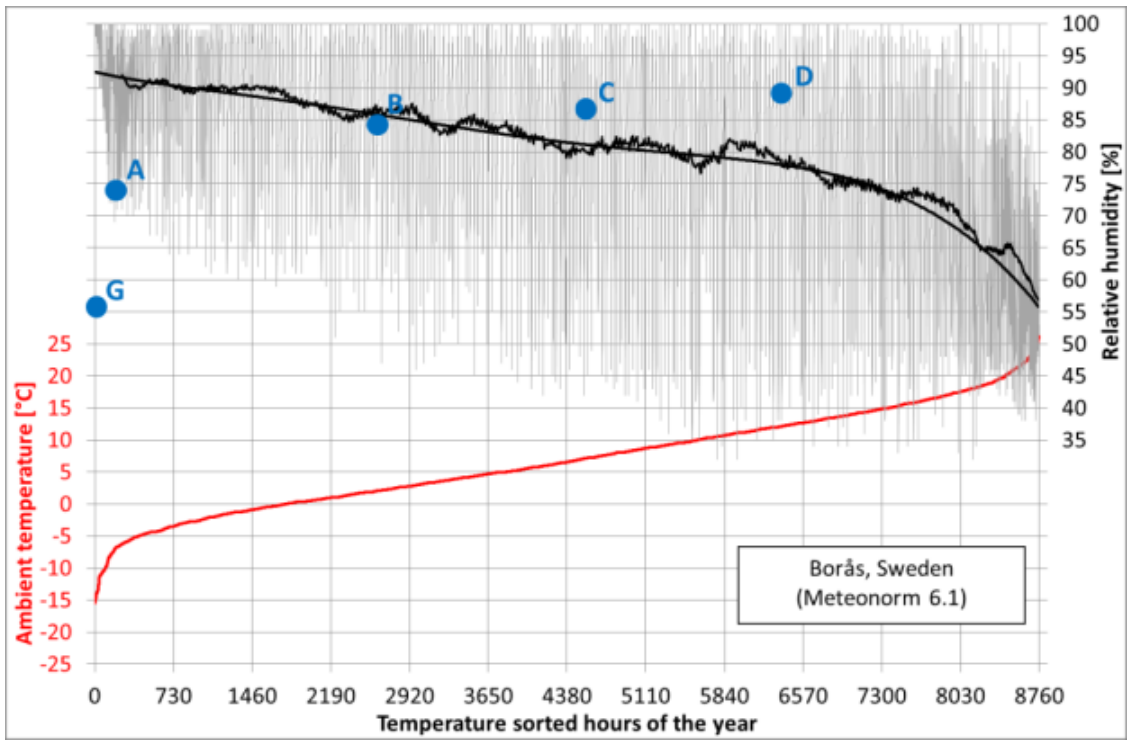


Figure 23: Temperature and relative humidity profile of Stockholm, Sweden

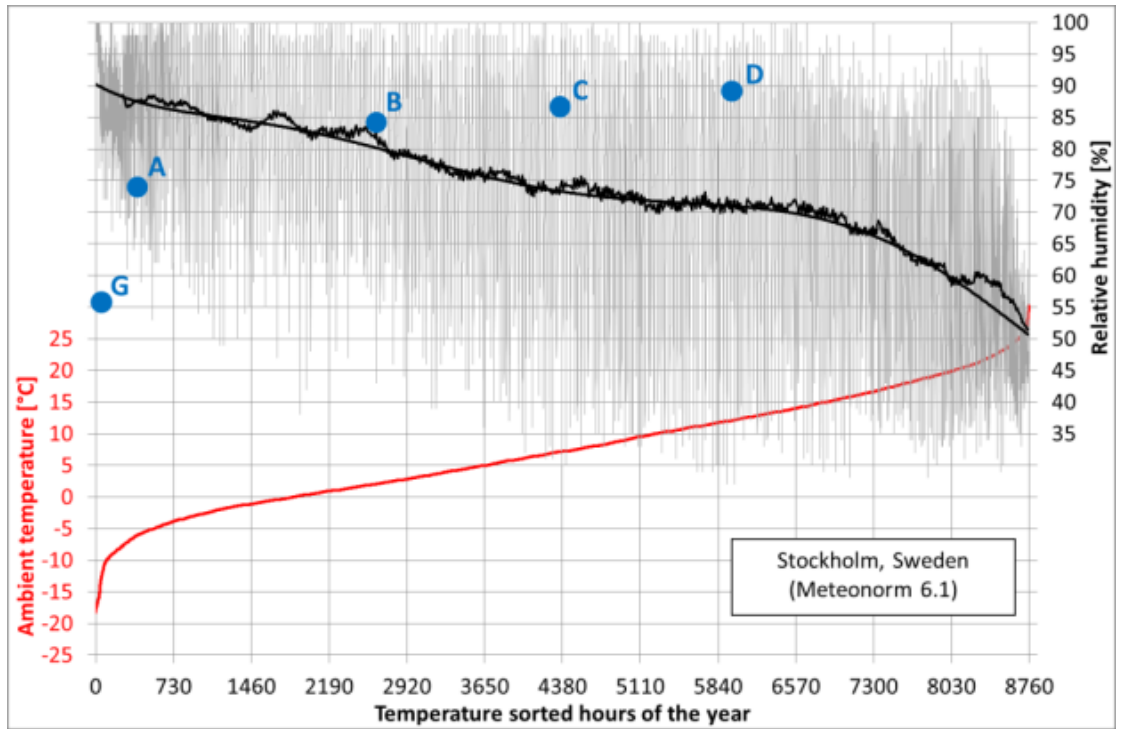

Figure 24: Temperature and relative humidity profile of Uppsala, Sweden

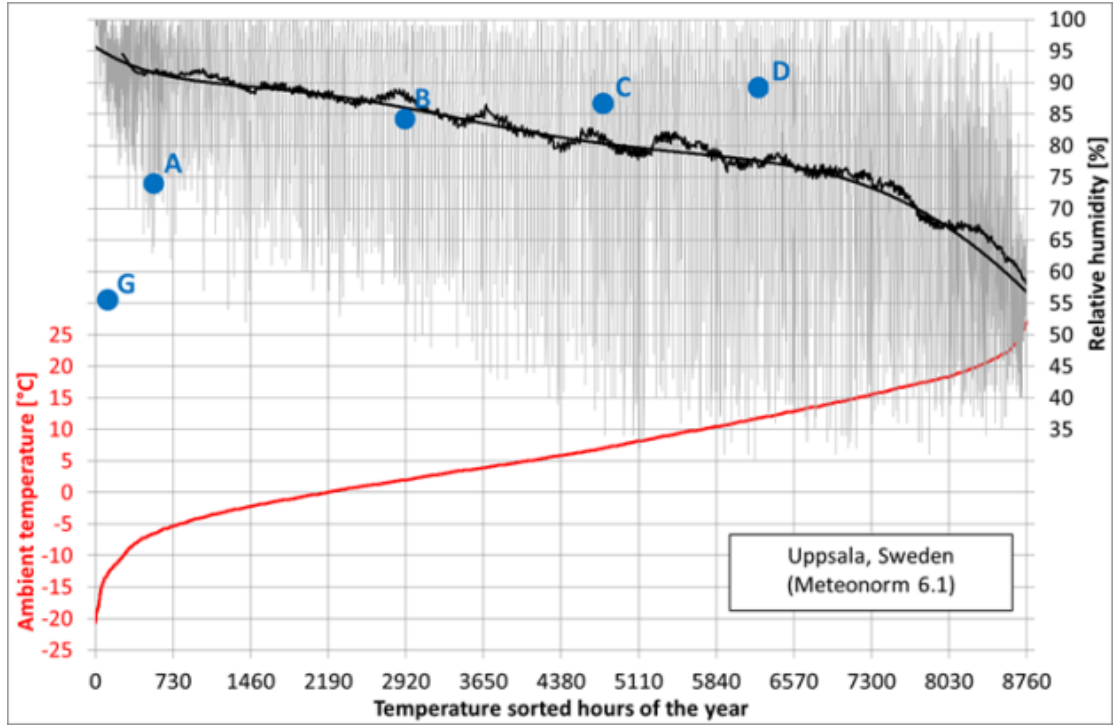


Figure 25: Temperature and relative humidity profile of Oslo, Norway

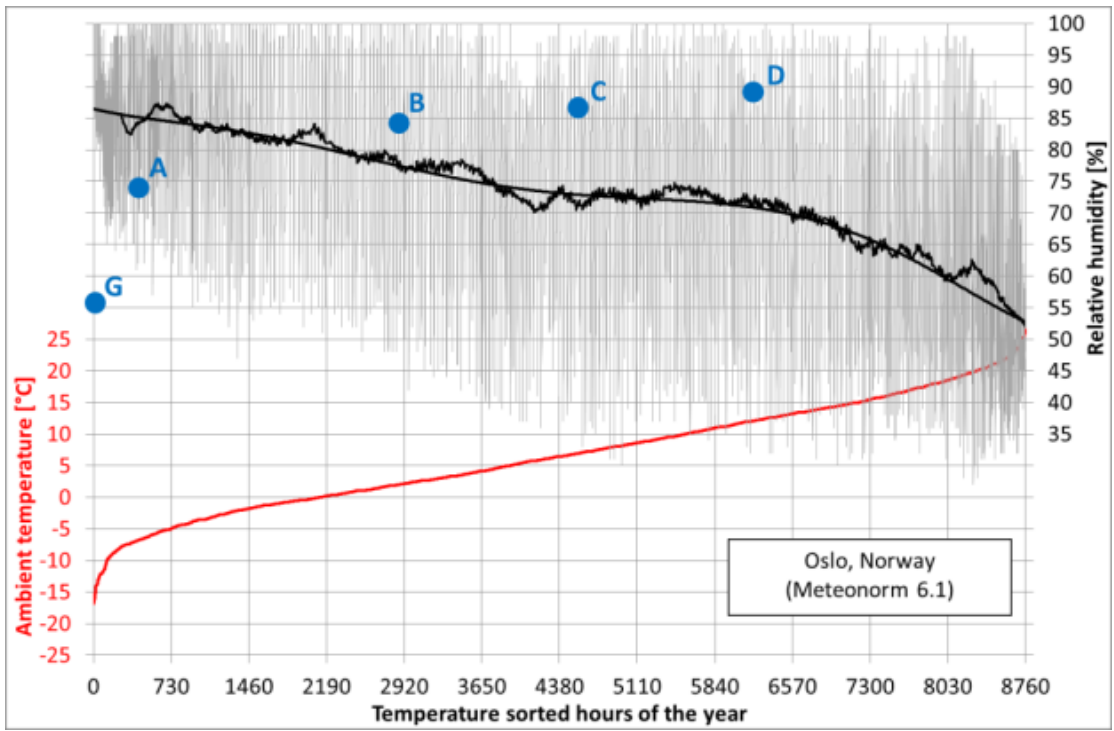

Figure 26: Temperature and relative humidity profile of Stavanger, Norway

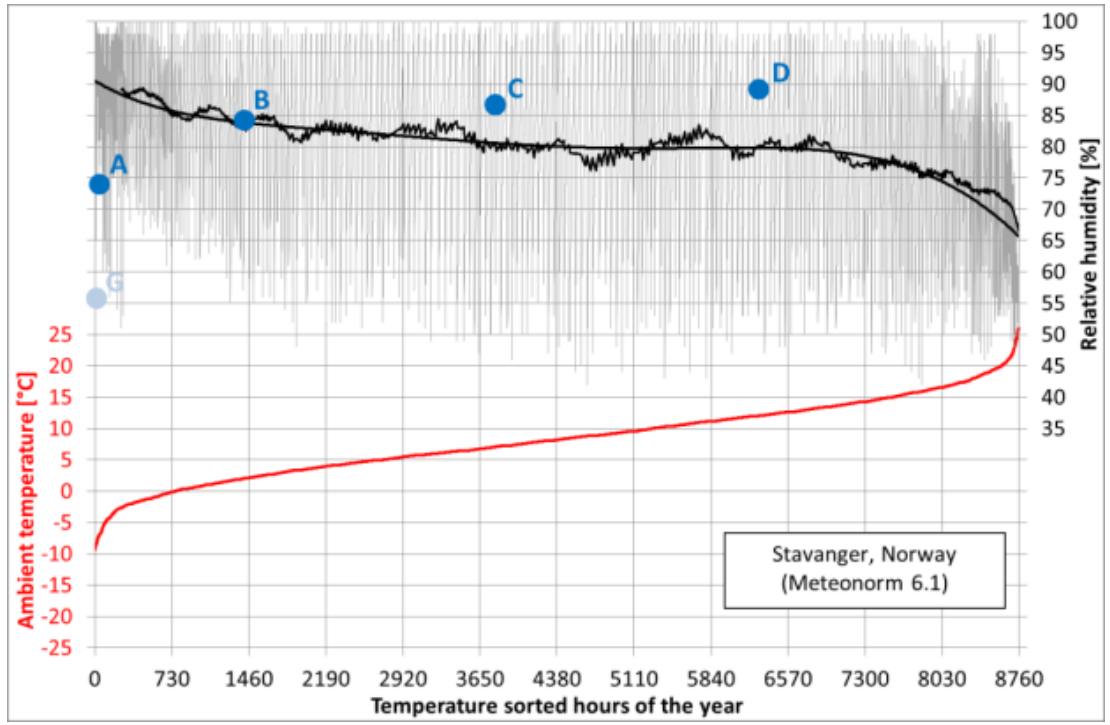


Figure 27: Temperature and relative humidity profile of Bergen, Norway

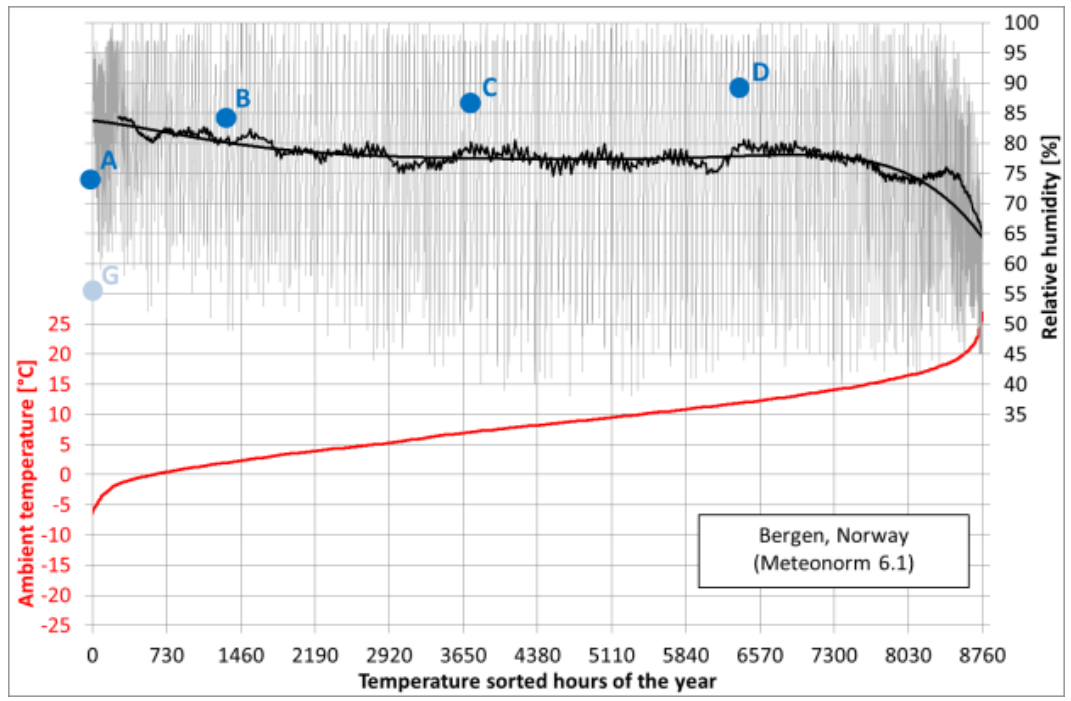

Figure 28: Temperature and relative humidity profile of Trondheim, Norway

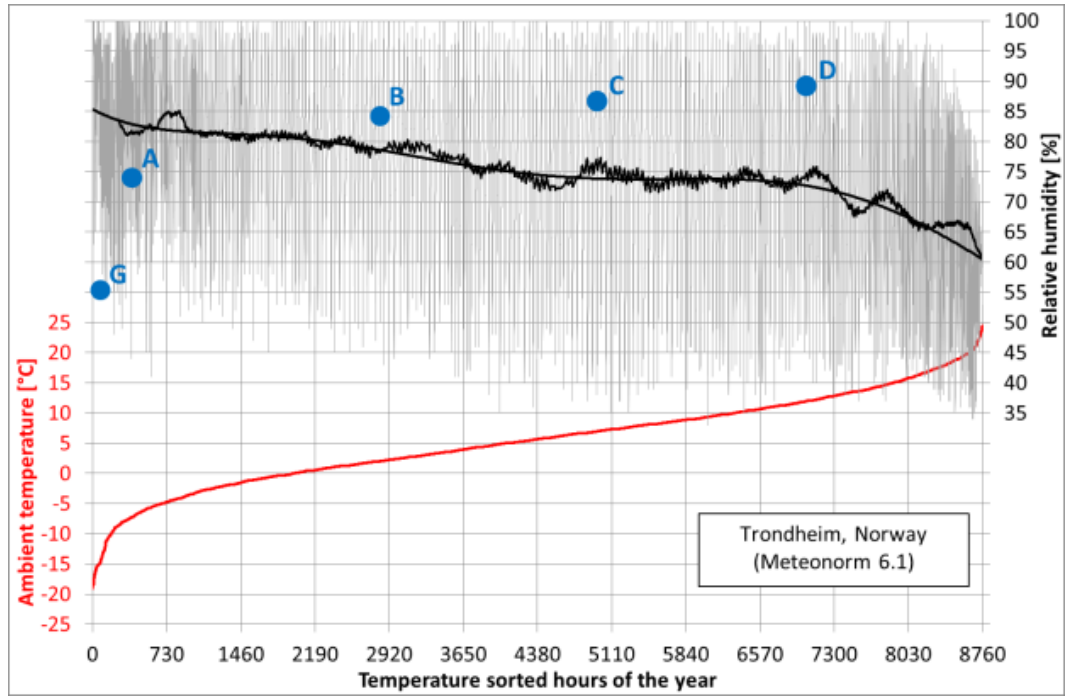

Note that no northern cities could be found in the Meteonorm 6.1 program. 


\subsubsection{Climate labelling of heat pump}

The Nordic countries are mainly in the Cold climate zone according to the Energy Labelling Regulation [2], Denmark being the exception, while the Average climate zone is found mainly on the continent of EU and UK, see Figure 1 on page 18.

Many heat pumps sold on the Swedish and Norwegian market are labelled for just the Average climate, as it is mandatory, Cold (and Warm) climate is not. Using Average climate will give an SCOP that is significantly higher. As the label is not perfectly simple to understand, at least not with " $x$ " marked at several positions, this can possibly mislead consumers. Two examples of energy labels are shown in Figure 29.

Figure 29: Example of information presented on the energy label of a heat pump sold in Norway or Sweden
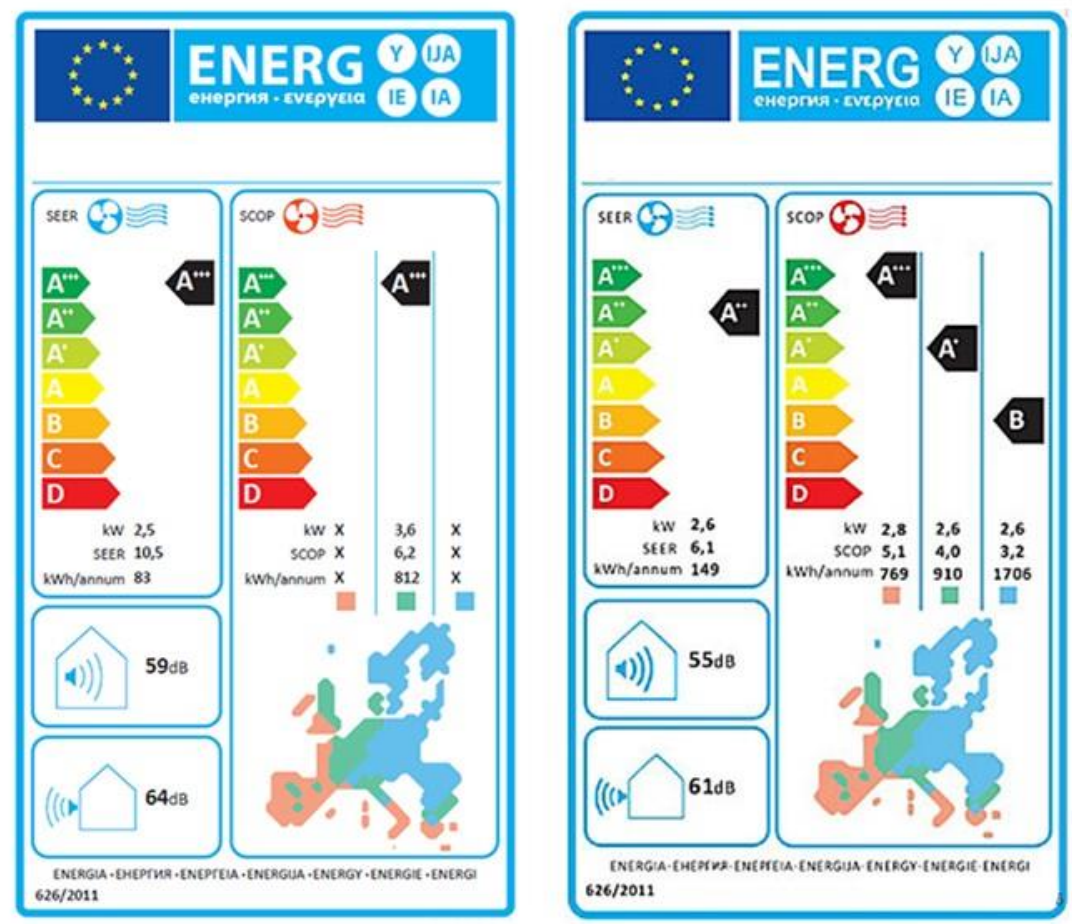

Note: Left with only Average climate presented, right with all climates presented. 
3.4.3 SCOP on the Energy label mostly displayed for the average climate only

Even though the Energy Label is designed to include data for all the three climates Average, Warm and Cold, it is only mandatory to present data for the Average Climate. Even for air-to-air heat pumps sold in the Nordic countries like Sweden and Norway, their labels most often only present data for the Average climate. However, there are a few exception, but not many. In the Folksam study [20] only one manufacturer had energy labelling for the colder climate. For two other manufacturers no energy labelling was found, a potential costumer would have to find the information in those manufacturers product sheets. 
Table 11: Online energy labelling investigation on the heat pumps in the Folksam study

\begin{tabular}{|c|c|c|c|c|}
\hline \multirow[t]{2}{*}{ Heat pump } & \multirow[t]{2}{*}{ Manufacturer } & \multirow[t]{2}{*}{ Energy label } & \multicolumn{2}{|c|}{ Climate zone } \\
\hline & & & Average & Colder \\
\hline 1 & $\mathrm{~F}$ & Yes & Yes & No \\
\hline 2 & $\mathrm{~F}$ & Yes & Yes & No \\
\hline 3 & $\mathrm{~F}$ & Yes & Yes & No \\
\hline 4 & G & Yes & Yes & No \\
\hline 5 & G & Yes & Yes & No \\
\hline 6 & G & Yes & Yes & No \\
\hline 7 & $C$ & Yes & Yes & No \\
\hline 8 & $C$ & Yes & Yes & No \\
\hline 9 & D & No & Yes* & No \\
\hline 10 & $\mathrm{H}$ & Yes & Yes & No \\
\hline 11 & $\mathrm{H}$ & Yes & Yes & No \\
\hline 12 & $E$ & Yes & Yes & No \\
\hline 13 & $E$ & Yes & Yes & No \\
\hline 14 & $E$ & Yes & Yes & No \\
\hline 15 & $E$ & No & Not found & No \\
\hline 16 & I & Yes & Yes & No \\
\hline 17 & I & Yes & Yes & No \\
\hline 18 & A & No & Yes* & No \\
\hline 19 & A & No & Yes* & No \\
\hline 20 & A & No & Yes* & No \\
\hline 21 & A & No & Yes* & No \\
\hline 22 & $A$ & No & Yes** & No \\
\hline 23 & $A$ & No & Yes* & No \\
\hline 24 & A & No & Yes* & No \\
\hline 25 & B & Yes & Yes & No \\
\hline 26 & B & Yes & Yes & No \\
\hline 27 & B & No & Yes* & No \\
\hline 28 & $\mathrm{~J}$ & Yes & Yes & Yes \\
\hline 29 & J & Yes & Yes & Yes \\
\hline 30 & $\mathrm{~J}$ & Yes & Yes & Yes \\
\hline 31 & $\mathrm{~K}$ & Yes & Yes & No \\
\hline
\end{tabular}

Note: * Information from product sheet. ** Information available in product sheet, but climate zone not stated.

As all data on the Energy Labels are for the average climate, the SCOP will be significantly higher than what would be expected in a real installation in a Nordic climate, especially since the heat pumps are declared for a house with a very low

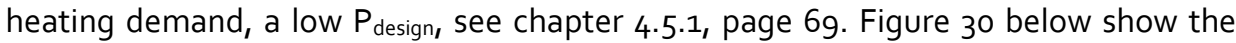
SCOP values for the different heat pumps in the Folksam study together with the declared performance at two different outdoor temperatures. 
Figure 30 : SCOP according to Energy labelling and COP at $+7{ }^{\circ} \mathrm{C}$ and $-15^{\circ} \mathrm{C}$ from Folksam [20]

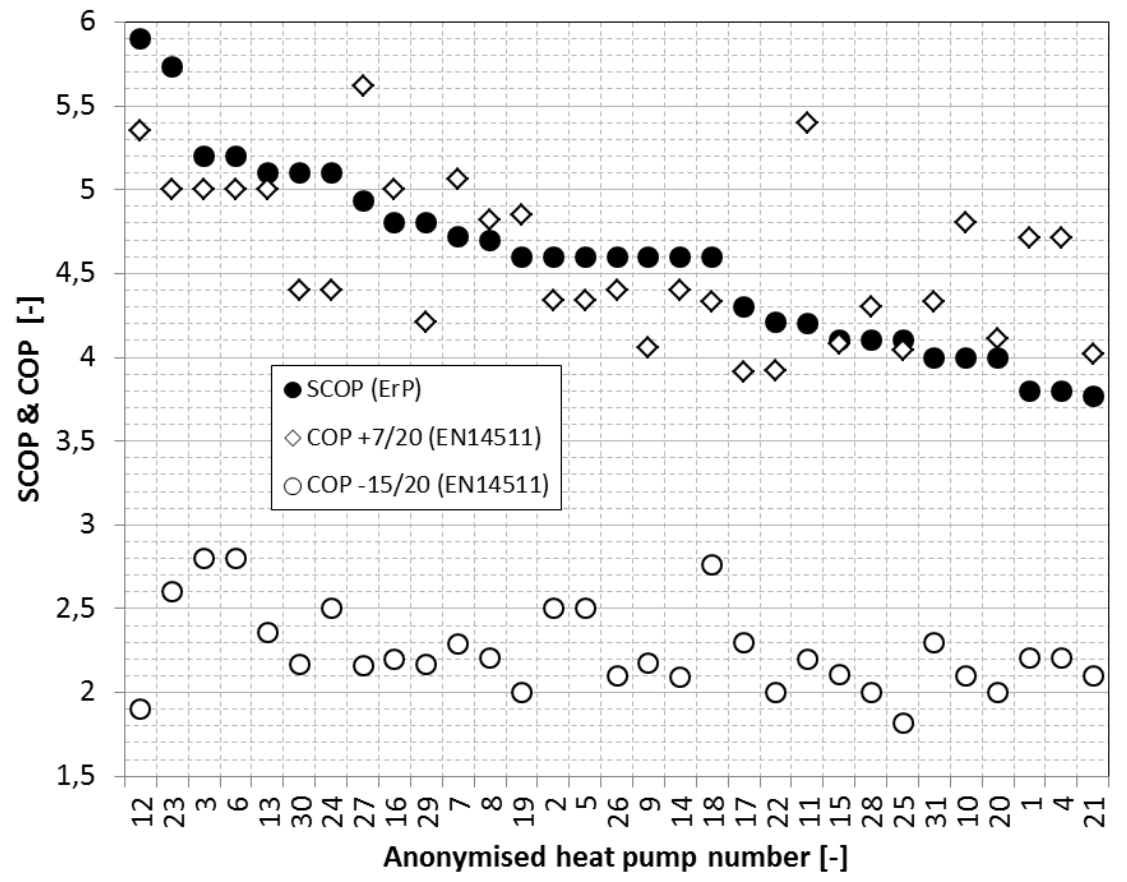

In Figure 30 the SCOP is higher than the COP at $+7^{\circ} \mathrm{C}$ on about half of the heat pumps, meaning that the heat pump would have to operate on average at higher temperatures than $+7{ }^{\circ} \mathrm{C}$ and to be able to have that SCOP, if the rated heating capacity of the heat pump according to $\mathrm{EN}_{14511}$ is used. With lower or significantly lower heating capacity used, see chapter 4.5.1, page 69, a higher SCOP is possible as COP increases at lower compressor speeds and thereby lower heating capacities.

The SCOP is calculated and presented only for the average climate zone, if the cold climate had been used the SCOP would probably have been lower. With more relevant heating capacity the SCOP would have been significantly lower. The general decrease in SCOP has not been possible to quantify, as very little data is available for the colder climate. The decrease in SCOP is also dependent on the relation between $\mathrm{P}_{\text {Design }}$ for the different climates, chosen by the manufacturer. Two examples are shown in Figure 31. 
Figure 31: Two anonymised heat pumps showing PDesign and SCOP for both Average and Colder climate
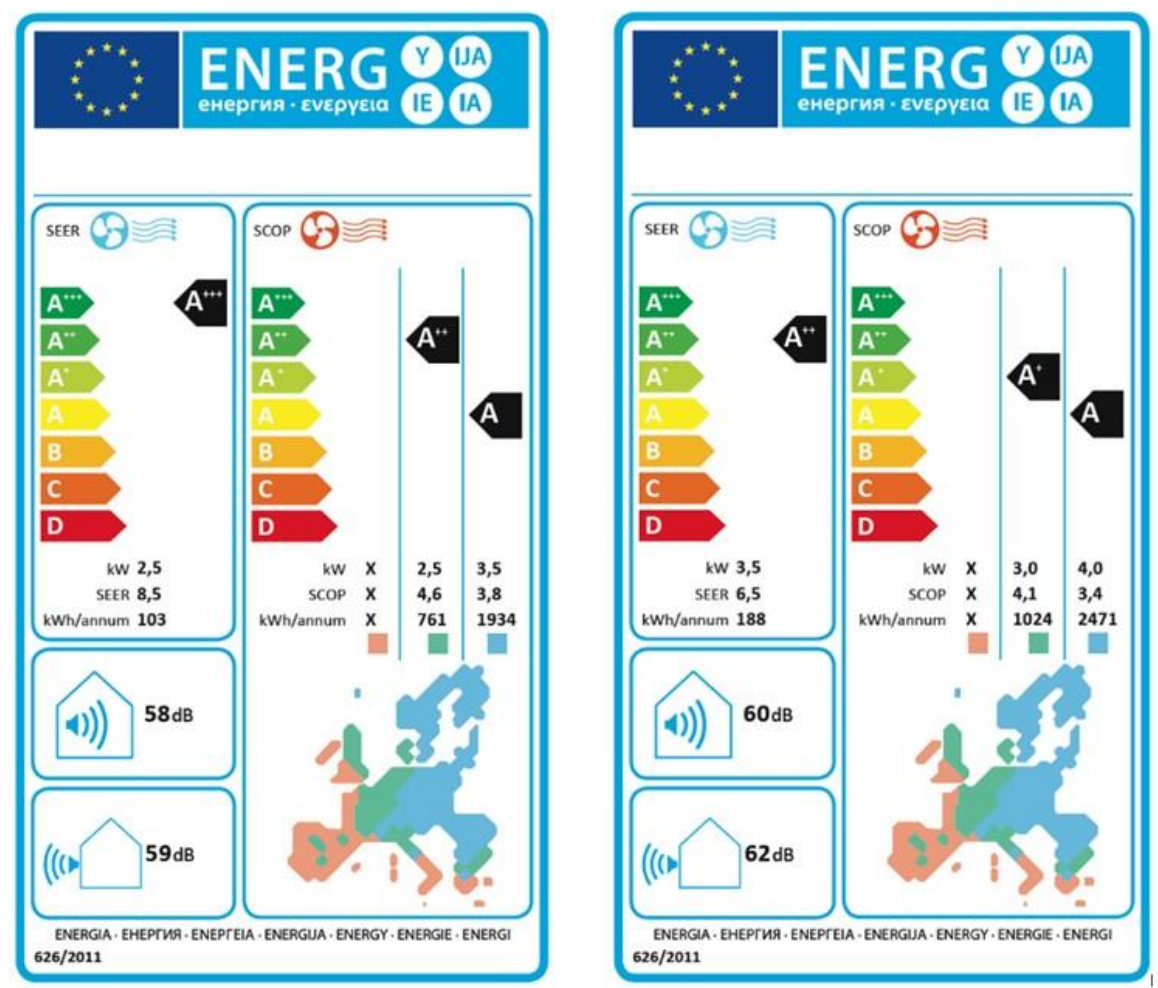

\subsection{The heat pumps are declared at lower capacity than they operate at}

By browsing marketing data for air-to-air heat pumps it can be concluded that they are declared with a relatively low $\mathrm{P}_{\text {design }}$ on the energy labels. The question is if they are mainly used in houses with such low heating demand, or if this is a reason for the perceived discrepancies between data on the energy labels and real performance. 


\subsubsection{Heating capacity rating of heat pump}

The $P_{\text {design }}$ is freely (with some limitations) chosen by the manufacturer/importer of the heat pump. Choosing a low $\mathrm{P}_{\text {design }}$ compared to the real heat output of the heat pump gives in many cases a higher SCOP, as the heat pump will be able to meet the most of the bins in the SCOP calculations with just the heat pump (no back-up heater needed). In addition, for an inverter controlled heat pump, the COP is generally higher a lower capacities. Choosing a higher $\mathrm{P}_{\text {design, }}$ as done by the major Swedish manufacturers, gives a more realistic SCOP and annual electricity consumption, but is instead resulting in a lower SCOP.

As not all heat pumps have digitally searchable Energy Labels it is not always possible to find their declared $P_{\text {design, }}$ at least not with high reliability.

In Figure $32 P_{\text {design }}$ is shown for a number of heat pumps marketed in Sweden. All of them, except for one manufacturer, where labelled only for the average climate. $P_{\text {design }}$ for the average climate is thus shown. The manufacturer showing colder climate has unreadable energy label for one of their products, but the other are presented correctly. The maximum heating capacity at $+7^{\circ} \mathrm{C},-7^{\circ} \mathrm{C}$ and $-15^{\circ} \mathrm{C}$, presented in the marketing of the heat pump are also shown in the graphs. This proves that many heat pumps are labelled for a low $\mathrm{P}_{\text {design }}$ compared to what they are able to deliver. In many cases we see that the maximal capacity at $-7{ }^{\circ} \mathrm{C}$ and $-15^{\circ} \mathrm{C}$ are higher than $\mathrm{P}_{\text {design, }}$ which is the maximal heat demand the coldest hour (at $-10^{\circ} \mathrm{C}$ for the average climate, see Figure 4 for a graphic illustration of $P_{\text {design. }}$.). This might be very confusing for at consumer, especially in a Nordic Climate, selecting a heat pump for their house! They might be misled to believe that the heat pump is much more efficient than it actually will be when installed in their house. 
Figure 32: PDesign and heating capacity, at $+7^{\circ} \mathrm{C},-7^{\circ} \mathrm{C}$ and $-15^{\circ} \mathrm{C}$, for each heat pump (anonymised, numbers used instead of names)

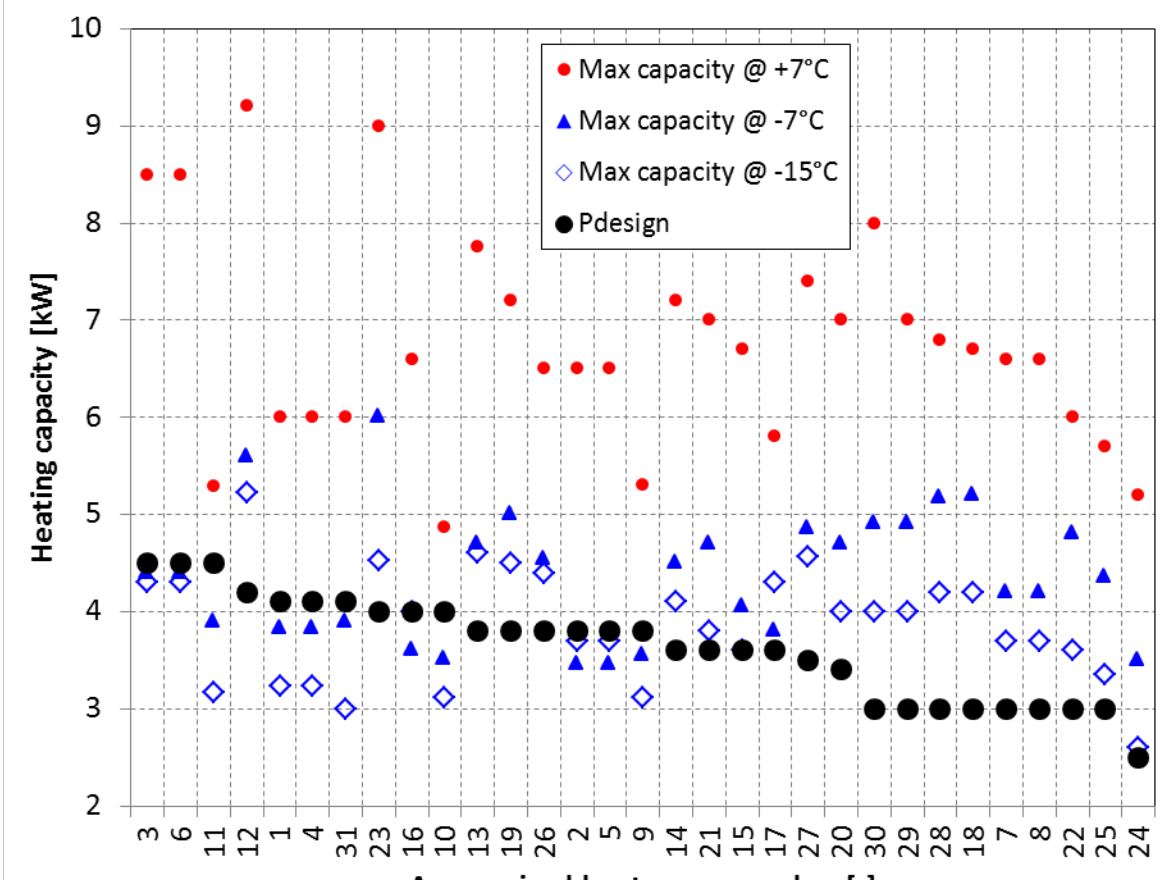

Anonymised heat pump number [-]

Source: From Folksam 2016 [20].

\subsubsection{Power consumption on energy label}

From the data in the Folksam survey [20] the electrical power consumption on each heat pump's Energy Label could be calculated, as below for the average climate:

Electrical power consumption, $P_{e}=\frac{P_{\text {Design }} \times 1400 h}{S C O P}$

All data presented in the Folksam study and in Figure 33 is for the average climate zone, not for the cold climate zone covering all of the Nordic countries (except Denmark). 
Figure 33: Energy labelling electrical consumption, for the average climate, calculated

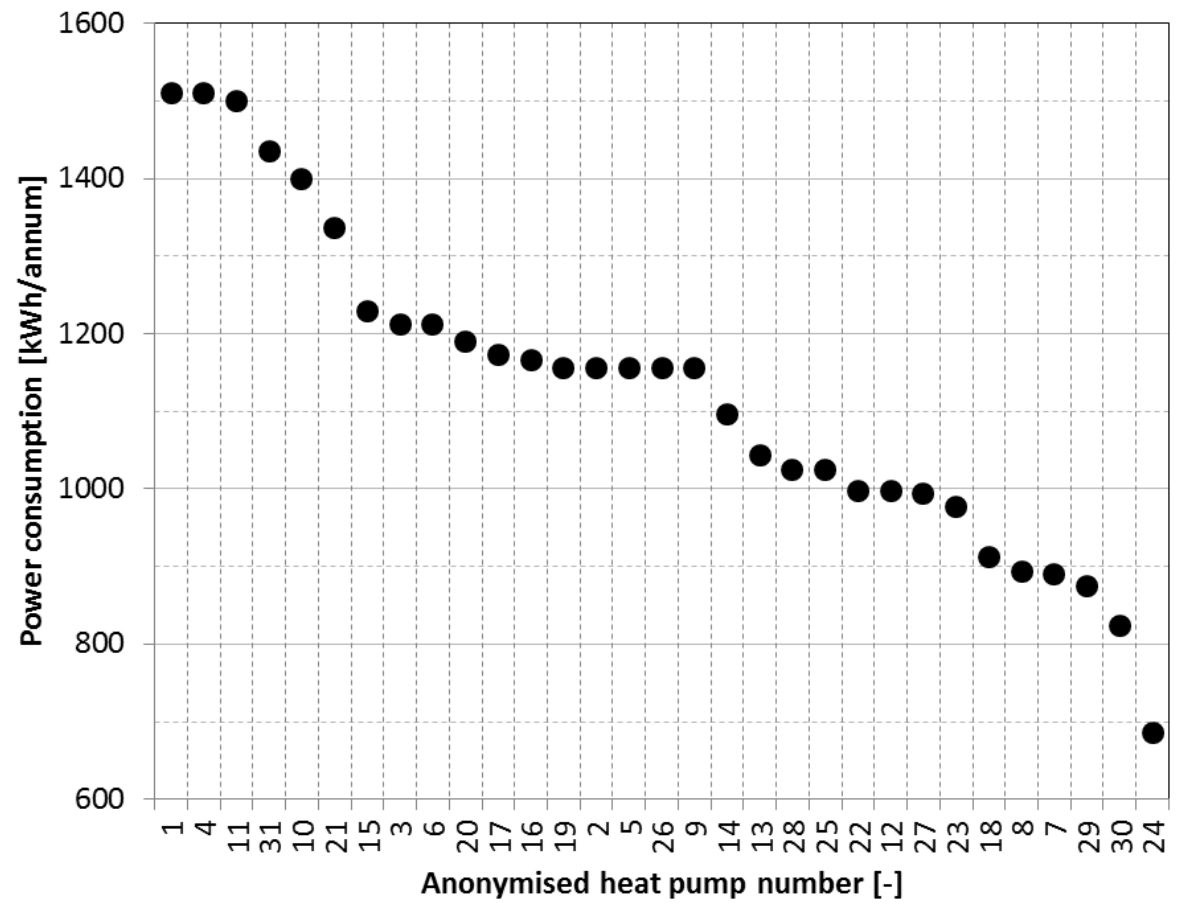

Note: Numbering not the same between the different diagrams.

Source: From Folksam 2016 [20].

An electrical power consumption of less than 1,500 kWh per annum is well below what would be expected in a villa in the Nordic climate. With an estimated real SPF of about 3 and a heating demand of $15,000 \mathrm{kWh}$ a real power consumption would be around $5,000 \mathrm{kWh}$ per annum. The results from the field measurements in Sweden [9] reported in chapter 3.1 showed electric energy consumptions of 2,650 to 3,960 per year. The electrical power consumption clearly mislead the consumers in the Nordic countries! 


\subsubsection{SCOP versus maximum heating capacity and $P_{\text {design }}$}

From the Folksam survey [20] a very good match between SCOP and maximum heating capacity can be found at $+7^{\circ} \mathrm{C}$. The higher the maximum heating capacity the better SCOP, see Figure 34 .

Figure 34: SCOP as a function of maximum heating capacity at $+7^{\circ} \mathrm{C}$

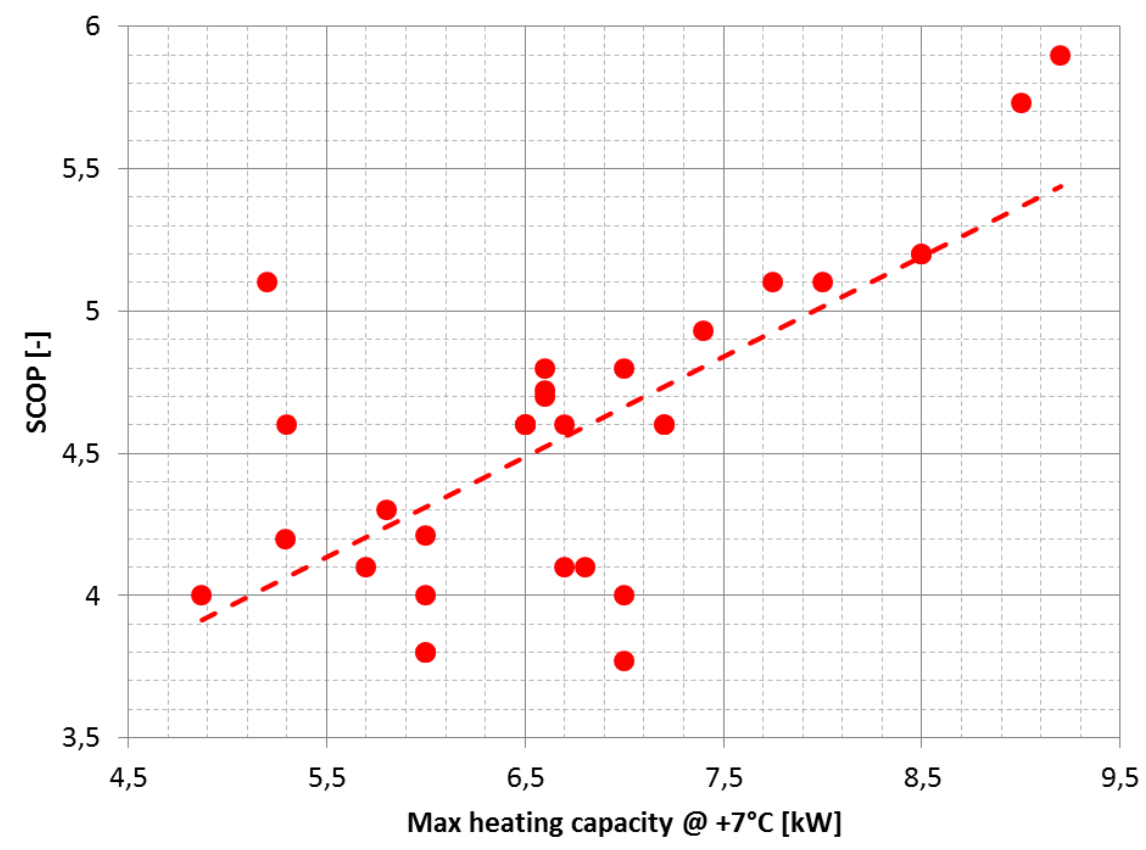

Source: Data from Folksam 2016 [20].

With good control and low lowest compressor speed limit this could be correlating to performance in real operation.

The match between SCOP and $P_{\text {design }}$ is not clear, see Figure 35. Even though it is beneficial to obtain a high SCOP, to declare the heat pumps for a lower $\mathrm{P}_{\text {design, }}$ a large variation in performance in shown. 
Figure 35: SCOP as a function of $\mathrm{P}_{\text {Design }}$

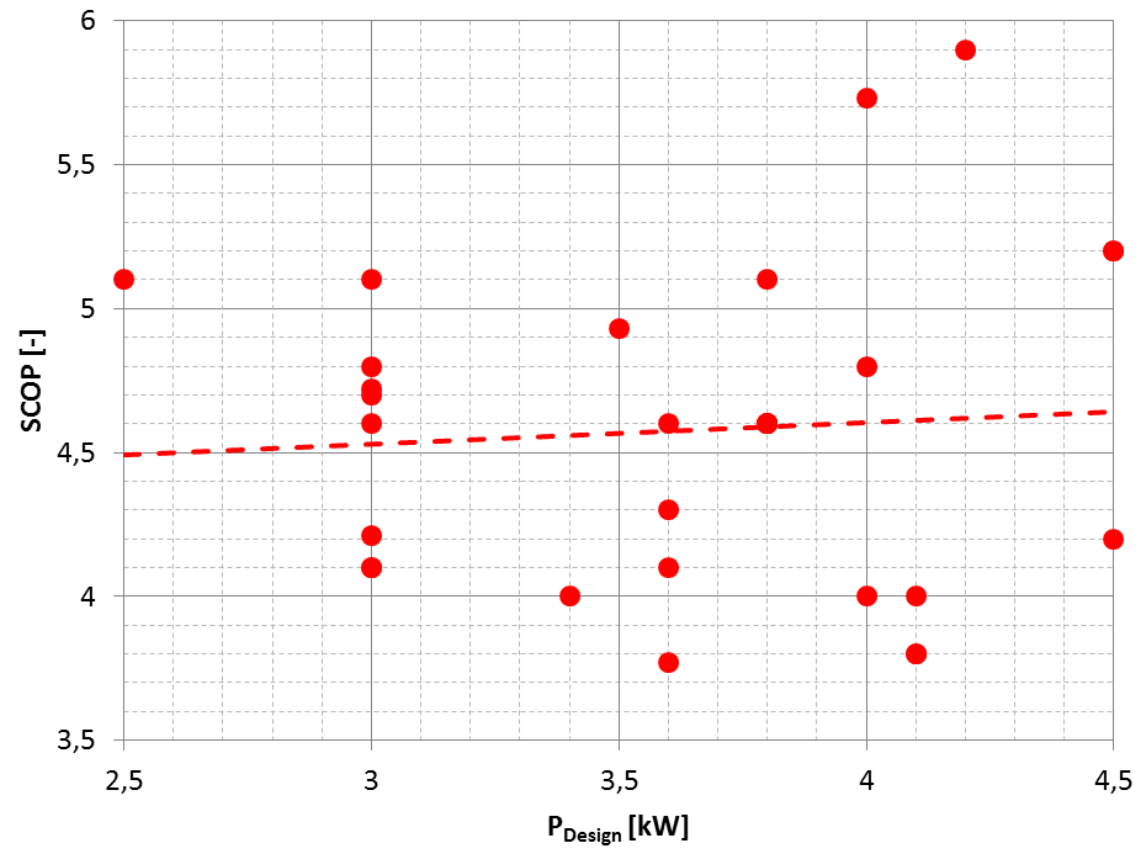

Source: Data from Folksam 2016 [20].

\subsubsection{Test according to Kyl \& Värmepump Importörerna (Sweden)}

Kyl \& Värmepump Importörerna (KVI), an association for companies importing airconditioning systems and heat pumps in Sweden, did a test of a handful of air-to-air heat pumps at SP (RISE) in 2016. The test was performed with the compensation method, which means that the compressor frequency was not set or fixed, but heat pumps control system controlled the heat pump (as it would do in a real heating situation). The tests periods were also longer than stipulated in $\mathrm{EN}_{14511}$ and $\mathrm{EN}_{141825}$, which also means that it was more likely that defrosting occurred in the laboratory tests (if it should occur in the field at the same outdoor conditions) and was then accounted for in the evaluation. Besides those exceptions from the standards, the tests were performed according to EN14511 and the same calculation approach was used as in EN14825. 
Heating demand and electric power consumption were calculated for villas with heating demands of 4,6 and $8 \mathrm{~kW}$ at $-15^{\circ} \mathrm{C}$, geographically placed at three different locations: Malmö, Stockholm and Luleå. This means that a $4 \mathrm{~kW}$ villa in Luleå will have a "Pdesign" of about $5.9 \mathrm{~kW}$ at $-29^{\circ} \mathrm{C}$. In Stockholm and Malmö the same villa will ha a "P design" of about 4.5 kW (@ $-18^{\circ} \mathrm{C}$ ) and $3.3 \mathrm{~kW}$ (@-10 ${ }^{\circ} \mathrm{C}$ ). The assumption that the heat is perfectly spread in the villa is made when calculating the performance of the heating system, meaning that the auxiliary heaters are only used at low temperatures when the capacity of the heat pump is too low to heat the villa.

In the figures below, the $\mathrm{P}_{\text {design }}$ and SCOP are shown together with the SPF values (comparable with $\mathrm{SPF}_{\mathrm{H}_{4}}$ in Figure 6) calculated from the presented data for heating demand and electricity consumption presented from the tests and calculation on the website of Kyl\&Värmepump Importörerna (www.kvi.se).

Note that it was difficult to find consistent values for the $P_{\text {design }}$ and SCOP for the different heat pump models. When possible to find for the heat pump model, the Energy Label was of course the first alternative. If no Energy Label was found, the rest of the marketing information was checked. If $\mathrm{P}_{\text {design }}$ and $\mathrm{SCOP}$ values were found there, it was used. The last alternative was to use the test by Folksam as source. See Table 12 for a summary.

The data presented in the graphs below, show that heat pumps are labelled for lower capacities (heat loads) than they are intended to be, and probably are, normally used for. The reason for this is probably competition, since a lower $P_{\text {design }}$ often result in a higher SCOP and "letter" on the label. The presented SPF values are in all cases lower than the presented SCOP values. However, they give probably more realistic information to a consumer in a cold climate compare to the data presented on the Energy Label. However, it should be emphasized that all the companies follows the Energy Label regulation (on condition that an Energy Label can be found for the model) and no fault information is given. 
Figure 36: Calculation results on the five (A-E) air-to-air heat pumps based on tests
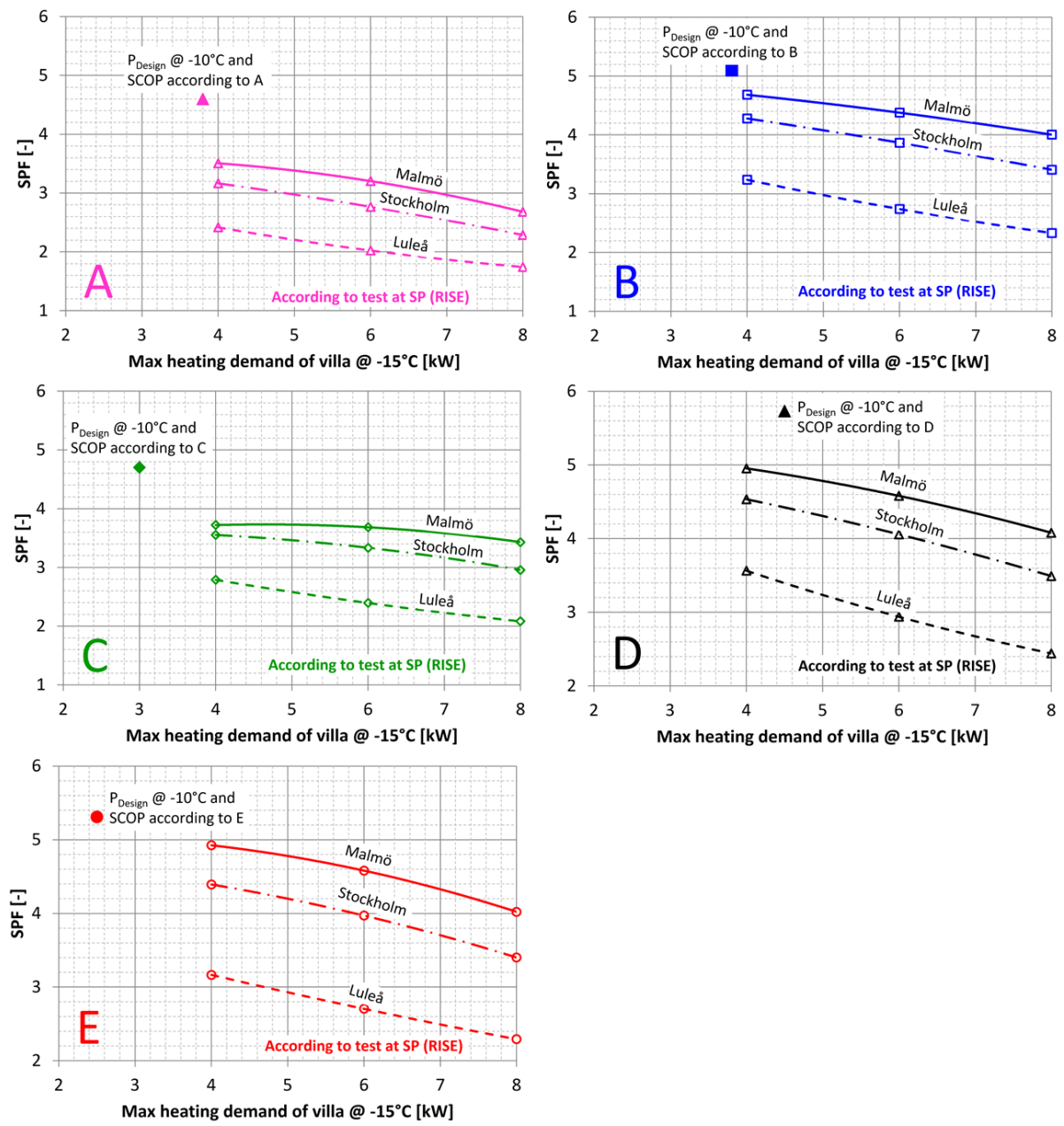

Note: Presented by Kyl \& Värmepump Importörerna in Sweden. 
Table 12: PDesign values for the different heat pumps in the Kyl \& Värmepump Importörerna test

\begin{tabular}{llll} 
Heat pump & Energy label $[\mathrm{kW}]$ & Marketing $[\mathrm{kW}]$ & Folksam $[\mathrm{kW}]$ \\
\hline A & Not found & 4.5 & 4 \\
B & 2.5 & $3.2^{*}$ & Not in test \\
C & 3.0 & 3 & 3 \\
D & Not found & $3.6 * *$ & 3.8 \\
E & Not found & $4.2 * *$ & 3.8
\end{tabular}

Note: *Value stated as heating capacity. ** Value stated as "nominal" in marketing.

$P_{\text {design }}$ for the average climate is the assumed heating demand of the house the coldest hour of the year, at $-10^{\circ} \mathrm{C}\left(\mathrm{T}_{\text {design }}\right)$. In Figure 37 below the dashed coloured lines in diagram shows the heating demand that each of the tested heat pumps are calculated for according to the Energy Label data, i.e. the heat load curve. The solid lines of the left diagram show the heating demand of the assumed houses/villas used in the SPF calculations generated from the data presented by Kyl and Värmepump importörerna, for the 4, 6 and $8 \mathrm{~kW}$ villas. The graph in Figure 38 show the bin hours used for each climate for which data is presented.

These graphs shows that an air-to-air heat pump only declared and tested for an average climate might not have been evaluated for sufficiently low outdoor temperatures and high capacities that are relevant when used in a cold climate, especially those for frosting conditions. On the contrary, the heat pumps tested according to the "Kyl \& Värmepump importörerna" test has been well evaluated for cold outdoor temperatures and higher capacities. 
Figure 37: Heat load curves for the different assumed houses for the data presented on the Energy Labels and in the tests performed by Kyl \& Värmepump Importörerna

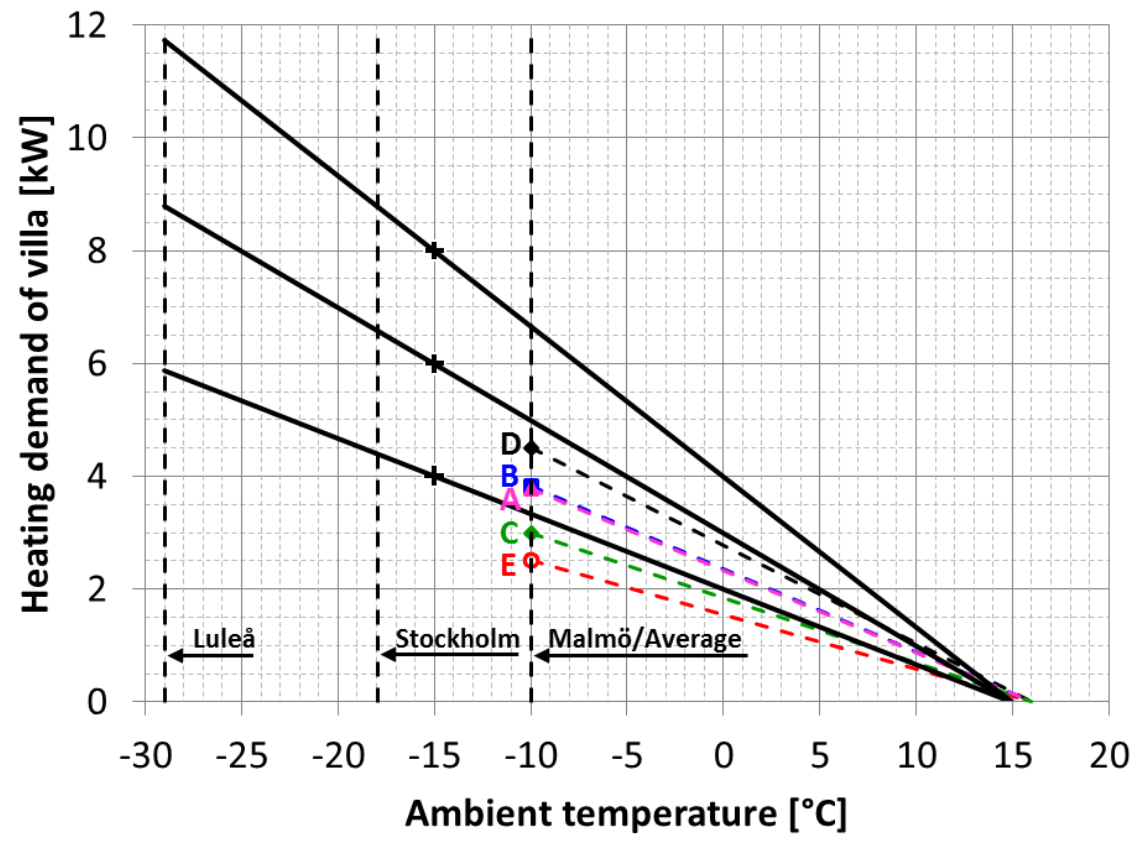

Note: The dashed coloured lines of the left diagram shows the heating demand that each of the tested heat pumps are calculated for according to the Energy label data. The solid lines of the left diagram show the heating demand used in the Kyl \& värmepump importörerna SPF calculation, for the 4,6 $\& 8 \mathrm{~kW}$ villas. 
Figure 38: The bin hours used for each calculation in Figure 37

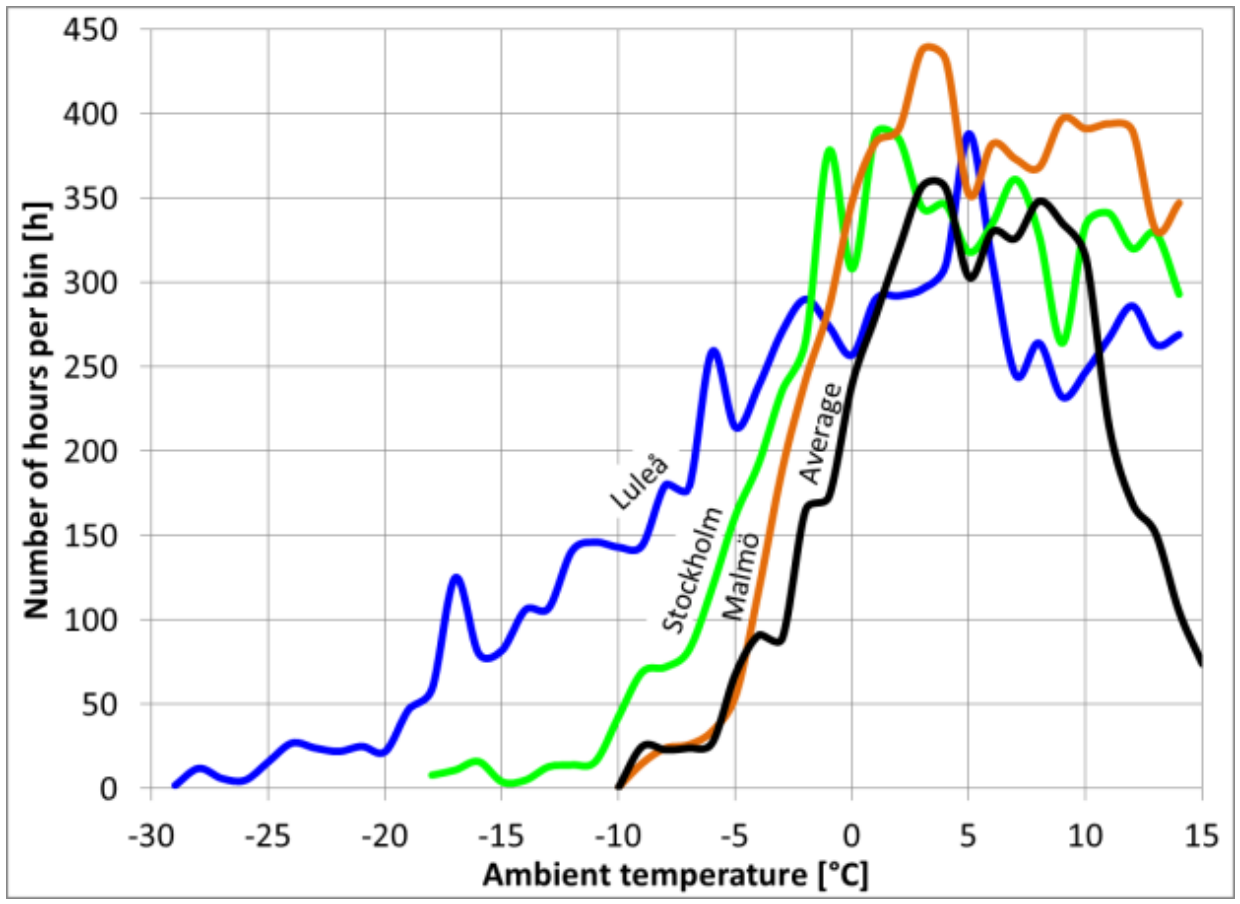




\subsection{Summary possible reasons for performance discrepancy}

There are several possible reasons why the performance presented on the energy labels are differing (higher) than the performance experienced in real life installations.

One reason, especially for non-ducted air-to-air heat pumps, is the non ideal distribution of heat in the house due to the floor plan of the house. The consequence of this is that the electric radiators (back-up heaters) are used in some parts of the house, even though the capacity of the heat pump itself is still sufficient for the heating demand.

Another possible reason is that during laboratory measurements the frequency is normally set according to the manufacturers' instructions for the different test points and the normal control system, used in real life installations, is by passed. This could result in the fact that the heat pump operates differently with different performance.

A third reason can be that the test point is not long enough for enough frosting and thereby defrosting to take place, especially at low capacities.

A forth reason can be that the heat pumps are declared and labelled for much lower capacities and warmer climate than they are normally used for in a Nordic climate.

Results from market surveillance tests show that it has become more and more rare that heat pumps defrost during the laboratory tests. In addition, many heat pumps are declared for low capacities, lower than their "real" capacity, to obtain a higher SCOP value. The reason it has become more and more rare the heat pumps defrost during market surveillance test, could be a result of improved defrost control. It could also be the result of that defrost control is optimized to manage to avoid defrost during the standard test period, especially at the low capacities that they are declared for on the Energy Label and hence evaluated at during market surveillance tests.

The climates defined in the standards that are the basis for the performance presented on the Energy Label agree relatively well for the $+2(1)$ test point for several example cities in Sweden and Norway. The frosting and defrosting is normally most severe at this test point if it takes place during tests. For the $-7(-8)$ test point situation is opposite, the test conditions means lower humidity levels than real conditions. This could still be a reason, but no real proof has been found. 


\section{Example of confusing advertising}

One company clearly shows that the $P_{\text {design }}$ is much lower than the real capacity of their heat pump. For $P_{\text {design, }}$ which should be the highest heating demand of the house the coldest day of the year, for the average climate at $-10^{\circ} \mathrm{C}$, a lower value is presented than the maximum heating capacity presented for $-25^{\circ} \mathrm{C}$, see Figure 39 below. The data declared is very transparent, so in that sense, the manufacturer cannot be blamed to hide anything or giving any false information. All the rules according to the regulations and standards are followed. Still, this information is misleading for the consumer, who will most likely think that the product is more efficient than it will be in a real installation in a Nordic cold climate.

The table below is just one example. Similar advertisements can be found for other models and companies.

Figure 39: Data sheet for an AAHP

\begin{tabular}{|c|c|c|c|c|}
\hline \multicolumn{3}{|l|}{ Maximalt kapacitet } & $7,80 \mathrm{~kW}$ & $9,20 \mathrm{~kW}$ \\
\hline Inomhusenhet & & & 1 & \\
\hline \multicolumn{3}{|l|}{ Utomhusenhet } & & 1 \\
\hline Värmekapacitet & Nominell [Min - Max] & kW & $3,60(0,60-7,80)$ & $4,20(0,60-9,20)$ \\
\hline COP \#1 & & WN & $6,43 \mathrm{~A}$ & $5,35 \mathrm{~A}$ \\
\hline Vărmekapacitet vid $-7^{\circ} \mathrm{C}$ & & kW & 5,59 & 5,60 \\
\hline $\mathrm{COP}$ vid $-7^{\circ} \mathrm{C}$ & & WN & 2,27 & 2,00 \\
\hline Värmekapacitet vid $-15^{\circ} \mathrm{C}$ & & KW & 4,80 & 5,22 \\
\hline $\mathrm{COP}$ vid $-15^{\circ} \mathrm{C} 11$ & & WW & 1,94 & 1,90 \\
\hline Värmekapacitet vid $-25^{\circ} \mathrm{C}$ [testat av SP] & & $\mathrm{kW}$ & 3,72 & 3,67 \\
\hline $\mathrm{COP}$ vid $-25^{\circ} \mathrm{C}$ (testat av SP) & & W/W & 1,63 & 1,50 \\
\hline Varmekapacitet vid - $35^{\circ} \mathrm{C}$ [testat av SP] & & $\mathrm{kW}$ & 2,51 & 2,44 \\
\hline COP vid $-35^{\circ} \mathrm{C}$ (testat av SP) & & WN & 1,32 & 1.15 \\
\hline SCOP & & W/W & 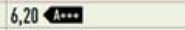 & $5,90 \subset \ldots$ \\
\hline Pdesign vid $-10^{\circ} \mathrm{C}$ & & kW & 3,60 & 4,20 \\
\hline Ineffekt värmedrift & Nominell [Min - Max] & kW & $0,640(0,140-2,720)$ & $0,830(0,140-3,160)$ \\
\hline Arlig energiförbrukning [värmedrift]" & & $\mathrm{kWh} / \mathrm{a}$ & 812 & 995 \\
\hline Kylkapacitet & Nominell [Min - Max] & KW & $2,50(0,60-3,00)$ & $3,50(0,60-4,00)$ \\
\hline SEER & & W/W & $10,50<\cdots$ & $10,00<+\cdots$ \\
\hline Pdesign (kyldrift) & & $\mathrm{kW}$ & 2,5 & 3,5 \\
\hline Ineffekt kyldrift & Nominell (Min - Max) & $\mathrm{kW}$ & $0,430(0,140-0,610)$ & $0,800(0,140-1,010)$ \\
\hline Arlig energiförbrukning (kyldrift) ${ }^{2]}$ & & $\mathrm{kWh} / \mathrm{a}$ & 83 & 122 \\
\hline Luftflöde & Värmedrift / Kyldrift & $\mathrm{m}^{3} / \mathrm{h}$ & 1.020 & 1.050 \\
\hline Ljudtrycksnivã ${ }^{11}$ & Värmedrift - Kyldrift (Hōg / Lảg / S-Làg) & $d B[A]$ & $44 / 26 / 18-44 / 27 / 18$ & $45 / 29 / 18-45 / 33 / 18$ \\
\hline Mătt / Nettovikt inomhusenhet & $\mathrm{H} \times \mathrm{B} \times \mathrm{D}$ & $\mathrm{mm} / \mathrm{kg}$ & $295 \times 798 \times 375 / 14,5$ & $295 \times 798 \times 375 / 14,5$ \\
\hline Mătt " / Nettovikt utomhusenhet & $H \times B \times D$ & $\mathrm{~mm} / \mathrm{kg}$ & $630 \times 799 \times 299 / 39,5$ & $630 \times 799 \times 299 / 39,5$ \\
\hline Driftomräde & Värmedrift / Kyldrift Min - Max & ${ }^{\circ} \mathrm{C}$ & $-35-+24 /-10-+43$ & $-35-+24 /-10-+43$ \\
\hline
\end{tabular}

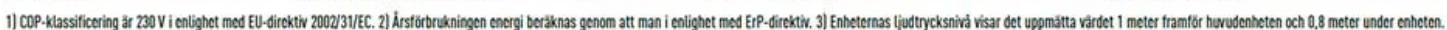

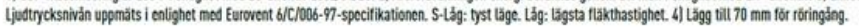


From another company's very extensive data the following diagram could be drawn, see Figure 40 . It clearly shows that the heat pump is declared at lower heating capacity than it in reality can produce. At $\mathrm{T}_{\text {Design }}$ (Average climate, $-10^{\circ} \mathrm{C}$ ) it is declared at $50 \%$ capacity, meaning the heat pump is only running at $50 \%$ of maximum speed. This heat pump has no declared capacity for the cold climate, the dashed blue line in the figure is extrapolated.

Figure 40: Real maximum heating capacity and declared heating capacity of one heat pump found

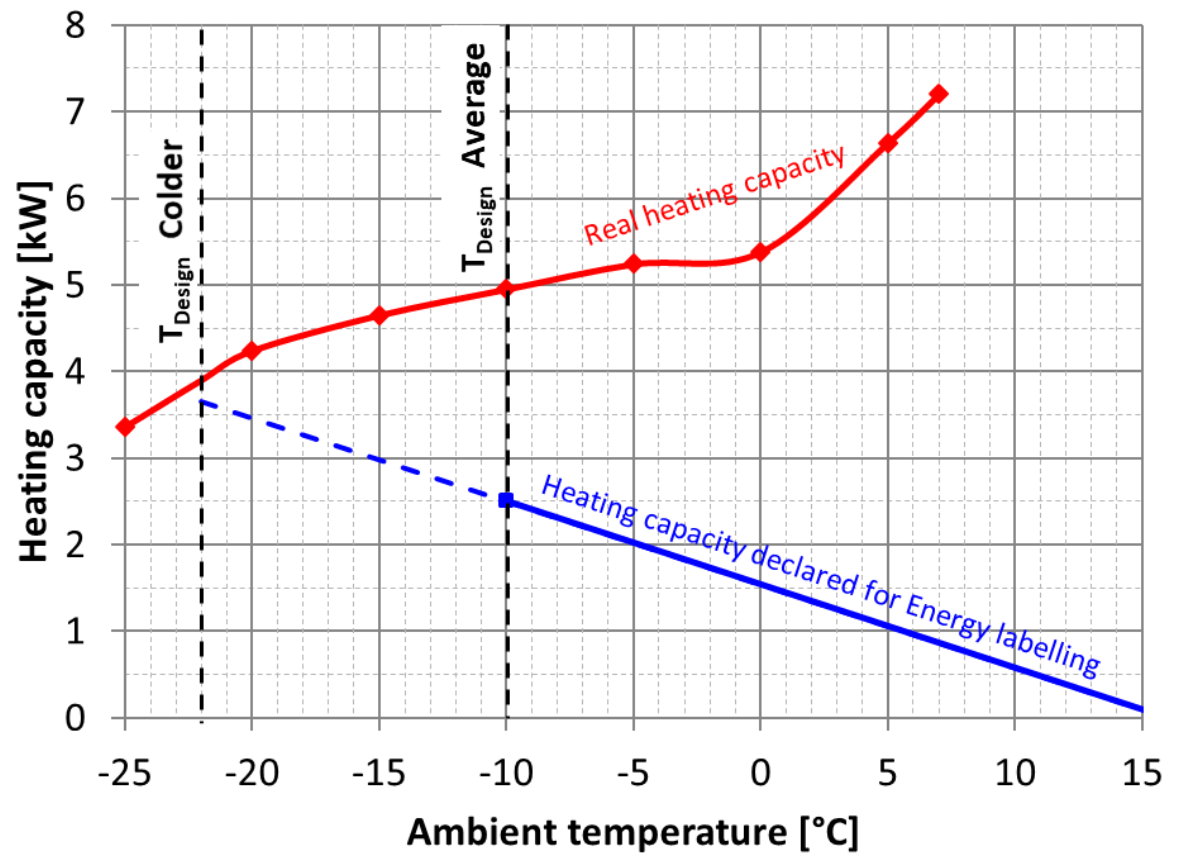

A third company does not mention that the heat pump has a fixed speed compressor, thus having very high heat capacity, compared to the heat demand, at higher ambient temperatures. On the service manual first page "Inverter" is printed, but nothing can be found that the compressor is inverter controlled, but the fans are, see Figure 41. 
Figure 41: Another company's heat pump service manual

Service Manual

Indoor

INUE्RTER 
$84 \quad$ Nordsyn study on air-to-air heat pumps in humid Nordic climate 


\section{Conclusions}

As explained in the beginning of this report some of the Nordic market surveillance authorities suspects or have the perception that the declared efficiencies for the products on the energy labels and supporting data sheets are considerably higher compared to what have been measured in real installations in the field, especially in cold and humid climates, which in such case gives the consumer misleading information. The purpose of this study was first and foremost to confirm or reject this suspicion.

Since there are very little data from field measurements on air-to-air heat pumps available in the open literature, it has not been possible to either confirm or reject this suspicion or perception.

However, the data available in combination with marketing data for different airto-air heat pumps show that the heat pumps are labelled for much lower capacities than they are intended to be used for in a Nordic climate, which also means that they are labelled for lower capacities than they are normally used for. Therefore, the efficiency displayed on the Energy Label, the SCOP value, is much higher than it will be in a real application. The Energy Label was developed to give sufficient but easy understandable guidance to be able to select an efficient product. However, as the heat pumps are marketed now different values for $P_{\text {design, }} P_{\text {rated }}$ and maximum capacity results in very unclear guidance to the consumer.

In addition, they are most often only labelled for an average climate, even though sold in a climate which is more similar to the cold climate defined in the Energy Label Regulation. This also means that the efficiency displayed on the Energy Label, the SCOP value, is much higher than it will be in a real application in a colder Nordic climate.

A third reason for a deviation of the SCOP presented on the Energy Label and the efficiency experience in real life is that the SCOP calculation assumes an ideal distribution of heat in the house. This can differ from house to house since it depends on the floor plan of the house.

A fourth reason for the experienced deviation can be that the normal control system is normally bypassed during the tests that are the basis for the data declared on the Energy Label, and instead the compressor frequency is set or fixed. This could result 
in the fact that the heat pump operates differently, with lower overall performance compared to in real installations.

The fact that the evaluation period in the standard might not be long enough to include enough frosting and a defrost could also be a reason for the deviation, but in such case in combination with the fact that the heat pump is tested at low capacities with set or fixed frequency.

No proof of that the reasons for the deviation between performance data on the Energy Label and performance in real installations should be that the standard tests do not take humidity sufficiently into account has been found in the study, but this reason can on the other hand not yet be dismissed. This should be monitored in the future in order to take into account that climate change might lead to a more humid climate. In addition, since there are more hours with a temperature between -7 and $+2{ }^{\circ} \mathrm{C}$ in the cold climate compared to the average climate it should be considered if an extra test point (declaration point) should be added for the cold climate in the standards. 


\section{Recommendations}

- First of all, stronger incentives should be created to label air-to-air heat pumps sold on a Nordic market (possibly with an exception for Denmark) for the Cold climate. As it is now, the arrows are just left out and the figures are replaced with an X. Since other performance data for colder and higher capacities are often declared in the marketing, much data is probably available for the manufacturer or importer, but due to competition reasons, performance data for the cold climate is left out (since it would show a lower efficiency). Therefore, we recommend that if the heat pump is not declared for any of the climate a text should be added on the label stating for example:

- "Not suitable for this climate";

- "Not evaluated for this climate"; or

- "Not tested for this climate".

- To avoid that the heat pumps are labelled for lower capacities than they are intended to be used for, it should not be allowed to state higher capacities in the promotion material than the $P_{\text {design }}$ value. $P_{\text {design }}$ should be representative for the maximal heating demand of your house the coldest day, and then it should not be of interest for the consumer if the heating capacity of the heat pump is larger at higher outdoor temperatures. In addition, $P_{\text {rated }}$ and maximum capacity should not be allowed to be used in the promotion material. In addition, a lower limit for the bivalent temperature (the outdoor temperature when the heat pump is assumed to cover the heating demand of the house alone) could be considered, at least for the cold climate.

- The manufacturer of air conditioners and comfort fans shall provide laboratories performing market surveillance checks, upon request, the necessary information on the setting of the unit. This does not mean that the manufacturer is allowed to use a specific software or other means to activate a mode dedicated to standard tests, in which the control of the unit is bypassed (or partially bypassed e.g. in case of the need to defrost). However, this is very hard to control, by market 
surveillance authorities or test laboratories. By using an alternative test method, a "compensation method" where the heat pump is tested with its normal control system activated, would probably result in performances more similar to what is obtained in the field. However, no such test method is yet described in any European standard, even though at least some test laboratories have experience from it. Nevertheless, it is important to continue the development of a compensation method as it could ultimately lead to seasonal figures closer to real life performances and the commission should encourage or mandate the standardization organization to develop such a method.

- The measures presented above will all lead to that, if frosting and defrosting take place for a heat pump in a real installations it will also do so to a larger extent in the standard tests that are the basis for the data displayed on the energy label.

- More data from continuous field measurements on air-to-air heat pumps during complete heating seasons, especially in the Nordic Climate, is needed in order to develop the regulations and standards in the direction to give the consumer more reliable data as basis for their selection. New measurement techniques for in situ measurements have been presented in the literature and commercial solutions are available. The energy agencies and market surveillance authorities in the Nordic countries should encourage that such measurement campaigns are performed.

- To evaluate if it is sufficient to test air-to-air heat pumps at $-7(-8)$ and $2(1)$ to obtain the performance during frosting conditions for a Nordic or cold climate, a study should be performed where several air-to-air heat pumps are tested at different temperatures and humidity levels in the range of those test points. In such a study the evaluations periods should be longer and the heat pumps should be tested both with set or fixed compressor frequency and according to a compensations method, where the normal control system of the heat pump is included in the test, in order to evaluate the effects of those aspects.

- Standardization work is costly since it requires a considerable amount of work hours to develop a standard. In the standardization committees today, normally manufacturers and test laboratories participate on their own expenses. Of course, both parties aim at fulfilling the mandate form the commission, when developing the standards and both have strong interest in that the test standards are robust, reliable and reproducible. The manufacturers are concerned that there is a level 
playing field among them and that the tests to perform are not too costly. However, the consumer side, is seldom represented in the standardization working group, nor is the market surveillance authorities. Therefore, to monitor and guarantee the interest from those parties, they should make sure that they are represented in the standardizations work when developing new or revising standards to be used for ecodesign or energy label regulations. 


\section{References}

[1] The COMMISSION REGULATION (EU) No 206/2012 of 6 March 2012 implementing Directive $2009 / 125 / E C$ of the European Parliament and of the Council with regard to ecodesign requirements for air conditioners and comfort fans

[2] COMMISSION DELEGATED REGULATION (EU) No 626/2011 of 4 May 2011 supplementing Directive 2010/30/EU of the the European Parliament and of the Council with regard to energy labelling requirements for air conditioners

[3] Viegand and Maagøe A/S, 2015, Strategic Nordic Products, Nordsyn

[4] Baijia Huang, Jan Viegand, Peter Martin Skov Hansen, Philippe Riviere, 2017, Review of Regulation 206/2012 and 626/2011 Air conditioners and comfort fans Task 1-2 report, Draft version.

[5] EN14511: 2013 Air conditioners, liquid chilling packages and heat pumps with electrically driven compressors for space heating and cooling, Part 1-4, Brussels, CEN

[6] EN14825: 2016 Air conditioners, liquid chilling packages and heat pumps, with electrically driven compressors, for space heating and cooling - Testing and rating at part load conditions and calculation of seasonal performance, CEN.

[7] Nordman, R., et al. 2012, SEasonal PErformance factor and MOnitoring for heat pump systems in the building sector SEPEMO-Build, FINAL REPORT, https://ec.europa.eu/energy/intelligent/projects/sites/ieeprojects/files/projects/documents/sepemo-build_final_report_sepemo_build_en.pdf

[8] Rivière, P., Nordman, R., Tran, C. T., Coevoet, M., 2011, SEPEMO D4.1. / D 3.3. guideline for heat pump field measurements on air- to air heat pumps, http://sepemo.ehpa.org/uploads/media/D4_1_D3_3_AA_Version_1_0_2011-09-21_01.pdf

[9] Lidbom, P., Axell, M., Stenlund, M., 2009, Fältmätning av Luft/Luft värmepumpar I svenska småhus, SP rapport 2009:26, SP, Energiteknik, Borås

[10] Tran, C.T., Rivière, P., Marchio, D., Arzano-Daurelle, C., 2013, In situ measurement methods of air to air heat pump performance, International Journal of Refrigeration, 36, $p$ $1442-1455$

[11] F. Karlsson, P. Lidbom, M. Axell, U. Lindberg, 2006, Air-to-air heat pumps evaluated for Nordic Circumstances, 6th International Cold Climate HVAC Conference 2006, Moskow.

[12] EN 14511-2, 2004. Air conditioners, liquid chilling packages and heat pumps with electrically driven compressors for space heating and cooling - Part 1-4. Brussels, CEN. Packages and heat pumps with electrically driven compressors for space $h$

[13] CEN/TS 14825, 2003. Air conditioners, liquid chilling pa heating and cooling - Testing and rating at part load conditions, CEN. 
[14] H. Nakos, C. Haglund Stignor, K. Andersson, P. Lidbom and S. Thyberg, 2014, Air-to-air heat pumps evaluated for Nordic climates, trends and standards, P.2.14, 11th IEA Heat Pump Conference in Montreal.

[15] Australian Standards: AS/NZS 3823, Performance of electrical appliances - Airconditioners and heat pumps.

[16] S. Prasad Mavuri, Field Behaviour of Inverter Air Conditioners Effect on Seasonal Performance, 2015, International Journal of Application or Innovation in Engineering \& Management (IJAIEM), Volume 4, Issue 8, August 2015, pp. 018-025, ISSN 2319 - 4847.

[17] L. Haugerud, I. Lien, 2015, Analyse av feltmålinger av varmepumper i boliger, Report, Enova SF

[18] William W Rode, 2017, Study of air source heat pumps in a changing more humid Nordic climate, presentation Oslo 18.10.2017 Energy Use and Technologies, Norwegian Energy Department

[19] Xian-Min Guo, Yi-Guang Chen, Wei-Hua Wang, Chun-Zheng Chen, Xi'an Jiaotong, 2008, Experimental study on frost growth and dynamic performance of air source heat pump system, Applied Thermal Engineering 28 (2008), pp 2267-2278

[20] Folksam testar, Olika sorters värmepumpar, https://www.folksam.se/tester-och-goda$\mathrm{rad} /$ vara-tester/test-av-varmepumpar

[21] Bernd Klein, 2012, Independent testing of heat pumps is needed for reliable COP, REHVA Journal - October 2012, pp 15-18

\section{References for air-to-water heat pumps not yet analysed}

Below are references for air-to-water heat pumps that have been found during the literature search, which has not yet been analyzed, but could be so in a possible continuation of this work.

\section{IEA HPT conference papers 2002-2014:}

[22] L. Dardenne, E. Fraccari, A. Maggioni, L. Molinaroli, L. Proserpio and E. Winandy, 2014, A wet-vapour injection and variable speed scroll compressor air to water heat pump model and its field test validation, Paper O.2.2.4 11th IEA Heat Pump Conference, Montreal

[23] E Dumont, M Frère, 2005, Performance measurement and modeling of air-source residential heat pumps, Paper P.7.7, 8th IEA Heat Pump Conference

[24] M. Albert, R. Sahinagic, L. Gasser, B. Wellig, K. Hilfiker, 2008, Prediction of ice and frost formation in the fin tube evaporators for air/water heat pumps, S.3.P.15, 9th IEA Heat Pump Conference, Zürich

[25] P. Fahlén, 2005, Performance audits of heat pumps-procedures and uncertainties, 0.3.4, 8th IEA Heat Pump Conference 
[26] M. Miara, 2008, Two large field-tests of new heat pumps in Germany, S.6.P.04, 9th IEA Heat Pump Conference, Zürich

[27] T. Nogawa, K. Shimizu, M. Ishikawa, I. Hongo, 2011, Development and performance measurement of room air-conditioner suitable for house in cold region, 1oth Heat Pump Conference,

\section{International Journal of Refrigeration:}

[1] P. Poredos, T. Čož, A. Kitanovski et al. Thermo-economic and primary-energy-factor assessment based on the field test of an air-to-water heat pump, 2017, International Journal of Refrigeration, volum 76, April 2017, pp 19-28

\section{HVAC CCC 2012 and 2015 (older conferences not searchable online):}

[1] Field measurements to demonstrate the potential for heat pump systems in cold climates, Pia Tiljander, PhD

Other sources

[2] M. Miara, D. Günther, R. Langner, S. Helmling, Efficiency of Heat Pumps in Real Operating Conditions - Results of three Monitoring Campaigns in Germany, REHVA Journal - September 2014, pp7-12

[3] R. Green, 2012, The Effects of Cycling on Heat Pump Performance, Report, Department of Energy and Climate Change, UK

[4] P. Dunbabin, C. Wickins, 2012, Detailed analysis from the first phase of the Energy Saving Trust's heat pump field trial, Report, Department of Energy and Climate Change, UK

[5] P. Dunbabin, H. Charlick, R. Green, Detailed analysis from the second phase of the Energy Saving Trust's heat pump field trial, Report, Department of Energy and Climate Change, UK

[6] C. Haglund Stignor, O. Gustafsson, P. Lidbom, M. Lindahl, J. Larsson, 2014, Air-to-water heat pumps evaluated for Nordic circumstances, P.1.14, 11th IEA Heat Pump Conference, Montreal 


\section{Sammanfattning}

Denna studie har utförts för Nordsyn finansierat av Nordiska Ministerrådet. Syftet var att analysera om informationen på energimärkningsetiketterna för luft-luftvärmepumpar ger konsumenter i nordiska länder tillräcklig information om energiprestanda. På grund av mycket få tillgängliga fältmätningar och flera möjliga anledningar till skillnader i uppmätta och deklarerade värden kunde misstanken, att fukt inte hanteras optimalt, varken konfirmeras eller förkastas. Studien visar att många värmepumpar deklareras för lägre kapacitet än deras verkliga kapacitet, för att få bättre SCOP-värde på energimärkningsetiketten. Marknadskontrolltest visar att det har blivit allt mer sällsynt att värmepumpar avfrostar under labbtest. Studien visar att energimärkningen inte ger tydlig guidning för konsumenterna och därför rekommenderas fältmätningar samt förbättringar av standarder och förordningar. 
Nordic Council of Ministers

Nordens Hus

Ved Stranden 18

DK-1061 Copenhagen

www.norden.org

\section{NORDSYN STUDY ON AIR-TO-AIR HEAT PUMPS IN HUMID NORDIC CLIMATE}

This study was performed for Nordsyn sponsored by Nordic Council of Ministers. The aim was to analyse if the energy labels of air-to-air heat pumps give consumers in Nordic countries sufficient information on energy performance, since declared performance was suspected to be higher than in reality. Due to very few field measurements available, this suspicion could not be confirmed nor rejected. It was found that many heat pumps are declared for lower capacities compared to their intended use in the Nordic countries, to obtain a higher SCOP value on the energy label. Market surveillance tests show that it has become rarer that heat pumps defrost during the laboratory tests. Altogether the study shows that the current energy label does not give clear guidance to the consumer. Recommendations for field measurements as well as suggestions for standard and regulation developments are given.

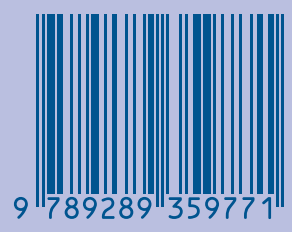

